University of Tennessee Health Science Center

UTHSC Digital Commons

$12-2008$

\title{
Structure-Activity Relationship and Mechanistic Studies on the Chemopreventive Activity of Dipyridamole and Its Analogues
}

Ja'Wanda Shavon Grant

University of Tennessee Health Science Center

Follow this and additional works at: https://dc.uthsc.edu/dissertations

Part of the Pharmacy and Pharmaceutical Sciences Commons

\section{Recommended Citation}

Grant, Ja'Wanda Shavon, "Structure-Activity Relationship and Mechanistic Studies on the Chemopreventive Activity of Dipyridamole and Its Analogues" (2008). Theses and Dissertations (ETD). Paper 100. http://dx.doi.org/10.21007/etd.cghs.2008.0114. 


\title{
Structure-Activity Relationship and Mechanistic Studies on the Chemopreventive Activity of Dipyridamole and Its Analogues
}

\begin{abstract}
There is an escalating demand in the area of cancer prevention and control for the development of novel agents and molecular targets that have potential to reduce the incidence of cancer. In this study, the JB6 mouse epidermal cell-culture based transformation model was used in efforts to identify novel chemopreventive agents and targets. The nucleoside transport inhibitor dipyridamole (DPM) showed potent chemopreventive activity against $\mathrm{JB} 6 \mathrm{P}^{+}$cells (tumor promotion sensitive). To probe the effects of DPM structural features on its antitumor promotion activity, the soft-agar colony forming efficiency assay was used to screen an in-house library of structurally varied novel DPM analogues. From this screening, Compound 145 was found to be more 30 times more potent than DPM $\left(145, I C_{50}=0.12 \mu \mathrm{M} ; \mathrm{DPM}, I_{50}=\right.$ $3.07 \mu \mathrm{M})$. Structure-activity relationships have been defined and will aid in the next phase of chemopreventive drug design. In regards to the antitumor promotion mechanism of DPM, a series of previously collected data are presented that support the novel hypothesis that nucleoside transporters may be potential chemoprevention targets involved in the antitumor promotion activity of DPMand analogues. Signaling pathways are pivotal in tumor promotion processes and were therefore tested for in the chemopreventive mechanism of DPM. In a previous study, the known chemoprevention target, AP-1, was studied for involvement in the antitumor promotion activity of DPM. Using a new AP-1-SEAP JB6 $\mathrm{P}^{+}$ reporter cell line, DPM was shown to inhibit TPA-induced AP-1 transactivation. Inhibition of AP-1 transactivation suggests the involvement of mitogen-activated protein kinase (MAPK) signaling pathways which are upstream effectors of AP-1 transactivation, and so the involvement of MAPKs was assessed in this study. DPM was shown to inhibit p38 MAPK activation in a dose-dependent manner, which suggests that this inhibition is a potential mechanism behind the chemopreventive activity of DPM.
\end{abstract}

\section{Document Type}

Dissertation

Degree Name

Doctor of Philosophy (PhD)

Program

Pharmaceutical Sciences

Research Advisor

John K. Buolamwini, Ph.D.

\section{Keywords}

chemoprevention, dipyridamole, MAP kinases, nucleoside transporters

\section{Subject Categories}

Medicine and Health Sciences | Pharmacy and Pharmaceutical Sciences 


\title{
STRUCTURE-ACTIVITY RELATIONSHIP AND MECHANISTIC STUDIES ON THE CHEMOPREVENTIVE ACTIVITY OF DIPYRIDAMOLE AND ITS ANALOGUES
}

\author{
A Dissertation \\ Presented for \\ The Graduate Studies Council \\ The University of Tennessee \\ Health Science Center
}

\author{
In Partial Fulfillment \\ Of the Requirements for the Degree \\ Doctor of Philosophy \\ From The University of Tennessee
}

By

Ja'Wanda Shavon Grant

December 2008 
Copyright (C) 2008 by Ja'Wanda Shavon Grant All rights reserved 


\section{DEDICATION}

I would like to dedicate this dissertation to my mother, Judy Grant, for her prayers, constant encouragement, and for being the confidant I needed to make it through this endeavor. This dissertation is also dedicated to my father, Jake Grant, for being a great listener and giver of wise advice throughout this experience. This is also dedicated to my sister, Ms. Jalarna Grant, for keeping a smile on my face and cheering for me along the way. And finally, I dedicate this dissertation to my grandparents, for showering me with prayers and admiration. 


\section{ACKNOWLEDGEMENTS}

First, I would like to thank my advisor, Dr. John K. Buolamwini, for the opportunity of this research training experience. Dr. Buolamwini has presented a great example of the untiring diligence and persistence required to be successful in research and in life in general. His patience, guidance, and support have steered my personal development as a research scientist, and for that I am sincerely grateful. I would also like to thank my committee members, Dr. Richard E. Lee, Dr. David Nelson, Dr. Duane D. Miller, and Dr. Jie Zheng, for their guidance, assistance, and valuable suggestions throughout this process.

I would like to thank the previous technicians in our lab, Mrs. Bing Cheng and Mrs. Peihong Guan, who assisted me in the development of various technical skills used throughout my research projects. I am also thankful to Mr. Rashid Abdulle from St. Jude Children's Research Hospital (SJCRH) for invaluable insights and technical savvy. I would like to thank Dr. Zorica Janjetovic and Dr. Michal Zmijewski for sharing equipment and space in the Cancer Research Building, and for technical advice.

I would like to thank my labmates, past and present, for their encouragement, assistance, and camaraderie: Dr. Shantaram Kamath, Dr. Amol Gupte, Dr. Wenwei Lin, Dr. Zhengxiang Zhu, Dr. Darius Mason, Dr. Rhonda Garner, Dr. Elizabeth Ambe, Dr. Chunmei Wang, Surekha Pimple, Horrick Sharma, and Shan Sun.

I would also like to express my gratitude to all of my colleagues, and faculty/staff associates that have offered any type of support during this process. In particular, I am very grateful for Dr. Kimberly Grimes, a great friend and supporter, who helped me through many challenging times during my research.

I would like to acknowledge and sincerely thank my wonderful family (my parents, sister, grandparents, aunts, uncle, cousins, and church family) who have cheered for me on the sidelines, and gave me the inspiration to finish this task.

And finally, I must thank God for giving me the strength, the will, and the faith to endure. 


\begin{abstract}
There is an escalating demand in the area of cancer prevention and control for the development of novel agents and molecular targets that have potential to reduce the incidence of cancer. In this study, the JB6 mouse epidermal cell-culture based transformation model was used in efforts to identify novel chemopreventive agents and targets. The nucleoside transport inhibitor dipyridamole (DPM) showed potent chemopreventive activity against JB6 $\mathrm{P}^{+}$cells (tumor promotion sensitive). To probe the effects of DPM structural features on its antitumor promotion activity, the soft-agar colony forming efficiency assay was used to screen an in-house library of structurally varied novel DPM analogues. From this screening, Compound 145 was found to be more 30 times more potent than DPM $\left(\mathbf{1 4 5}, \mathrm{IC}_{50}=0.12 \mu \mathrm{M}\right.$; DPM, $\left.\mathrm{IC}_{50}=3.07 \mu \mathrm{M}\right)$. Structure-activity relationships have been defined and will aid in the next phase of chemopreventive drug design. In regards to the antitumor promotion mechanism of DPM, a series of previously collected data are presented that support the novel hypothesis that nucleoside transporters may be potential chemoprevention targets involved in the antitumor promotion activity of DPM and analogues. Signaling pathways are pivotal in tumor promotion processes and were therefore tested for in the chemopreventive mechanism of DPM. In a previous study, the known chemoprevention target, AP-1, was studied for involvement in the antitumor promotion activity of DPM. Using a new AP-1SEAP JB6 $\mathrm{P}^{+}$reporter cell line, DPM was shown to inhibit TPA-induced AP-1 transactivation. Inhibition of AP-1 transactivation suggests the involvement of mitogenactivated protein kinase (MAPK) signaling pathways which are upstream effectors of AP-1 transactivation, and so the involvement of MAPKs was assessed in this study. DPM was shown to inhibit p38 MAPK activation in a dose-dependent manner, which suggests that this inhibition is a potential mechanism behind the chemopreventive activity of DPM.
\end{abstract}




\section{TABLE OF CONTENTS}

CHAPTER 1: RESEARCH OBJECTIVES .................................................................... 1

CHAPTER 2: INTRODUCTION..................................................................................... 2

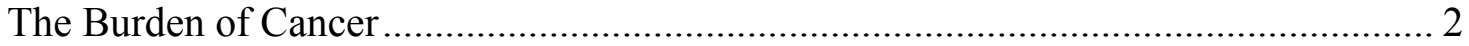

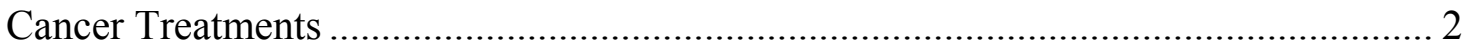

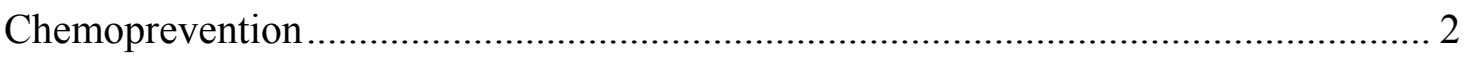

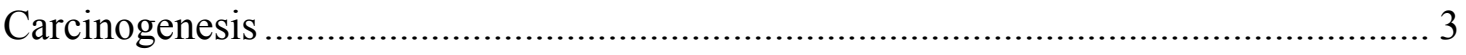

Models of Carcinogenesis.......................................................................................... 5

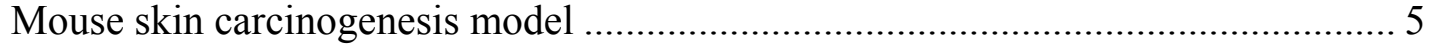

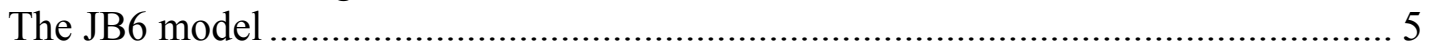

Tumor Promotion with TPA: Mechanisms Involved.................................................... 6

TPA-induced transformation requires AP-1 ..................................................... 6

MAPKs in AP-1 dependent transformation .......................................................... 8

Chemoprevention Targets .................................................................................... 10

Introduction to Nucleoside Transporters ........................................................ 10

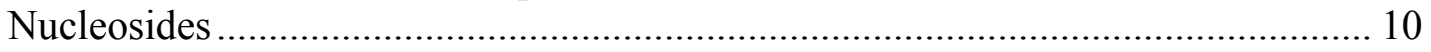

Nucleoside transporters: Classifications ............................................................. 13

Nucleoside transporters: Homology …………………....................................... 13

Equilibrative nucleoside transporters............................................................... 13

Concentrative nucleoside transporters ............................................................ 14

Nucleoside transporters: Topology/Structure ......................................................... 14

Nucleoside transporters: Localization/Tissue distribution/Abundance .................... 16

Nucleoside transporters: Substrates/Permeants ………………………………..... 16

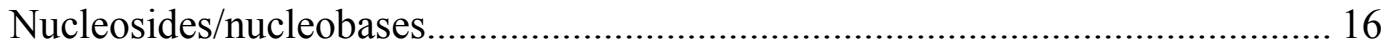

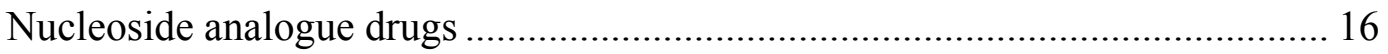

Anticancer nucleoside analogue drugs....................................................... 17

Antiviral nucleoside analogue drugs................................................................. 17

Nucleoside transporters in the efficacy of nucleoside analogue drugs ..................... 17

Physiologic roles of nucleoside transporters......................................................... 19

Regulation of nucleoside transporter expression and consequences ........................ 19

Nucleoside transporters as therapeutic targets: Nucleoside transport inhibitors ..... 21

Adenosine potentiation ............................................................................... 21

Antimetabolite potentiation ………………………............................... 23

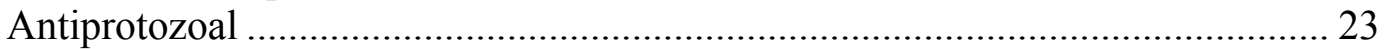

The Future of Nucleoside Transport Inhibitors: A Medicinal Chemistry

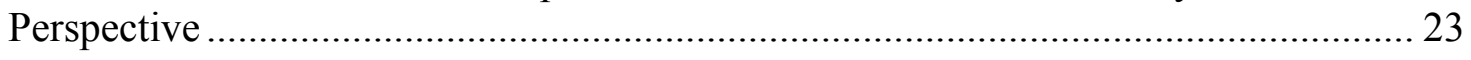

Summary of Nucleoside Transporters .................................................................... 24

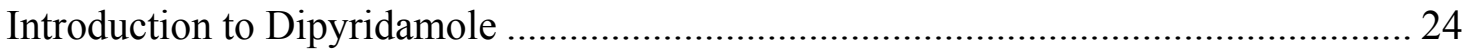


CHAPTER 3: PRELIMINARY DATA …........................................................... 26

Nucleosides and Nucleoside Transport Inhibitors in Carcinogenesis......................... 26

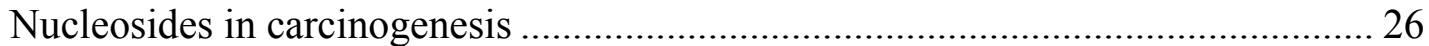

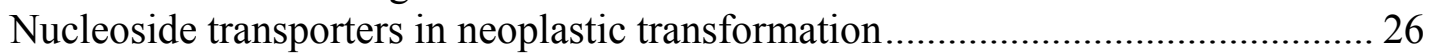

Nucleoside transport inhibitors and nucleosides in tumor promotion .................... 27

Characterization of Nucleoside Transport Phenotype in JB6 $\mathrm{P}^{+}$Cells ........................ 28

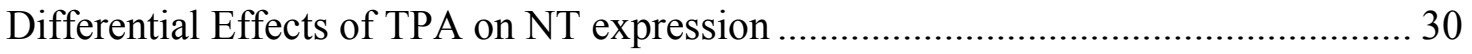

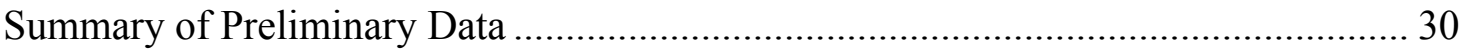

\section{CHAPTER 4: THE ANTITUMOR PROMOTION EFFECTS OF \\ DIPYRIDAMOLE AND ANALOGUES ............................................................... 32}

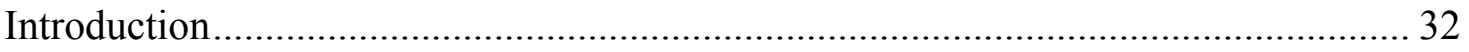

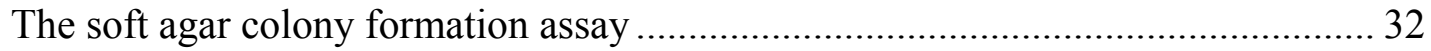

Overview of DPM analogues structural modifications......................................... 32

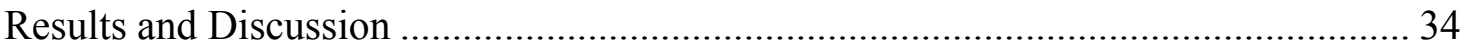

Cytotoxicity screening .............................................................................. 41

Nucleoside transport inhibition: A mechanism of antitumor promotion .................. 41

Selection of compounds for dose-response study .......................................... 46

Anti-tumor promotion dose response of DPM and analogues............................ 46

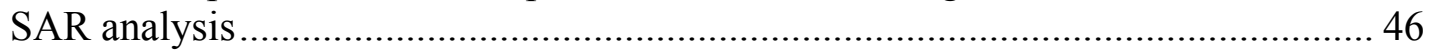

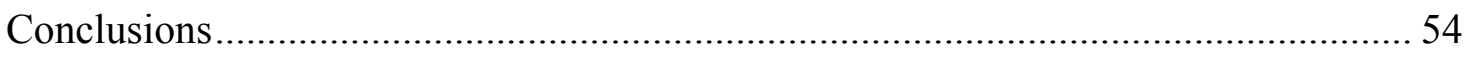

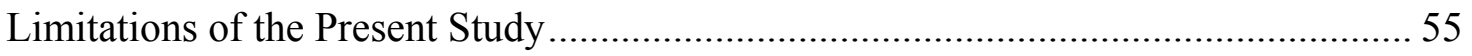

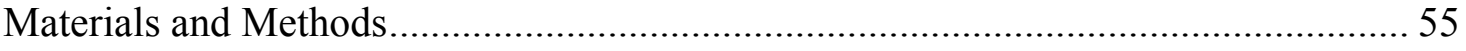

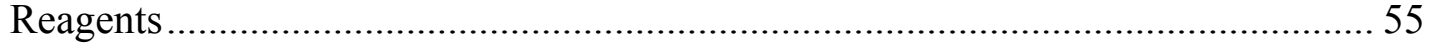

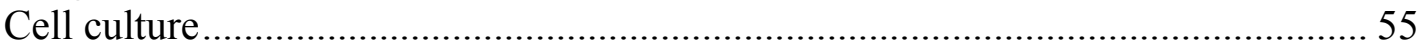

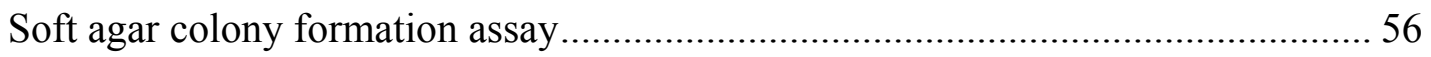

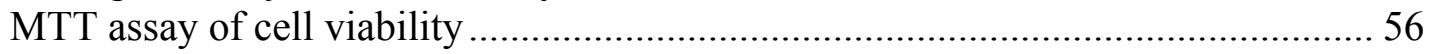

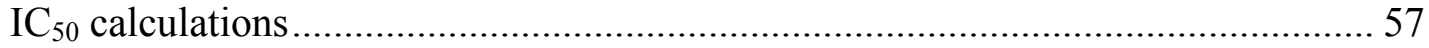

CHAPTER 5: THE EFFECTS OF DIPYRIDAMOLE ON MAP KINASES.......... 58

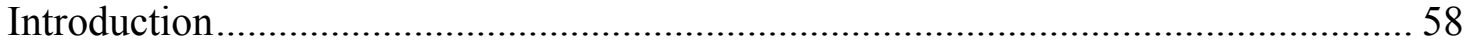

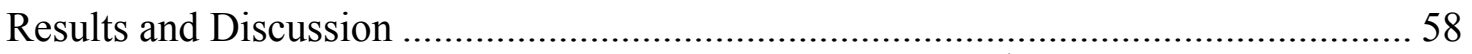

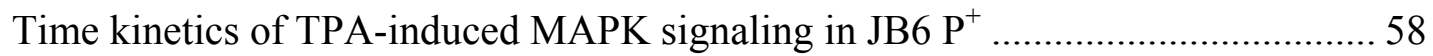

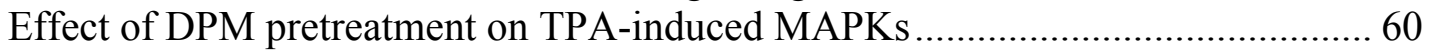

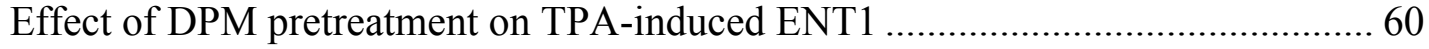

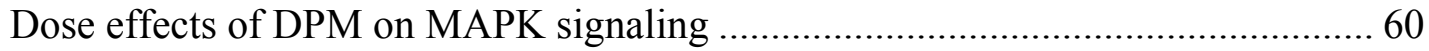

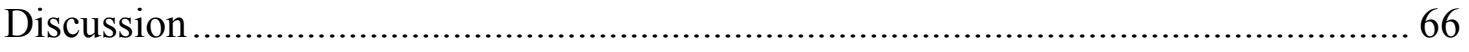

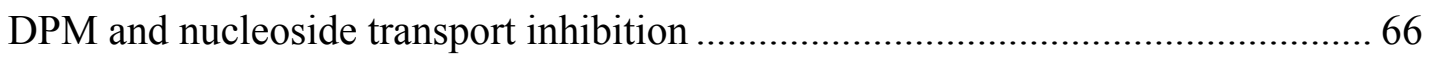

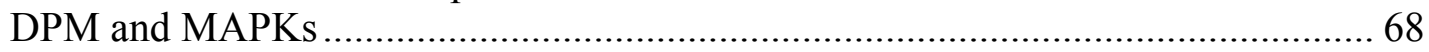

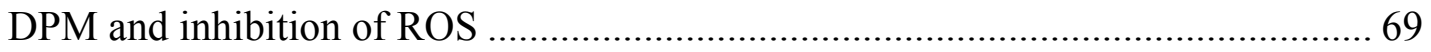

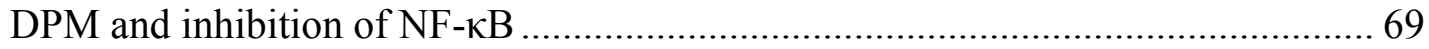




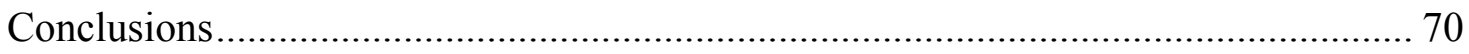

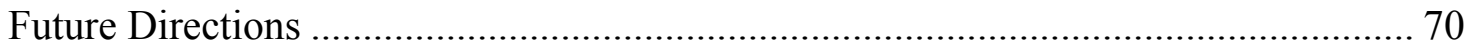

Time course of DPM chemoprevention........................................................... 70

DPM effects on AP-1 DNA binding …………………..................................... 71

DPM effects on TPA-induced NF-אB activity and DNA binding ............................ 71

DPM effects on ROS ...................................................................................... 71

DPM effects on EGF, TNF- $\alpha$, and UV-induced transformation................................ 72

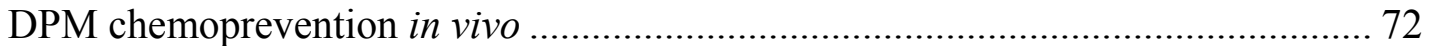

Mechanism studies on the novel DPM analogue, compound 145 .......................... 72

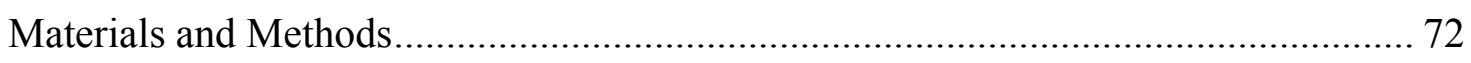

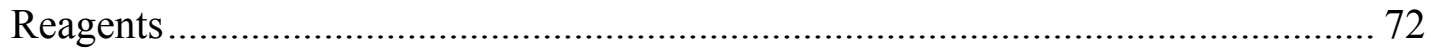

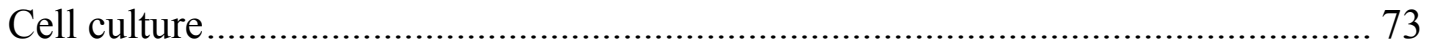

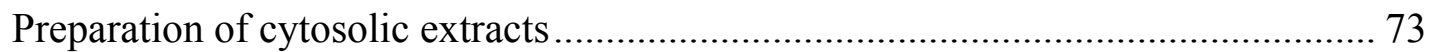

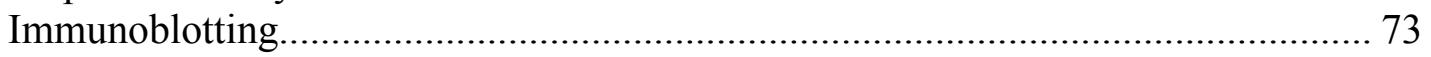

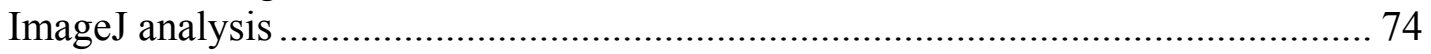

LIST OF REFERENCES............................................................................................. 75

APPENDIX A: DATA TABLES USED FOR REGRESSION ANALYSIS .............. 91

APPENDIX B: ANTITUMOR PROMOTION DOSE RESPONSE CURVES AND IC 50 DATA FOR DPM AND ANALOGUES...................................................... 95

VITA 


\section{LIST OF TABLES}

Table 4.1. Antitumor promotion activities of Group 1 DPM analogues.....................38

Table 4.2. Antitumor promotion activities of Group 2 DPM analogues....................39

Table 4.3. Antitumor promotion activities of Group 3 DPM analogues $(128-144)$

Table 4.4. Antitumor promotion activities of Group 3 DPM analogues $(145-157)$

Table 4.5. Antitumor promotion activities of Group 4 DPM analogues....................40

Table 4.6. Summary of the nucleoside transport inhibition and antitumor promotion activities of DPM and noncytotoxic analogues

Table 4.7. Summary of MTT and antitumor promotion data for selected DPM analogues

Table 4.8. Regression equations and calculated antitumor promotion $\mathrm{IC}_{50}$ for DPM and analogues

Table A.1. Cytotoxicity, nucleoside transport inhibition, and antitumor promotion data for Group 1 DPM analogues

Table A.2. Cytotoxicity, nucleoside transport inhibition, and antitumor promotion data for Group 2 DPM analogues

Table A.3. Cytotoxicity, nucleoside transport inhibition, and antitumor promotion data for Group 3 DPM analogues.

Table A.4. Cytotoxicity, nucleoside transport inhibition, and antitumor promotion data for Group 4 DPM analogues 


\section{LIST OF FIGURES}

Figure 2.1. Structures of chemopreventive phytochemicals and their dietary

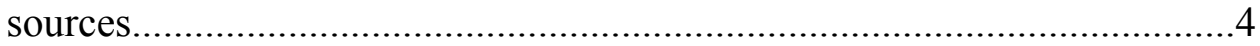

Figure 2.2. Structures of chemotherapeutic agents used in chemoprevention ...............4

Figure 2.3. TPA pathways in the JB6 tumor promotion model …………….................

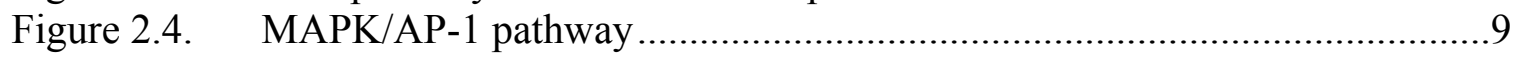

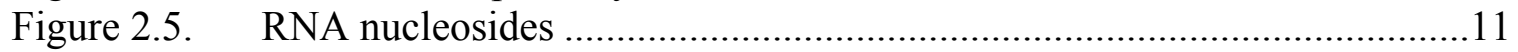

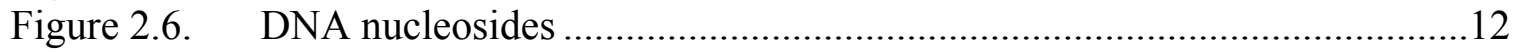

Figure 2.7. Topographical model of ENTs and CNTs ...............................................15

Figure 2.8. Various anticancer nucleoside analogue drugs .......................................18

Figure 2.9. Structures of representative nucleoside transport inhibitors ......................22

Figure 3.1. Effects of nucleosides and nucleoside transport inhibitors on the antitumor promotion activity of DHEA ...................................................28

Figure 3.2. Dose-response effects of nucleosides and (A) DHEA, (B) NBMPR, and (C) DPM on tumor promotion............................................................29

Figure 3.3. Real time PCR analysis of ENT1 gene expression in JB6 $\mathrm{P}^{+}$versus

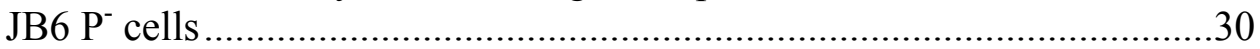

Figure 3.4. Real-time PCR analysis of ENT1 and ENT2 gene expression in JB6 $\mathrm{P}^{+}$and JB6 $\mathrm{P}^{-}$cells and the effect of TPA (PMA) treatment ..............31

Figure 4.1. TPA-induced colony formation in JB6 $\mathrm{P}^{+}$cells ...........................................33

Figure 4.2. Structure of dipyridamole and regions of structural modifications ............33

Figure 4.3. Core structures of Group 1 DPM analogues ...............................................35

Figure 4.4. Core structures of Group 2 DPM analogues .............................................

Figure 4.5. Core structures of Group 3 DPM analogues ..............................................36

Figure 4.6. Core structures of Group 4 DPM analogues ................................................36

Figure 4.7. Effects of DPM and analogues $(101-131)$ on TPA-induced tumor promotion ............................................................................................

Figure 4.8. Effects of DPM and analogues $(132-164)$ on TPA-induced tumor

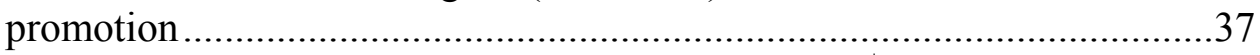

Figure 4.9. Effect of DPM and analogues $(101-135)$ on JB6 $\mathrm{P}^{+}$viability ..................42

Figure 4.10. Effect of DPM and analogues $(136-164)$ on JB6 $\mathrm{P}^{+}$viability ..................42

Figure 4.11. Linear regression of percent inhibition of ENT1 transport and percent inhibition of tumor promotion by DPM and analogues ..................44

Figure 4.12. Linear regression of percent inhibition of ENT2 transport and percent inhibition of tumor promotion by DPM and analogues .................45

Figure 4.13. Soft agar colony control (16 nM TPA only) ............................................48

Figure 4.14. DPM dose-response in the soft agar colony assay ....................................48

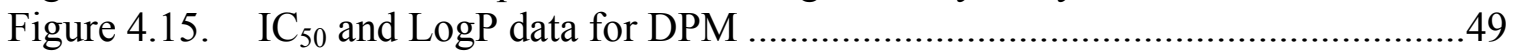

Figure 4.16. $\quad \mathrm{IC}_{50}$ and $\operatorname{LogP}$ data for DPM analogues from Group $1 \ldots \ldots \ldots \ldots \ldots \ldots \ldots \ldots \ldots . . . .50$

Figure 4.17. $\quad \mathrm{IC}_{50}$ and $\operatorname{LogP}$ data for DPM analogues from Group 2 ...........................51

Figure 4.18. $\quad \mathrm{IC}_{50}$ and $\log \mathrm{P}$ data for DPM analogues from Group 3 ...........................52

Figure 4.19. $\mathrm{IC}_{50}$ and $\operatorname{LogP}$ data for DPM analogues from Group 3 ...........................53

Figure 4.20. $\quad \mathrm{IC}_{50}$ and LogP data for DPM analogues from Group 4 ...........................53

Figure 4.21. Summary of DPM and analogues antitumor promotion SAR ………........54

Figure 5.1. DPM dose-dependent inhibition of AP-1 transactivation .........................59 
Figure 5.2. Time course of TPA-induced MAPKs.................................................59

Figure 5.3. DPM dose effects on TPA-induced MAPKs .......................................61

Figure 5.4. DPM dose effects on TPA-induced Erk.................................................62

Figure 5.5. DPM dose effects on TPA-induced Erk activation...................................63

Figure 5.6. DPM dose effects on TPA-induced $\mathrm{p} 38$ activation..................................64

Figure 5.7. DPM dose effects on TPA-induced ENT1 ..........................................65

Figure 5.8. Effects of DPM ad TPA on MAPKs.....................................................65

Figure 5.9. Comparison of MAPK induction versus activation by DPM and TPA ....67

Figure 5.10. Potential mechanisms of DPM in chemoprevention................................71

Figure B.1. Antitumor promotion dose response curves and $\mathrm{IC}_{50}$ data for $\mathrm{DPM}$,

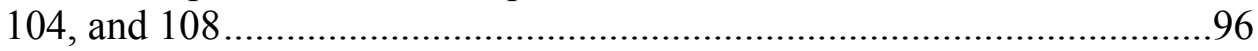

Figure B.2. Antitumor promotion dose response curves and $\mathrm{IC}_{50}$ data for 113 ,

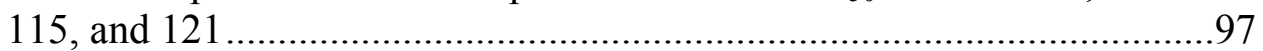

Figure B.3. Antitumor promotion dose response curves and $\mathrm{IC}_{50}$ data for 137 ,

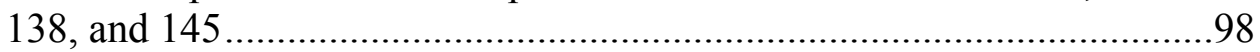

Figure B.4. Antitumor promotion dose response curves and $\mathrm{IC}_{50}$ data for 146 ,

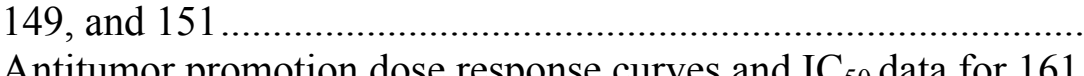

Figure B.5. Antitumor promotion dose response curves and $\mathrm{IC}_{50}$ data for 161 , and 164. 


\section{LIST OF ABBREVIATIONS}

5-FU

AIDS

AP-1

ATP

AZT

cAMP

cGMP

$\mathrm{CNT}$

CSF-1

DCFDA

$\mathrm{ddC}$

ddI

DHEA

DMBA

DMSO

DPM

EDTA

EGF

EGFR

ei

ENT

es

FBS

hCNT

hENT

LPS

MAPK

MAPKK

MAPKKK

mCNT

mENT

MKP-1

MTT

NBMPR

$\mathrm{NF}-\kappa \mathrm{B}$

$\mathrm{NO}$

NT

NTI

PBS

PCR

PK15NTD

PKC

rCNT

rENT 5-fluorouracil Acquired immune deficiency syndrome Activator protein 1 Adenosine triphosphate 3'-azido-3'-deoxythymidine Cyclic adenosine monophosphate Cyclic guanosine monophosphate Concentrative nucleoside transporter Colony-stimulating factor-1 Dichlorofluorescein diacetate 2'3'-dideoxycytidine 2'3'-dideoxyinosine Dehydroepiandrosterone 7,12-dimethyl benzanthracene Dimethyl sulfoxide Dipyridamole Ethylenediaminetetraacetic acid Epidermal growth factor Epidermal growth factor receptor

Equilibrative insensitive Equilibrative nucleoside transporter Equilibrative sensitive Fetal bovine serum Human concentrative nucleoside transporter Human equilibrative nucleoside transporter Lipopolysaccharide Mitogen activated protein kinase Mitogen activated protein kinase kinase Mitogen activated protein kinase kinase kinase Mouse concentrative nucleoside transporter Mouse equilibrative nucleoside transporter Mitogen activated protein kinase phosphatase 1 3-(4,5-Dimethylthiazol-2-yl)-2,5-diphenyltetrazolium bromide $S^{6}$-(4- nitrobenzyl)mercaptopurine riboside Nuclear factor kappa B Nitric oxide

Nucleoside transporter Nucleoside transport inhibitor Phosphate buffered saline Polymerase chain reaction Porcine kidney 15 nucleoside transporter deficient Protein kinase $\mathrm{C}$ Rat concentrative nucleoside transporter Rat equilibrative nucleoside transporter 
ROS

SAR

SEAP

SRE

TAM67

TBS

TM

TNF- $\alpha$

TPA

TRE

UV
Reactive oxygen species Structure activity relationship Secreted alkaline phosphatase Serum response element

Dominant negative c-Jun Tris-buffered saline Transmembrane domain Tumor necrosis factor alpha 12-O-tetradecanoyl-phorbol-13- acetate TPA response element Ultraviolet 


\section{CHAPTER 1: RESEARCH OBJECTIVES}

Nucleosides have been implicated as contributory agents to the processes of carcinogenesis. This concept was tested in a series of preliminary work, before this dissertation work began, and the results supported the postulate (summarized in Chapter 3). Using the JB6 chemoprevention model system, these preliminary studies showed that exogenous nucleosides reversed the chemopreventive effects of dehydroepiandrosterone (DHEA). Nucleosides require specialized transporters, namely nucleoside transporters, to permeate the plasma membrane and enter cells. To further investigate the carcinogenic potential of nucleosides, nucleoside transport inhibitors were added to the JB6 model system and were found to counteract the inhibitory effects of nucleosides as well as inhibit tumor promotion themselves with better potency than DHEA.

Subsequent investigations of nucleoside transport inhibitors as chemopreventive agents found that dipyridamole (DPM), a known clinically used nucleoside transport inhibitor, showed better antitumor promotion effects than DHEA. Concurrently, another unrelated project designed to screen a library of dipyridamole analogues for inhibition of equilibrative nucleoside transporters afforded a novel series of DPM analogues, which guided the conception of the following research objectives of this dissertation.

The research presented in this dissertation revolves around structure-activity relationship (SAR) and mechanistic studies of a series of 64 structurally varied DPM analogues. The pursuit of the objectives of this work has been described in two chapters. Chapter 4 addresses the screening and structural insights into the chemopreventive potential of DPM analogues. These studies encompass the following aims:

- To determine the antitumor promotion activity of these DPM analogues.

- To quantify the relative activities by determining the $\mathrm{IC}_{50}$ values of selected analogues.

- To use the $\mathrm{IC}_{50}$ activity data to probe structural trends in the activity to develop an SAR model for further drug design and optimization efforts.

- To choose potent compounds for future mechanistic studies.

Chapter 5 presents insights into the mechanism(s) involved in the antitumor promotion activity of DPM and the selected analogues. The aim of this study was to determine if mitogen-activated protein (MAP) kinases are involved in the antitumor promotion activities of DPM and analogues. Chapters 2 and 3 provide introductory materials relevant to the scope of this dissertation and preliminary data used as the basis of this dissertation work, respectively. 


\section{CHAPTER 2: INTRODUCTION}

\section{The Burden of Cancer}

There is much effort across the globe to minimize the burden of cancer. To present a glimpse of the cancer epidemic, here are a few facts and statistics reported by the American Cancer Society (ACS) about cancer in 2007 (1) .

- More deaths are attributed to cancer than to AIDS, tuberculosis, and malaria combined.

- Only outranked by heart disease, cancer is the second leading cause of death in the USA and other economically developed countries, causing nearly 600,000 deaths per year.

- It has been predicted that by the year 2050, the global burden of cancer will reach 27 million new cancer cases and 17.5 million deaths simply due to increasing life expectancy and overall size of the population.

- The estimated overall financial cost of cancer is \$200 billion dollars each year.

\section{Cancer Treatments}

One of the oldest records of cancer was found in Egypt and dates to around 1600 B.C. The breast tumors or ulcers that were described in this writing were treated by cauterization, an antiquated method that used fire to burn and destroy abnormal tissues (2). Since then, cancer has become a world-wide epidemic with disheartening mortality statistics as presented above. Today, cancer treatment has tremendously advanced because of a better understanding of this disease. Often, multiple treatment approaches are used in each case depending on the prognosis, which usually include surgery, radiotherapy, and/or chemotherapy (1). Even with the advances in cancer treatment methodologies, we are still faced with the grim statistics mentioned above. There is therefore an urgent need to present alternatives methods of approaching and attacking cancer, such as chemoprevention.

\section{Chemoprevention}

The concept of chemoprevention emerged in the late1960's. At the time, Dr. Lee Wattenburg found that various chemicals were able to inhibit carcinogenesis by a mechanism he termed chemoprophylaxis (3). The modern term, chemoprevention was coined by Michael Sporn in 1976 (4). Potential chemopreventive agents currently under investigation are diverse in chemical structure and physiologic effects. Many of the agents that are well documented and tested have been identified from epidemiologic 
evidence regarding the dietary and health benefits of fruits and vegetables, and other dietderived chemicals which include vitamins and minerals, and compounds isolated from teas, soybeans, broccoli, potatoes, grapes, ginger, rice, and some herbs and spices (Figure 2.1) $(5,6)$. Even a few agents currently used as cancer chemotherapeutics (i.e. tamoxifen, finasteride) have shown chemoprevention potential in the clinical setting (Figure 2.2) $(7,8)$.

The cancer statistics presented at the beginning of this chapter represent the disconnect between the advances in cancer treatment and the resulting outcomes. Cancer chemotherapy involves the use of pharmaceutical drugs in efforts to remove or alleviate the symptoms, or to achieve a cure in by killing cancer cells throughout the body. Despite the benefits of chemotherapy, these treatments are often ineffective with severe side effects (9). Chemoprevention offers another method to approach the attack on cancer. This preventive method targets individuals who have recovered from cancer and may be at higher-risk for secondary cancer (10). In addition, chemoprevention may benefit individuals who are otherwise healthy but have hereditary factors placing them at risk for developing cancer (11). Identification of high-risk individuals may be a challenging endeavor but available diagnostic methods, including genetic screening, are helpful tools (10).

Current cancer chemoprevention studies rely on the knowledge of how cancer begins and how it progresses (carcinogenesis) in order to design therapies to target these processes. A great deal has been learned about cancer since 1946, when nitrogen mustards, chemical warfare agents, were observed to have therapeutic potential in treatment of cancer, specifically lymphomas (12). Since then, many research efforts have focused on carcinogenesis and, the cellular processes involved in cancer development. Various models and theories regarding the causes and progression of cancer were presented in the 1950's with some attributing cancer to age, and some to time and frequency of carcinogen exposure (13). In the early 1970's, the malignant phenotype (or manifestation of cancer) was attributed to mutations in DNA (14). It is now clear that cancer is a multistage and often multifactorial process that begins with DNA mutation within one cell. It is now accepted that this mutation begins the multistage process of carcinogenesis, which is denoted by three distinguishable steps: initiation, promotion, and progression.

\section{Carcinogenesis}

Carcinogenesis is generally accepted as a multistep process. The first stage, initiation, is a rapid (1-2 days), high frequency, and irreversible process which involves the induction of a gene mutation as the result of the uptake of or exposure to a carcinogenic agent. In contrast to initiation, promotion is a relatively lengthy ( $>10$ years), low frequency, reversible process that requires sustained chronic exposure to 

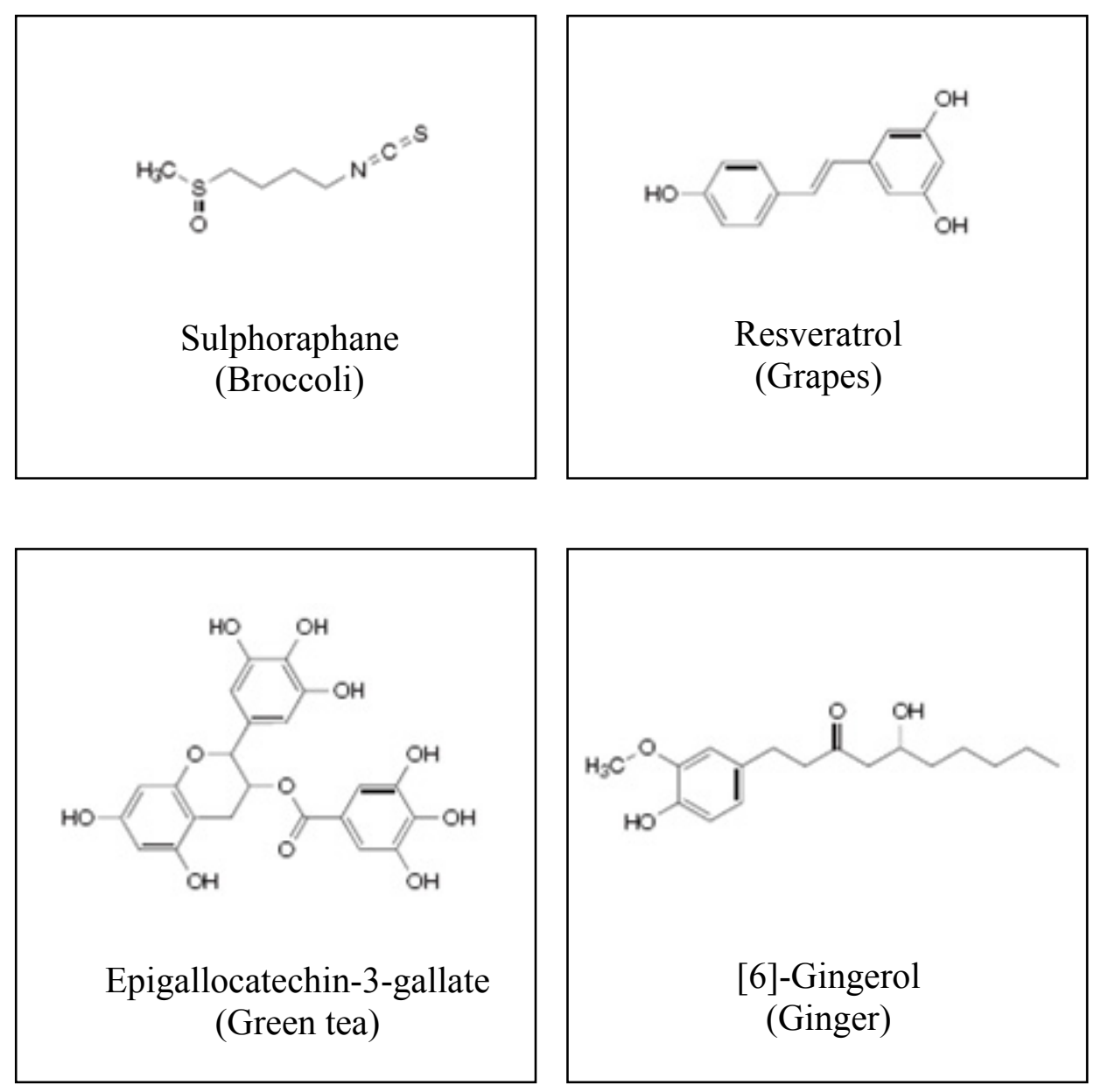

Figure 2.1. Structures of chemopreventive phytochemicals and their dietary sources.
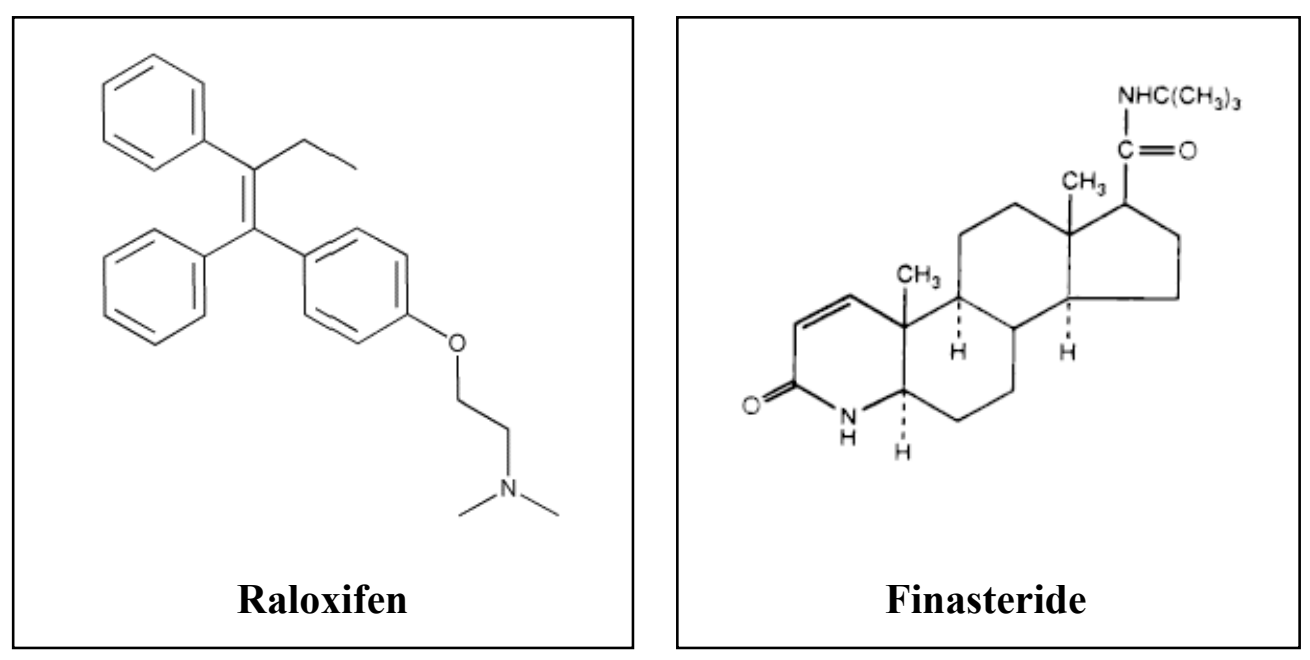

Figure 2.2. Structures of chemotherapeutic agents used in chemoprevention. 
tumor promoter(s), which supports the conversion from the initiated cell to a preneoplastic cell.

During the promotion phase, actively proliferating preneoplastic (precancerous) cells begin to accumulate. In the case of benign preneoplastic growths, these are the end point of tumor promotion. In the final stage of neoplastic transformation, progression, benign tumors become malignant (cancerous) with invasive and metastatic potential $(5,15)$. Although each stage of carcinogenesis can potentially be inhibited, the promotion stage has the most potential to be reversed because of its extensive length (16).

Chemoprevention is defined as the inhibition, arrest, or reversal of carcinogenesis by pharmacologic intervention with synthetic or naturally occurring chemicals that protect against the establishment of cancer or neoplastic transformation $(5,8,17)$. Several models have been used to understand the molecular mechanisms involved in carcinogenesis and serve as tools to analyze and design chemopreventive agents. Two of these models are discussed in the next section.

\section{Models of Carcinogenesis}

\section{Mouse skin carcinogenesis model}

The mouse skin carcinogenesis model is a well-characterized experimental model that has determined the potential roles of several genes in tumorigenesis. The study of the mechanisms involved in the activation of these genes during promotion has unveiled a series of signaling pathways as valid targets for chemoprevention.

In the mouse skin carcinogenesis model, skin tumors are induced in mice by a single application of a mutagen (initiation) followed by repeated application of a noncarcinogenic tumor promoter. This is a model of carcinogenesis because it goes through the initiation, promotion, and progression phases mentioned previously. Initiation, which is induced by a single topical application of a subthreshold dose of a carcinogen, such as 7,12-dimethyl-benzanthracene (DMBA), results in irreversible DNA damage. Promotion consists of repeated application of a noncarcinogenic agent, most commonly phorbol esters represented by $12-O$-tetradecanoyl-phorbol-13-acetate (TPA), a potent skin tumor promoter (18). TPA induces biochemical processes that facilitate the selective clonal expansion of initiated cells giving rise to numerous benign tumors (papillomas). Progression, the final stage, is a spontaneous process characterized by high levels of genetic instability (19). This in vivo model is important in that the data obtained are relevant to the whole organism. However, in vitro models are easier to manipulate and more efficient in terms of cost and time.

\section{The JB6 model}

The mouse epidermal JB6 model is one such in vitro model designed to further the understanding of molecular mechanisms involved in the promotion of neoplastic 
transformation. Because these are epithelial cells, it is a relevant model to most human cancers, which have predominantly epithelial origins, particularly in skin carcinogenesis. The JB6 model consists of clonal genetic variants of mouse epidermal cells derived from $\mathrm{BALB} / \mathrm{c}$ mice. In this model system, the JB6 $\mathrm{P}^{+}$cells are promotion-sensitive. These cells are "sensitive" in that they respond irreversibly to tumor promoters with subsequent colony growth in anchorage-independent conditions and tumorigenicity in nude mice. JB6 $\mathrm{P}^{-}$cells are resistant to these promotion effects (20). Epidermal growth factor (EGF) and tumor necrosis factor alpha (TNF- $\alpha)$ are also inducers of anchorage independent transformation in this model (21-23). From studies using the JB6 in vitro carcinogenesis model, a few molecular events have been implicated in tumor promotion, and have proved to be predictive of tumorigenic phenotypes in vivo (24).

\section{Tumor Promotion with TPA: Mechanisms Involved}

TPA, one of the most potent tumor promoters in the JB6 model, is not a genotoxic agent. However, it does induce transient changes in gene expression via signal transduction pathways (25-28). This results in pleiotropic effects ranging from changes in cellular morphology to alterations in cell cycle and apoptosis (28). Epidermal growth factor (EFG) receptor (EGFR) activation is a mediator of TPA-induced signal transduction and transformation (Figure 2.3) (29). EGFR kinase inhibitors suppress TPA-induced phosphorylation of Erks, AP-1 transactivation, and cell transformation. TPA-induced phosphorylation of Erks and AP-1 DNA binding is inhibited in EGFR knockout cells (EGFR ${ }^{-}$). In studies with EGF-induced transformation, inhibitors of p38 and the expression of a p38 dominant negative mutant both inhibit EGF-induced cell transformation (30). This adds to the understanding of mitogen activated protein kinases (MAPKs) in tumor-promoter induced transformation.

Protein kinase $\mathrm{C}(\mathrm{PKC})$ is an intracellular receptor for TPA and is activated upon TPA binding (Figure 2.3) (31,32). Because of the interaction of TPA with PKC, the PKC/MAP kinase/AP-1 pathway has been implicated in TPA-induced tumor promotion (33-36). This is supported by the observation that activation of $\mathrm{PKC}$ results in rapid activation of Erks $(35,37)$. However, in PKC-depleted mice, TPA is still able to transactivate AP-1. Several studies show TPA-induced PKC activation is a transient process and that continuous exposure to TPA actually downregulates PCK activity (3840). In vivo, $\mathrm{PKC} \alpha$ had no role in TPA-induced promotion of skin tumors. In addition, $\mathrm{PKC} \delta$ and $\mathrm{PKC} \varepsilon$ overexpression reduced TPA-induced papillomas $(41,42)$. Taken together, these data suggest that other mechanisms in addition to the PKC pathway are involved in tumor promotion, which may be due to the presence of additional TPA receptors (43).

\section{TPA-induced transformation requires AP-1}

In 1989, AP-1 was first implicated as having a key role in tumor promotion based on the observation that JB6 $\mathrm{P}^{+}$cells but not JB6 $\mathrm{P}^{-}$cells gave a tumor promoter-induced AP-1 response (44). This idea that tumor promotion required AP-1 dependent gene 


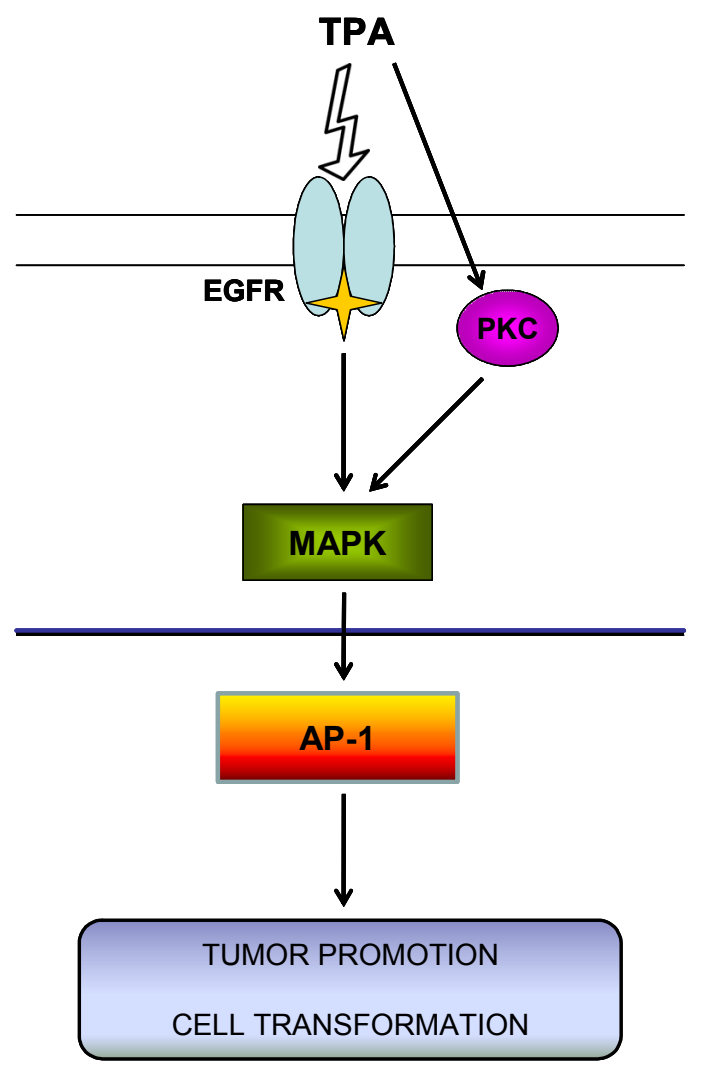

Figure 2.3. TPA pathways in the JB6 tumor promotion model. 
transcription was later found to have application in in vitro and in vivo mouse models, in human keratinocyte progression, and in other human progression models (45-47).

AP-1 is a eukaryotic transcription factor composed of various dimeric combinations of proteins from the jun and fos oncogene families (Figure 2.4) $(48,49)$. The activated dimers bind to specific transactivation promoter regions or TPA response elements (TREs) on DNA to induce transcription of genes involved in cell proliferation, differentiation, tumor promotion, and apoptosis (programmed cell death) (50). Elk-1, a transcription factor that binds to the serum-response element (SRE), mediates activation of $c$-fos transcription (Figure 2.4) $(51,52)$.

AP-1 shows progressive activation in preneoplastic-to-neoplastic transformation and is critical in tumor promotion, progression, and metastasis $(33,53,54)$. A dominantnegative mutant form of the c-Jun protein, TAM67, along with other inhibitors of AP-1 have been used to show that AP-1 activation is required for tumor promotion and progression $(33,55-57)$.

\section{MAPKs in AP-1 dependent transformation}

In JB6 $\mathrm{P}^{+}$, promotion with TPA results in high levels of AP-1 through the mitogen-activated protein kinase MAPK pathway (Figure 2.3 - 2.4) (45). The MAPK family includes the extracellular signal-related kinase (Erk), c-Jun N-terminal kinase (Jnk) and p38 kinase which are vital mediators in the regulation of cellular proliferation, malignant transformation, inflammation, and apoptosis (Figure 2.4) (58-62).

The MAPK cascade is shared by more than one signaling pathway is therefore organized into three generic sequential steps (Figure 2.4). MAPKs are activated by phosphorylation by a MAPK kinase (MAPKK), which is in turn phosphorylated by a MAPKK kinase (MAPKKK). Activation of MAPKKKs generally results from ligandreceptor interactions that trigger activation and recruitment of RAS (a GTP binding protein), GRB2 (an adaptor molecule) and SOS (a guanine nucleotide exchange factor) which signals the intracellular MAPK cascade (63).

Low levels of the MAPKs, Erk1 and Erk2, contribute to the tumor-promotion resistant phenotype in JB6 cells (64). JB6 $\mathrm{P}^{-}$cells stably transfected with Erk2 become sensitive to tumor promoter-induced AP-1 activation and neoplastic transformation, while inhibition of Erk 2 converts JB6 $\mathrm{P}^{+}$to the resistant phenotype $(64,65)$. The conclusion is that Erk1 and Erk2 are required for tumor promoter induced AP-1 activation and for transformation in the JB6 model. TPA-induced transformation does not require Jnk activation. This was determined by the observation that JB6 cells expressing a dominant negative Jnk1 mutant are still susceptible to TPA-induced transformation (66). 
Tumor Promoters (EGF, UV irradiation, TPA, etc.), Growth Factors, Hormones, Stress

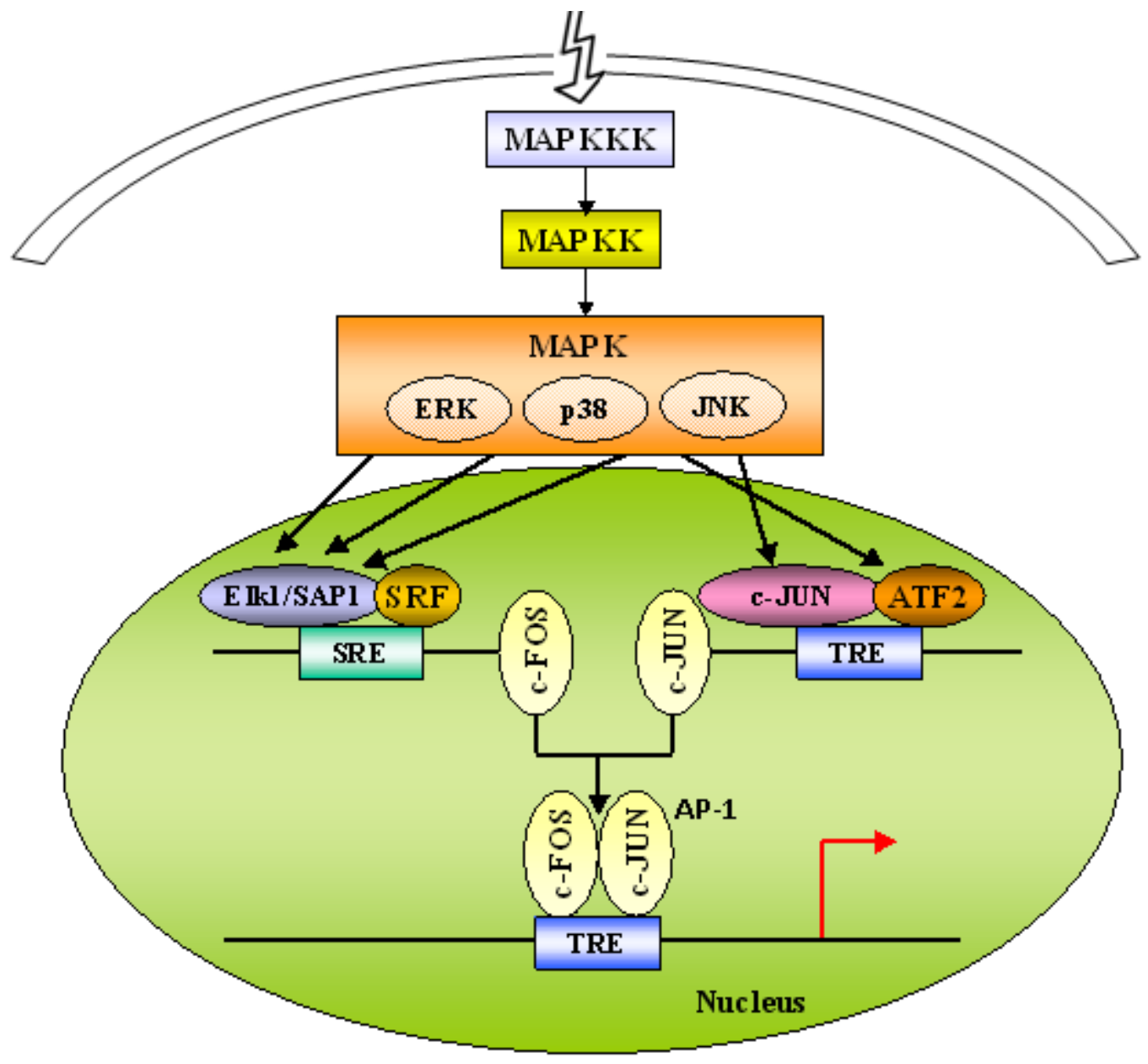

Figure 2.4. $M A P K / A P-1$ pathway 


\section{Chemoprevention Targets}

Signal transduction pathways appear to be good targets for chemoprevention in that they influence the regulation of diverse cellular pathways, particularly those involved in tumor promotion. It is clear that MAPKs and AP-1 are important in tumor promoter induced transformation, making them valid targets for chemoprevention. Many of the identified chemopreventive natural products target these signaling pathways (16). Hence, this pathway was pursued in the dissertation studies (Chapter 5). Nucleoside transporters, a novel potential target for chemoprevention, were also investigated (explained in Chapter 3). Nucleoside transporters are introduced in the next section.

\section{Introduction to Nucleoside Transporters}

Nucleoside transporters (NTs) are integral membrane glycoproteins responsible for the cellular uptake of physiologic nucleosides and nucleobases. In addition, nucleoside transporters are carriers for nucleoside analogue drugs used in the treatment of cancer and viral infections. Because nucleoside transporters are the gateway into cells for these drugs, they play key roles in the physiologic responses to, and therapeutic effectiveness of natural and synthetic nucleosides.

\section{Nucleosides}

Nucleosides are the precursors to nucleotides and consist of a purine or pyrimidine nitrogenous base linked to a pentose sugar (usually ribose or deoxyribose) by an N-glycosidic linkage. Nucleotides are the subunits of the nucleic acids, RNA and DNA. The nucleoside units of RNA are adenosine, guanosine, cytidine, and uridine (Figure 2.5), while those of DNA are deoxyadenosine, deoxyguanosine, deoxcytidine, and thymidine (Figure 2.6). Structurally speaking, nucleotides are nucleosides with phosphate groups attached to the sugar moieties by an ester linkage which allows polymerization through repeated sugar-phosphate groups in turn forming the nucleic acid backbone. The bases connected to each sugar phosphate protrude from the backbone, which through hydrogen bonding, help to fashion the DNA double helix.

In addition to the nucleotide subunits of nucleic acids, other biologically vital nucleotides (e.g. ATP, cAMP) are formed from nucleosides and therefore, nucleosides indirectly sustain various cellular processes including energy provision, protein synthesis, cell replication, and signal transduction.

As mentioned above, nucleosides are the building blocks for nucleotides. Nucleotide biosynthesis can occur via de novo or salvage pathways based on cell type (67). For instance, hepatocytes are capable of de novo purine nucleotide synthesis, while specialized cells including enterocytes and brain and bone marrow cells, do not have de novo synthesis pathways (68). These cells depend solely on salvage mechanisms which recruit extracellular nucleosides for nucleotide biosynthesis (69). In the salvage pathway, 


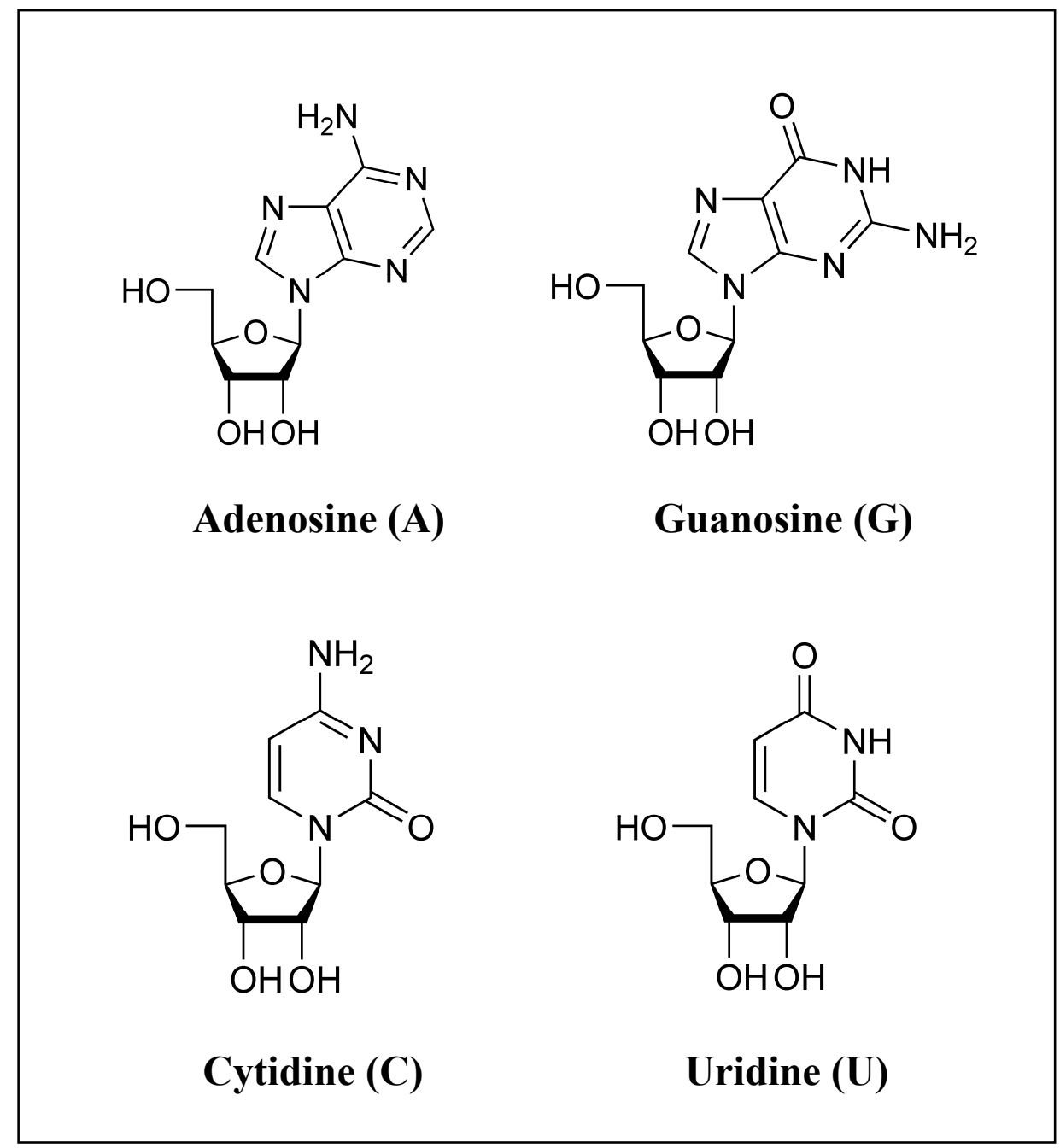

Figure 2.5. RNA nucleosides. 


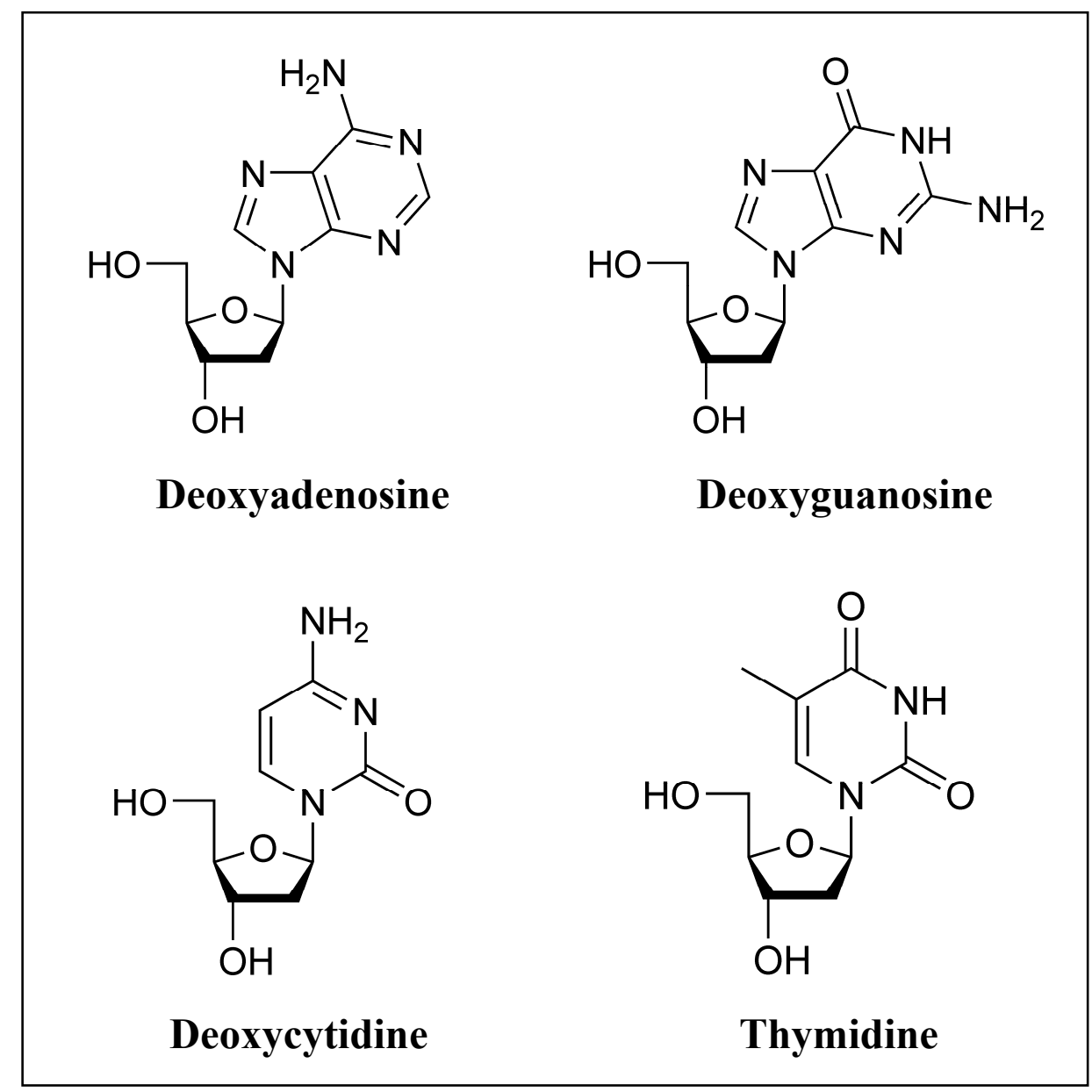

Figure 2.6. DNA nucleosides. 
extracellular nucleotide metabolites are recycled and redistributed making cellular reuptake mechanisms of key importance. Because of the hydrophilic nature of nucleosides, their cellular uptake is dependent upon specialized carrier proteins, in this case, nucleoside transporters.

\section{Nucleoside transporters: Classifications}

There are two major classes of structurally unrelated nucleoside transporters identified in mammals, the equilibrative nucleoside transporters (ENT; SLC29 family) and the concentrative nucleoside transporters (CNT; SLC28 family). Differences in permeant selectivity, regulation, kinetics, and localization has resulted in the heterogeneity of mammalian nucleoside transporters (69). The first nucleoside transporters extensively studied were originally classified based on their sensitivity to inhibition by nitrobenzylmercaptopurine riboside (NBMPR) giving the designations es (equilibrative sensitive) or $e i$ (equilibrative insensitive) transporters (70). Upon successful sequencing and cloning of the human cDNAs, these two transporters were designated as ENT1 and ENT2, respectively. ENT3 and ENT4 were identified upon completion of the human genome project. In addition, ENT-like proteins have been identified in nonmammalian organisms (i.e. prokaryotes, fish) through exhaustive sequence homology searches (71).

Though ENTs are predominantly bidirectional transporters that function by facilitated diffusion, some family members are proton-dependent concentrative transporters (72). The ENT subtypes are widely distributed within the human body and are the most studied and best characterized nucleoside transporters (73). The CNT proteins are unidirectional cation symporters and are found in eukaryotes and bacteria (73). There are five classifications of concentrative nucleoside transport process (cit, cif, $c i b, c s g, c s$ ). Six functional CNT subtypes have been identified in humans. The three best characterized are the $\mathrm{Na}^{+}$-dependent transporter designated as cit (CNT1), cif (CNT2) and $c i b$ (CNT3) (74).

\section{Nucleoside transporters: Homology}

\section{Equilibrative nucleoside transporters}

Human ENT1 (hENT1) was first purified from human erythrocytes in 1988 (75). Approximately ten years later, it was successfully cloned from human placenta and found to encode a 456-residue glycoprotein. Molecular cloning and functional characterization of the rat homologue (rENT1) revealed a 457-residue protein with $78 \%$ identity to hENT1 (76). Cloning of a mouse homologue (mENT1.1) revealed a 460 -residue protein $79 \%$ identical to hENT1 (77). A 458-residue splice variant of the mouse protein (mENT1.2) was identified and shown to be widely distributed. This variant lacks a putative casein kinase II phosphorylation site, but exhibits normal transporter functions (77). 
Like hENT1, the cDNA clone encoding human ENT2 (hENT2) was also isolated from human placenta and identified as a 456-residue protein $46 \%$ identical to hENT1 (78). Cloning of the rat (rENT2) and mouse (mENT2) revealed them both to be 456residue proteins with $88 \%$ identity to hENT2 $(76,79)$. One ENT2 splice variant shows high sequence homology with HNP36 (326-residues), a growth factor induced delayed early response gene $(76,78,80)$. This spliced product does not have the first three transmembrane helices of ENT2 and is not a functional transporter (80). Another splice variant is widely distributed and encodes a 301-residue protein truncated at the $\mathrm{C}$ terminus (hENT2A) and lacks transporter activity (81).

Human ENT3 (hENT3) has 475-residues and is 29\% identical to hENT1. hENT3 has $74 \%$ sequence identity with the 475 -residue mouse variant (mENT3) (72). Human ENT4 (hENT4) has 530-residues and is $86 \%$ identical to its 528-residue mouse homologue (mENT4). hENT4 has only 18\% homology with hENT1 which represents some phylogenetic divergence for the hENT4 subtype (82).

\section{Concentrative nucleoside transporters}

Human CNT1 (hCNT1), cloned from the kidney, is a $71 \mathrm{kDa}$ protein of 650 residues. Human CNT2 (hCNT2) is also a $71 \mathrm{kDa}$ proteins but 658 residues and $72 \%$ identical to hCNT1. Rat CNT1 (rCNT1) is $83 \%$ identical to hCNT1 $(83,84)$. Human CNT3 (hCNT3), cloned from the human mammary gland, is a 691 residue protein $78 \%$ identical to the mouse CNT3 (mCNT3). Human CNT3 (hCNT3) is 47 and 48\% identical to hCNT2 and hCNT1, respectively (85).

\section{Nucleoside transporters: Topology/Structure}

Equilibrative nucleoside transporters (ENT1-4) are predicted to have 11transmembrane spanning domains with glycosylation sites in the loop between transmembrane domain (TM)1 and TM2 (Figure 2.7) $(69,75,86)$. Glycosylation sites are similarly located in ENT2 and ENT3 whereas ENT4 has putative glycosylation at the Cterminus (87). Various structural studies have been done to better understand permeant/and or substrate binding to nucleoside transporters. Chimera and mutagenesis studies between ENTs of various species indicate that TM1, TM2, TM4, TM5, TM8, and TM11 arrange to form a solvent-accessible substrate binding site $(69,88-90)$. This arrangement suggests the ENT family may have 3D structures similar to members of the major facilitator superfamily (i.e. bacterial lactose transporter, LacY) despite little sequence homology between the two families $(69,88,91)$.

Both the ENT and CNT family proteins have a cytoplasmic N-terminus and an extracellular C-terminus (Figure 2.7). A characteristic difference between $\mathrm{h} / \mathrm{mENT} 3$ and the other ENTs is its long (51 residue) N-terminus (73). The topology of CNT is believed to consist of 13 membrane spanning domains with TM7 and TM8 implicated in permeant selectivity. Cation binding sites are likely located in the $\mathrm{C}$-terminal region of the protein (92). 

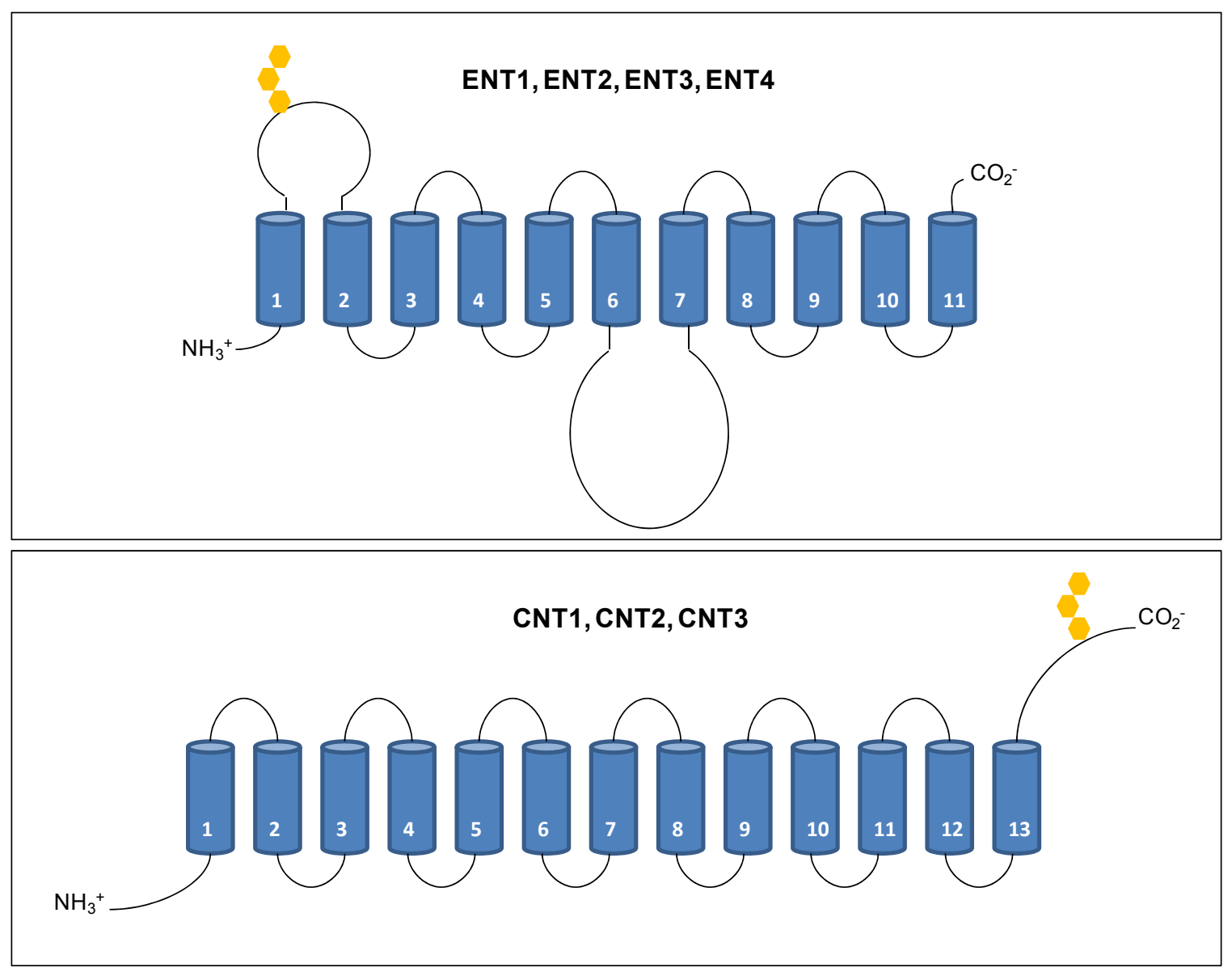

N-linked oligosaccharide chain

Figure 2.7. Topographical model of ENTs and CNTs. 


\section{Nucleoside transporters: Localization/Tissue distribution/Abundance}

All of the ENTs are widely distributed in mammalian tissues but each subtype has regions of noteworthy localization compared to other family members. ENT1 can be found in erythrocytes, heart, kidney and CNS (81,93-96). ENT2 is particularly abundant in skeletal muscle but is also found in brain, heart, lung, thymus, prostate and pancreas $(80,96)$. ENT3 is particularly abundant in the heart and brain while ENT4 is more abundant in brain and skeletal muscle.

CNTs are predominantly found in highly differentiated tissues (i.e. intestine and kidney epithelia) $(96,97)$. CNT1 is found in the liver, kidney, and small intestines and present at low levels in other tissues $(92,96)$. CNT2 and CNT3 are widely distributed (96). CNT1 and CNT2 are primarily localized to the apical membrane of polarized kidney epithelial cells while ENT1 and 2 are localized to the basolateral membrane. This arrangement implies that nucleoside reabsorption in kidney is mediated by nucleoside transporters $(69,98) . \mathrm{h} / \mathrm{mENT} 3$ is localization to mitochondria and lysosomal membranes (72).

\section{Nucleoside transporters: Substrates/Permeants}

Nucleoside transporters are important for the provision of dietary or physiologic nucleosides as well as various nucleoside analogue drugs.

\section{Nucleosides/nucleobases}

ENT1-3 transport a broad range of purine and pyrimidine nucleosides, whereas ENT2-3 can also transport nucleobases $(69,99)$. There are variations in substrate affinities between ENT1-ENT3. A deviation within this family in terms of permeant selectivity is presented by hENT4, which transports monoamines and other organic cations. Adenosine is transported by all four ENT family members (73). ENT4 is not known to transport other nucleosides besides adenosine. CNT1 transports pyrimidine nucleosides and adenosine while CNT2 transports purine nucleosides and uridine $(84,100)$. CNT3 is broadly selective for purine and pyrimidine nucleosides (101).

\section{Nucleoside analogue drugs}

A variety of nucleoside analogs are of great therapeutic significance as antitumor, antiviral, and antibiotic agents (102). Nucleoside analogue drugs are metabolized to activated triphosphates intracellularly and interfere with nucleic acid synthesis by targeting enzymes involved in nucleoside metabolism or nucleic acid synthesis, or by

DNA/RNA incorporation which interferes with repair mechanisms, among others. In the end, the cytotoxic response to nucleoside analogue drugs is cellular apoptosis $(69,103)$. 
Most nucleoside analogue drugs are hydrophilic, therefore the resultant therapeutic response mainly depends on nucleoside transporter mediated uptake into the cells so that nucleoside analogue drugs can be metabolized and activated. For this reason NTs have become a focal point in studies regarding the clinical efficacy of nucleoside analogue drugs.

\section{Anticancer nucleoside analogue drugs}

Some of the first chemotherapeutic agents in the treatment of cancer were nucleoside analogue drugs. Cladribine and fludarabine are purine nucleoside analogues used mainly in treatment of hematologic malignancies. Pyrimidine nucleoside analogs include cytarabine, which is mainly used in the treatment of acute leukemia, and gemcitabine which is used to treat solid tumors and some hematologic malignancies. Flurouracil and capecitabine, fluorinated pyrimidine drugs, are used to treat colorectal and breast cancer (103).

CNT1 is a high affinity transporter for fluoropyrimidines. Fludarabine transport is mediated by hENT1, hENT2, hCNT2, and hCNT3 (101,104-106). Cladribine is a permeant of the same transporters as fludarabine which implies similar structural specificities $(101,104,107-109)$. Gemcitabine is a permeant for most NT subtypes, but particularly hENT1 and hENT2 (101,110-112). Cytarabine is a permeant of hENT1 and hENT2 but not hCNT1, hCNT2, or hCNT3 $(111,113)$. Figure 2.8 shows various anticancer nucleoside analogue drugs.

\section{Antiviral nucleoside analogue drugs}

The first drug approved for the treatment of AIDS and HIV was the antiviral nucleoside analog drug, zidovudine (AZT), which inhibits reverse transcriptase (103). Through the enzymatic reactions of reverse transcriptase, viral RNA is transcribed into DNA which becomes integrated into the genome of the host and ultimately replicated. Other NAD reverse transcriptase inhibitors include lamivudine and tenofovir (103).

$\mathrm{h} / \mathrm{rENT} 2$ is the primary transport mechanism for the antiviral nucleoside analogue drugs 2'3'-dideoxycytidine (ddC) and 2'3'-dideoxyinosine (ddI) and 3'-azido-3'deoxythymidine (AZT). On the other hand, $\mathrm{h} / \mathrm{rENT} 1$ only poorly transport ddC and ddI and does not transport AZT which suggests that the 3'-hydroxyl group is important in substrate recognition by ENT1 (114).

\section{Nucleoside transporters in the efficacy of nucleoside analogue drugs}

The abundance and tissue distribution of NT proteins has been connected to cellular specificity and sensitivity to Nucleoside analogue drugs (115). A study comparing NT expression in normal and tumor tissues provided evidence that interindividual variations in nucleoside analogue drug response and development of resistance may result from the observed differences in functional expression and/or 


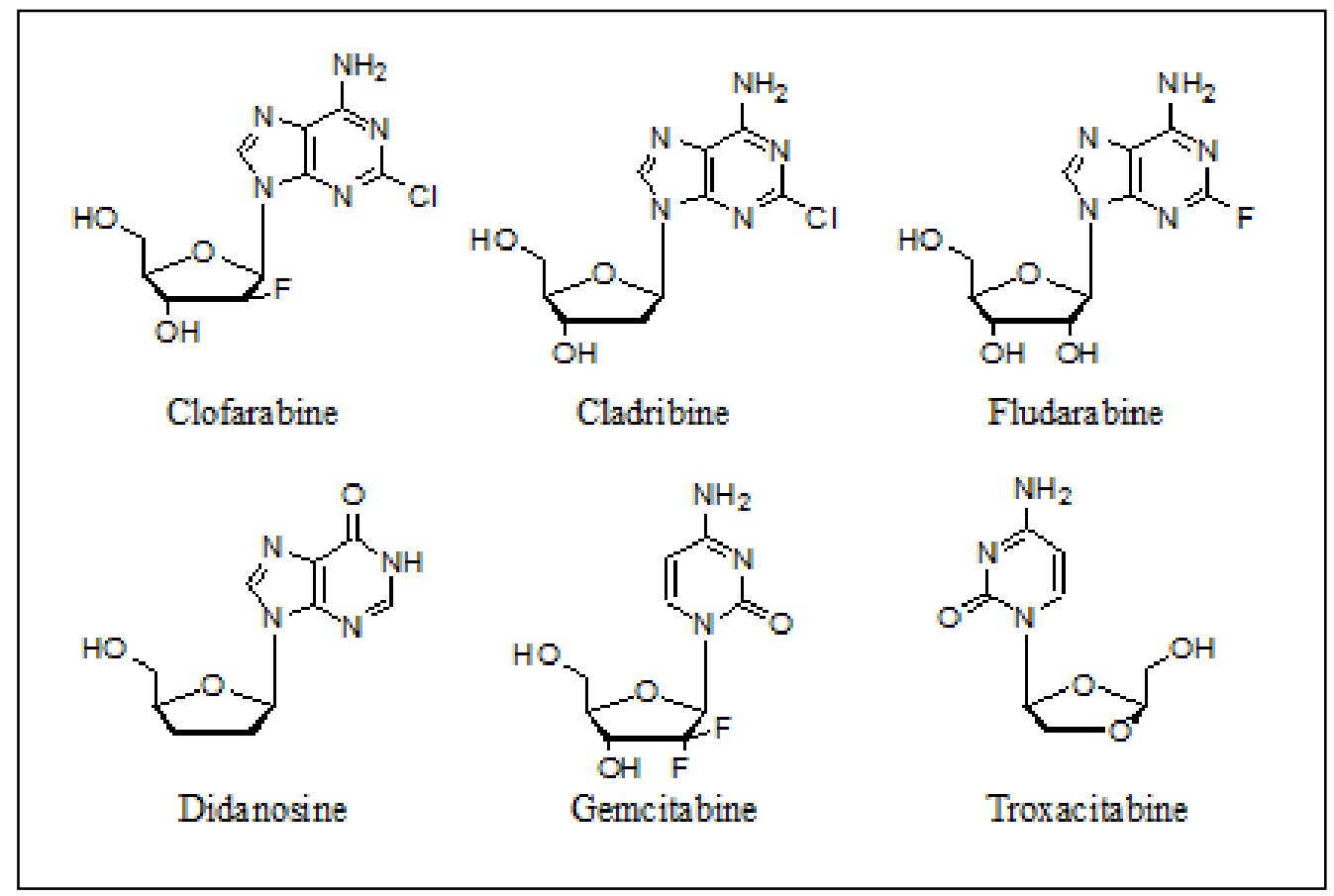

Figure 2.8. Various anticancer nucleoside analogue drugs.

genetic polymorphisms in nucleoside transporters $(74,116)$. In this NT profiling, levels of hENT1 mRNA were lower in some tumors compared to normal tissues. However, in breast, lung, stomach, and rectal cancers, hENT1 expression was higher than normal. Ovarian tumor showed higher hCNT1 expression compared to normal tissue samples while other tumors had lower hCNT1 expression. Most of the breast, prostate, uterine, ovarian, and lung cancers expressed more hCNT2 mRNA than the normal tissues. Significant differences in NT expression between cell types within the same tissue were also observed (116).

It is postulated that increased expression of hENT1 may confer selectivity of Nucleoside analogue drugs to certain malignant cells as evidenced by the association of increased proliferation rates to increased es-type transporter levels $(117,118)$. This is supported by the observation that levels of NTs correlated to cladribine sensitivity in acute lymphoblastic leukemia cells in vitro (119).

Resistance to Nucleoside analogue drugs may result from poor uptake due to inadequate transporter expression. In the case of the pyrimidine nucleoside analogue drug gemcitabine, hENT1 has been shown to be the major route of uptake and deficiency in hENT1 has been associated with gemcitabine resistance (120). Amongst patients with pancreatic adenocarcinoma, the absence of hENT1 showed a positive correlation to a decrease in survival time (121). hENT1 expression has also been implicated as a potential mechanism of resistance to cytarabine by leukemias $(122,123)$. 
hENT1, hENT2 and hCNT1 levels were determined in nearly 300 gynecologic tumors and it was found that hCNT1 was lost in a much higher number of cases than hENT1 or hENT2. NT-negative tumors were associated with poor prognosis which could be due to the fact that these transporters recognize fluoropyrimidines as substrates (124). The identification of NT genetic polymorphisms in transporters can also aid in the predictive aspects of NT profiling (125).

\section{Physiologic roles of nucleoside transporters}

Adenosine has a broad range of important physiologic roles in the body and requires nucleoside transporters for cellular translocation. Adenosine controls the supply and demand of energy in tissues through ATP. Metabolic stress and cell damage trigger the release and accumulation of adenosine in extracellular space. This accumulation of adenosine has various downstream effects some of which involve modulation of homeostasis. In the cardiovascular system, adenosine protects against injury produced during ischemia and reperfusion (126). Adenosine mediates cytoprotection in the central nervous system in response to metabolic insults such as ischemia and hypoxia (126). Other noted roles of adenosine include inhibition of lipolysis, regulation of the immune system, and involvement in sedation and vasorelaxation $(102,126)$. The physiologic effects of adenosine are mediated partly through interaction with plasma membrane adenosine receptors. Four receptor types have been cloned to date (A1, A2A, A2B, and A3) all of which are 7 transmembrane spanning G-protein coupled receptors (127).

Adenosine produced via de novo mechanisms intracellularly or salvage mechanisms is transported in and out of cells by nucleoside transporters distributed throughout the CNS (69). Stressful conditions such as cerebral ischemia, inflammation, and seizure trigger cytoprotective and neuromodulatory adenosine responses $(69,126)$. Studies also suggest adenosine involvement in the neuronal responses involved in alcoholism and drug addiction $(128,129)$. Cellular ethanol models of intoxication have shown that in response to ethanol exposure, adenosine is a common mediator in the resultant changes in neuronal function, signal transduction, and gene expression $(129,130)$. Adenosine has also been found to have neuromodulatory effects on sleep and wakefulness, and inflammatory or neuropathic pain $(131,132)$.

Cardioprotection mediated by adenosine has been extensively studied. The pharmacologic cardiovascular benefits of adenosine result from its actions as an antithrombotic, antiarrhythmic, and a vasodilator (133).

\section{Regulation of nucleoside transporter expression and consequences}

Nucleoside transporter abundance is partly dependent upon cellular proliferation and differentiation signals. Various mechanisms have been proposed for the cell and tissue specific regulation of NT expression. In cultured adrenal chromaffin cells, it was observed that TPA-induced activation of PKC resulted in a decrease in the number of high affinity NBMPR binding sites (i.e. hENT1) (134). In another study, TPA-induced 
differentiation of HL60 cells resulted in a rapid decrease in NBMPR-sensitive nucleoside transport via activation of PKC (135). Another study was aimed at determining the acute affects of TPA-stimulation in cultured human MCF-7 and HeLa cells. These cancer cells have well-characterized NT and are known to express hENT1 and hENT2 but not CNTs. It was shown that acute TPA stimulation results in a rapid increase in hENT1-dependent nucleoside uptake. PKC $\delta$ and/or $\varepsilon$ were found to mediate the observed acute effects. This study also confirmed the decrease in NBTI-sensitive transport after long-term PMA treatment as seen in the HL60 and chromaffin cells (136).

Study of the regulation of nucleoside transport in human B-lymphocytes found TPA and lipopolysaccharide stimulation resulted in a decrease in equilibrative nucleoside transport and hENT1 mRNA levels. In contrast, these stimuli upregulated concentrative transport systems in the B-lymphocytes (137).

Several postulates have been put forward regarding PKC regulation of NTs including: $\mathrm{PKC}$-induces conformational changes which may be a result of posttranslational modifications (phosphorylations) altering transport capacity and binding affinities. Underlying regulatory factors in NT expression are rates of internalization/recycling and rates of synthesis/breakdown (136).

The regulatory response of es has been shown to require nitric oxide (NO) in B lymphocytes (138). Nerve growth factor stimulates adenosine transport in cultured bovine chromaffin cells (139). Colony-stimulating factor 1 (CSF-1), macrophage growth factor, was found to stimulate es-type transport activity in mouse macrophage cells, also with connections to cell cycle (140).

NT expression has also been correlated with the cell-cycle. hENT1 transporter expression doubles between the G1 and G2-M phases in cultured human cancer cells. Hydroxyurea and 5-FU (antimetabolites that inhibit de novo synthesis of DNA precursors or that inhibit DNA synthesis), produced an increase in hENT2 expression suggesting transporter synthesis and/or expression is regulated by cellular nucleotide levels (141). Much like the ENTs, CNT1 and CNT2 expression has similar reports of expression being dependent upon cell cycle, hormones, cytokines, and proliferative status $(137,142$ 144).

Together these data suggest that rapid functional modifications of NTs in addition to more transient effects on NT expression are involved in NT regulation in response to various stimuli. Changes in expression of NTs will have an effect on intracellular drug bioavailability in addition to efficacy of drugs directly targeting NTs. Better understanding of NT regulation can help elucidate the factors involved in drug targeting and sensitivity, and possibly carcinogenesis. Variations in NT regulation between cell types may also offer a guide in the development selectively targeted therapies (cell-type specific). 


\section{Nucleoside transporters as therapeutic targets: Nucleoside transport inhibitors}

The classification of the family of NT transporters began based on sensitivity to inhibition by the nucleoside analogue nitrobenzylmercaptopurine riboside (NBMPR), the prototype ENT1 inhibitor. ENT1-mediated transport is strongly inhibited by NBMPR at subnanomolar levels $\left(\mathrm{K}_{\mathrm{i}}=0.4-2 \mathrm{nM}\right)$ while ENT2 is inhibited weakly in the micromolar range (69). NBMPR is a potent nucleoside transport inhibitor but its potential immunosuppressive and mutagenic effects have hampered its establishment as a clinically useful agent $(145,146)$. Other potent nucleoside transporter inhibitors are dipyridamole (pyrimidopyrimidine), draflazine and soluflazine (piperazines), and dilazep which are used as coronary vasodilators. Figure 2.9 shows a few of these compounds. A host of structural classes have been identified as inhibitors of nucleoside transport (reviewed in Buolamwini 1997 (102)).

hENT1 is the pharmacologic target for the coronary vasodilators dipyridamole and dilazep (75). Among the ENT1 mammalian isoforms, only rENT1 is insensitive to inhibition by these NT inhibitors $(75,76,79)$. Otherwise, the mammalian ENT1 isoforms are more sensitive to inhibition by NBMPR, dipyridamole, and dilazep than the ENT2 isoforms $(75,76,79,80)$. Inhibitors of the sodium dependent concentrative nucleoside transporters are less characterized. The few concentrative transport inhibitors that are known currently are phloridzin, 5'-position modified nucleoside derivatives, benzimidazole ribofuranosides, and 8-position modified purine nucleoside derivatives (147-150).

In a study to determine the effects of p38 MAP kinases on regulation of cytaribine (Ara-C), protein kinase inhibitors were also observed to inhibit nucleoside transport. Since this discovery, a range of structurally diverse serine/threonine kinase inhibitors have been screened and found to inhibit hENT1. SB203580-iodo, a p38 MAPK inhibitor and Ro 31-6045, a PKC inhibitor analogue showed low nanomolar $K_{\mathrm{i}} \mathrm{s}(151,152)$.

\section{Adenosine potentiation}

Inhibition of nucleoside transporters potentiates the effects of adenosine by blocking its reuptake and causing its extracellular accumulation. Dipyridamole, dilazep, draflazine, and lidoflazine are inhibitors of ENT1 which therefore inhibit adenosine reuptake. This results in vasodilation via the interaction of adenosine with the $\mathrm{A}_{2}$ receptors. Nucleoside transporter inhibitors have also been proposed to have potential use in open heart surgery to prevent ischemic damage, and in heart transplantation for preservation of cardiac tissues $(95,153)$.

In the CNS, extracellular accumulation of adenosine mediates neuroprotection (154). The moderate nucleoside transport inhibitor propentofylline has been shown to increase adenosine levels and prevent ischemia-induced brain damage in rats $(155,156)$. Nucleoside transport inhibitors may also potentiate the anti-inflammatory antinociceptive effects of adenosine. 


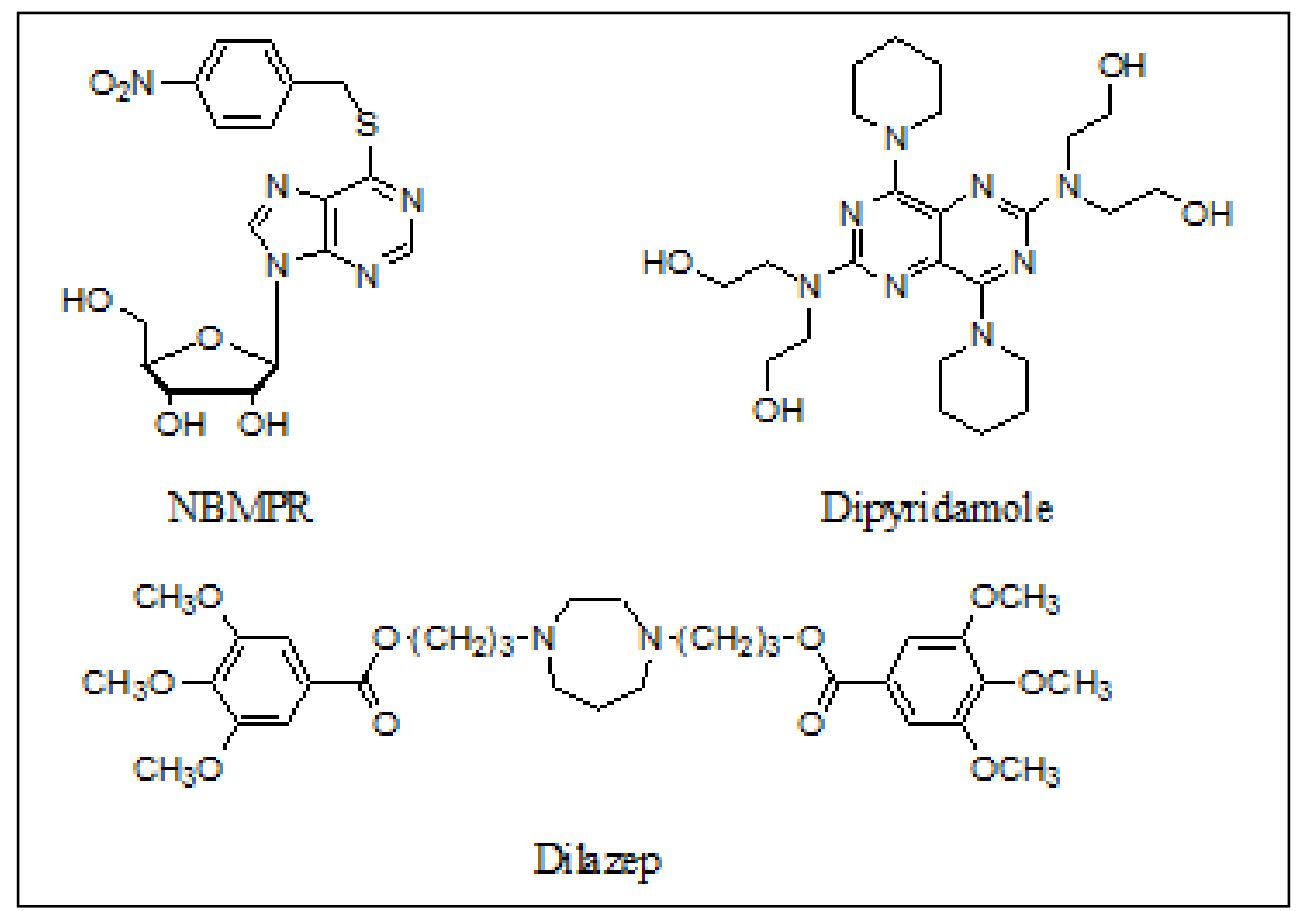

Figure 2.9. Structures of representative nucleoside transport inhibitors. 


\section{Antimetabolite potentiation}

Nucleoside analogue drug cancer (antimetabolite) therapies rely heavily on nucleoside transport for cellular uptake and clinical efficacy. Nucleoside transporters are also key players in the salvage of preformed nucleosides which present a means to circumvent antimetabolite drug activity. The salvage of nucleosides and nucleobases is enhanced in many human tumors which may allow cancer cells to overcome antimetabolite toxicity (157). This results in antimetabolite resistance which is a serious problem in cancer chemotherapy $(125,158)$. Inhibition of nucleoside transport has been studied in preclinical and clinical models as a mechanism to modulate antimetabolite resistance and efficacy.

ENTs are bidirectional and therefore mediate both the uptake and efflux of therapeutic Nucleoside analogue drugs. Therefore, selective inhibition of ENTs is a promising method to enhance the efficacy of Nucleoside analogue drugs, particularly those taken up into cells by concentrative nucleoside transporters. This theory has been tested with promising results. Acute lymphocytic leukemia cells exposed to cladribine followed by treatment with NBMPR to prevent efflux shows enhanced cladribine cytotoxicity (159).

Dipyridamole has been studied most extensively in the clinical setting with promising potential (discussed in more detail in a later section), however partly due to pharmacologic limitations, the clinical use of this agent in antimetabolite potentiation has been abandoned. The search continues for more potent and clinically acceptable nucleoside transport inhibitors.

\section{Antiprotozoal}

Most pathogenic parasites lack salvage pathways of purine nucleotide biosynthesis and rely on uptake of nucleoside and nucleobases from the host for salvage synthesis. In protozoa involved in human diseases such as sleeping sickness, lieshmaniasis and malaria, the equilibrative nucleoside transporters are important in the acquisition of salvage nucleosides. Methods of targeting NTs in antiparasitic therapies aim to exploit variations in permeant selectivity between the host and parasite NTs (160). Possible selective toxicity towards the parasite coupled with host protection could be attained using host specific nucleoside transport inhibitors. This has been demonstrated by using a phosphate-derivative of NBMPR to protect mice infected with Schistosoma mansoni from tubercidin toxicity while retaining toxicity against the parasite (161).

\section{The Future of Nucleoside Transport Inhibitors: A Medicinal Chemistry Perspective}

The therapeutic use of NTIs has been unsuccessful due to poor pharmacologic profiles in regards to toxicity and lack of in vivo efficacy. In the absence of any crystal structures of the nucleoside transporters, the development of novel inhibitors with better clinical profiles relies heavily on ligand-guided drug design. Studies in our research 
group have used current nucleoside transport inhibitors (i.e. NBMPR, DPM) as structural scaffolds from which to extract structural activity relationships (SAR) to direct the synthesis of agents with better potency and ADME/TOX profiles.

Known agents are useful as molecular probes in screening for novel NTIs. The fluorescent es transporter ligand, SAENTA-X8-fluorescein, has been used in the identification of potent NTIs from structure-guided synthesis and flow cytometric analysis (162-164).

Other structure-based design efforts are underway in our lab to probe the NTI binding site(s) to enhance the specificity of NTIs. Structural analogs of NBMPR have been designed and used to probe binding conformation of inhibitors and as photoaffinity probes to identify the amino acids involved in inhibitor binding $(165,166)$.

\section{Summary of Nucleoside Transporters}

Overall, nucleoside transporters indirectly regulate a host of physiologic processes that require or are affected by nucleoside uptake. They are also important in the pharmacologic responses to nucleoside analogue drugs. Nucleoside transport inhibitors can also be used to modulate responses to nucleoside analog drugs in addition to physiologic nucleosides, such as adenosine. DPM, the nucleoside transport inhibitor around which this dissertation is focused, is formally introduced in the next section.

\section{Introduction to Dipyridamole}

Dipyridamole, a pyrimidopyrimidine, inhibits both ENT1 and ENT2 transporters. DPM inhibits [ $\left.{ }^{3} \mathrm{H}\right]$ uridine uptake in PK15 hENT1 and hENT2 cells with an $\mathrm{IC}_{50}$ of $5 \mathrm{nM}$ and $356 \mathrm{nM}$, respectively (164). Its NT inhibitory activity has been exploited in clinical trials in efforts to increase cytotoxicity of the antimetabolite 5-fluorouracil (5-FU). Inhibition of NT by DPM showed enhance 5-FU cytotoxicity in vitro, however, this response was not seen in the clinical setting (167-170). A DPM analogue, BIBW22BS, increased the antiproliferative effects of 5-FU in colon cancer cell lines but not in human tumor xenografts grown subcutaneously in nude mice. DPM has also been shown to potentiate the growth inhibitory effects of the antifolate drug, methotrexate, through inhibition of thymidine transport in HCT116 human colon cancer cells. Unfortunately, this enhanced toxicity effects normal cells as well $(171,172)$.

Dipyridamole has broad pharmacological effects such as vasodilation, antiinflammatory, and antioxidant effects (173). DPM is known in the clinical setting as the cardiovascular agent Persantine. In 1979, the cardiovascular response to DPM was attributed to the prevention of platelet aggregation via inhibition of adenosine uptake (174). Extracellular adenosine comes from the breakdown of ATP by nucleases. DPM blocks nucleoside transport mediated adenosine reuptake into the cells and adenosine levels accumulate outside the cell $(175,176)$. Adenosine interacts with the $\mathrm{A}_{2}$ adenosine receptors which stimulate adenylate cyclase resulting in increased levels of intracellular 
cAMP. cAMP is a potent inhibitor of platelet activation. DPM also increases cAMP and cGMP by preventing breakdown by phosphodiesterase $(177,178)$. Prostacyclin $\left(\mathrm{PGI}_{2}\right)$, a potent inhibitor of platelet aggregation, is stimulated by DPM through its activation of cAMP (179). Combined, these actions facilitate vasodilation.

Due to its vasodilatory effects, DPM is used in cardiac stress tests. During these tests, DPM is administered IV and increases local adenosine. This results in vasodilation of healthy arteries while blood flow in the blocked arteries remains low. The effects of which are monitored by electrocardiographic or imaging techniques $(180,181)$.

Because of the antiplatelet activities of DPM, it is most commonly used as an antithrombotic. Thrombosis is the formation of blot clots within blood vessels. Platelets accumulated on the surfaces of diseased vessels become adhesive substrates for monocytes. The platelet-monocyte interaction stimulates a proinflammatory and prothrombotic activities, with clinical manifestations such as stroke or myocardial infarction (182-186). One caveat in the clinical administration of DPM is its binding plasma $\alpha$-acid glycoprotein and albumin which limits available free serum concentrations (187). Therefore, DPM has a compromised bioavailability.

The clinical agent Aggrenox is a combination of extended-release DPM and aspirin, which results in the additive antiplatelet actions of these two drugs. Aggrenox is used to reduce the risk of a secondary stroke in patients with previous occurrence of stroke/transient ischemic attack (188). In cardiovascular medicine, the introduction of chemopreventive drugs such as Aggrenox which inhibits platelet aggregation and others agents that inhibit cholesterol synthesis, and lower blood pressure, has significantly reduced heart disease incidence and mortalities. Some of the agents are widely used, even in otherwise healthy asymptomatic patients, despite their undesirable and potentially serious side effects (17). It should then only be rational to adamantly pursue the discovery of cancer chemopreventive agents in order to minimize the burden of cancer across the globe. This dissertation work investigates the chemopreventive activity of DPM using structure-based and mechanistic approaches. 


\section{CHAPTER 3： PRELIMINARY DATA}

\section{Nucleosides and Nucleoside Transport Inhibitors in Carcinogenesis}

A few key pieces of evidence guided the rational basis of our interest in studying the roles of nucleosides and nucleoside transporters (NTs) in carcinogenesis. Neoplastic (cancer) cells are quite distinguishable from their normal counterparts in that they do not succumb to the regulatory mechanism of growth and differentiation. When a somatic cell has aged or becomes damaged, it commits suicide (apoptosis) for the sake of the integrity of genome. Cancer cells are more selfish and have a more renegade agenda: to make more copies of themselves. This happens in a more rapid and uncontrolled manner than normal due to an acquired ability to evade the mechanisms that regulate cell proliferation and cell death. Increased propogation rates then places an escalating demand on nucleic acid synthesis, and some cancer cells may accommodate this pressure by increasing de novo and/or salvage nucleotide biosynthesis. Nucleoside transporters are essential for transport of the nucleosides required for nucleotide biosynthesis.

We present the concept that nucleoside transporters may be a valid target in chemoprevention efforts. This hypothesis has supporting evidence from other labs in addition to studies done by our research group which are presented in this chapter.

\section{Nucleosides in carcinogenesis}

Two decades ago, it was reported that increased activities of key enzymes involved in both salvage and de novo nucleotide biosynthesis have positive correlations with neoplastic transformation and subsequent progression (157). Other reports observed that supplementation with deoxyribonucleosides or ribonucleosides resulted in resistance to the antitumor promotion effects of DHEA and its derivative fluasterone in TPAinduced skin tumors in mice $(189,190)$. Other independent research found that exogenous supplies of ribonucleosides were able to reverse the antitumor promotion effects of DHEA in bladder cancer (191).

\section{Nucleoside transporters in neoplastic transformation}

From the introductory materials in Chapter 2, it is clear that NTs are important in cancer chemotherapy. Stimulation of growth and cell cycle progression, which are often dysregulated in cancers, have been shown to affect nucleoside transport activity. Some neoplastic cells are able to increase the intake of exogenous nutrients based on cellspecific demands (192). Higher levels of nucleoside transport (mainly hENT1) were observed in rat-2 v-fps transformed fibroblasts compared to the wild-type cells (193). Nucleoside transport in quiescent S1 macrophages is predominantly via the es transporter which was increased 3-fold by stimulation with CSF-1. A progressive increase in es transporter expression was also observed in vivo upon administrations of granulocytemacrophage colony stimulating factor-1 to patients with acute myeloid leukemia (194). 
Rapid cell division has been found to stimulate es transporters in a variety of hemapoietic cells and $\mathrm{Na}+$-dependent transport in the liver $(118,194,195)$. The thymus is a recognized site of active T-lymphoid cell proliferation and DNA synthesis. This proliferative increase in NT in human thymocytes and lymphocytes has a direct connection to DNA synthesis. T-acute lymphoblastic leukemia, believed to arise in the thymus, is characterized by high proliferation rates paralleled by a high density of nucleoside transport sites (196). These facts only add to the connection between nucleoside transporters and transformation in particular through the demand for higher levels of DNA synthesis. A rapid decrease in growth and a decrease in the number of es transporter accompanies PMA or DMSO-induced differentiation of HL-60 promyelotic leukemia cells (135). Prolonged tamoxifen exposure resulted in the expected retardation in cell growth in MCF-7 cells accompanied by a decrease in the total number of NBMPR-binding sites. Freshly harvested tumor tissues from human breast, colorectal, liver, and stomach cancer had higher numbers of NBMPR binding sites than their normal counterparts (197).

Taken together, the above mentioned observations lead to the idea that preformed ribonucleosides and deoxyribonucleosides may be used in salvage pathways of cellular nucleic acid biosynthesis by preneoplastic or neoplastic cells for tumor promotion and progression. Since nucleoside transporters are required for the cellular uptake of these nucleosides, they may therefore be potential chemoprevention targets. A series of preliminary data was accumulated that supported this hypothesis and sparked the subsequent studies of this dissertation (Chapters 4 and 5). The results of the preliminary studies are presented in the following sections.

\section{Nucleoside transport inhibitors and nucleosides in tumor promotion}

In efforts to test the hypothesis that nucleoside transport inhibitors have potential use in chemopreventive therapies, in vitro experiments were performed looking at effects of nucleoside transport inhibitors on tumor promotion. The chemopreventive agent, DHEA, was used to analyze the chemopreventive potential of the studied nucleoside transport inhibitors.

The first experiments were performed to observe the effects of exogenous nucleosides, and nucleoside transport inhibitors on the anti-tumor promotion activity of DHEA. Based on the fact that inhibition of nucleoside transport using compounds such as NBMPR and DPM effectively interferes with salvage nucleotide biosynthesis, NBMPR and DPM were the NTIs of choice in this investigation.

A summary of the results is as follows: 1) DHEA shows an anti-tumor promotion effect in the JB6 P+ TPA-induced tumorigenic model, 2) the addition of the deoxyribonucleoside cocktail had a significant antagonistic effect on the antitumor promotion effect of DHEA in this model, and 3) the nucleoside transport inhibitors NBMPR $(10 \mu \mathrm{M})$ and dipyridamole $(5 \mu \mathrm{M})$ reversed the antagonistic effects of the extracellular nucleosides, thus restoring the anti-tumor promotion activity of DHEA, with DPM being better than NBMPR in this regard. The results indicate that, as is the case 
reported in the literature for mouse skin cells, external nucleosides do negate the anticarcinogenesis effects of DHEA in the JB6 tumor promotion model as well, at the concentrations used (Figure 3.1).

Additional experiments tested the concentration-dependent effects of NTIs in comparison to DHEA. Below are the resulting dose-response curves after treatment of $\mathrm{JB} 6 \mathrm{P}^{+}$cells with various concentrations of the chemopreventive agent DHEA, or nucleoside transport inhibitors, NBMPR or dipyridamole (DPM). The cells were incubated with $16 \mathrm{nM}$ TPA in the presence or absence of a $50 \mu \mathrm{M}$ deoxyribonucleoside cocktail (Figure 3.2).

These experiments show that in the presence of the tumor promoter, TPA, the nucleoside transport inhibitors have antitumor activity with DPM being more potent. In the presence of nucleosides, the effects of the nucleoside transport inhibitors were antagonized. The reduction in antitumor promotion activity was more pronounced with nucleosides and nucleoside transport inhibitors than with nucleosides and DHEA. This indicates that the effects of the nucleosides are possibly connected to the nucleoside transport activity.

\section{Characterization of Nucleoside Transport Phenotype in JB6 $\mathrm{P}^{+}$Cells}

To validate using JB6 $\mathrm{P}^{+}$cells to study the chemopreventive potential of NTIs, the NT phenotype was first characterized in these cells. The functional expression of concentrative and equilibrative nucleoside transporters was measured by the dependence or independence of nucleoside transport on a sodium ion $\left(\mathrm{Na}^{+}\right)$gradient, a standard method in NT characterization. After determining $\mathrm{Na}^{+}$-dependent or independent transport, NTs are further classified as es (ENT1) or ei (ENT2) subtypes based on their sensitivity to NBMPR inhibition.

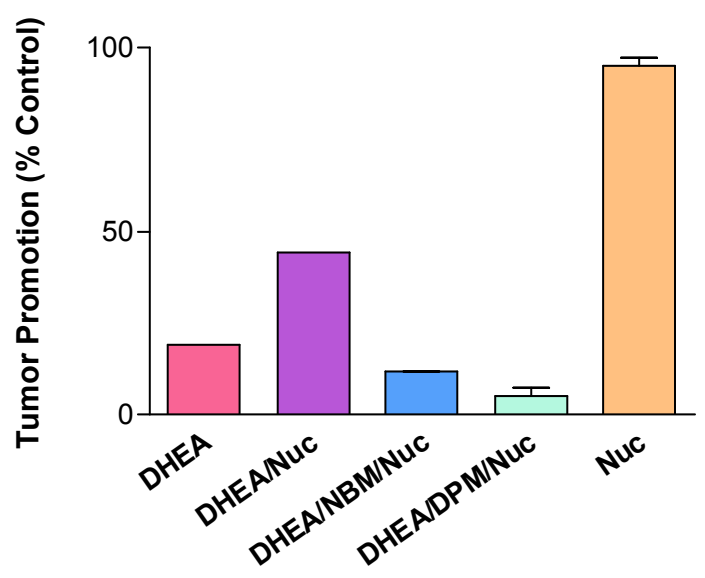

Figure 3.1. Effects of nucleosides and nucleoside transport inhibitors on the antitumor promotion activity of DHEA. 

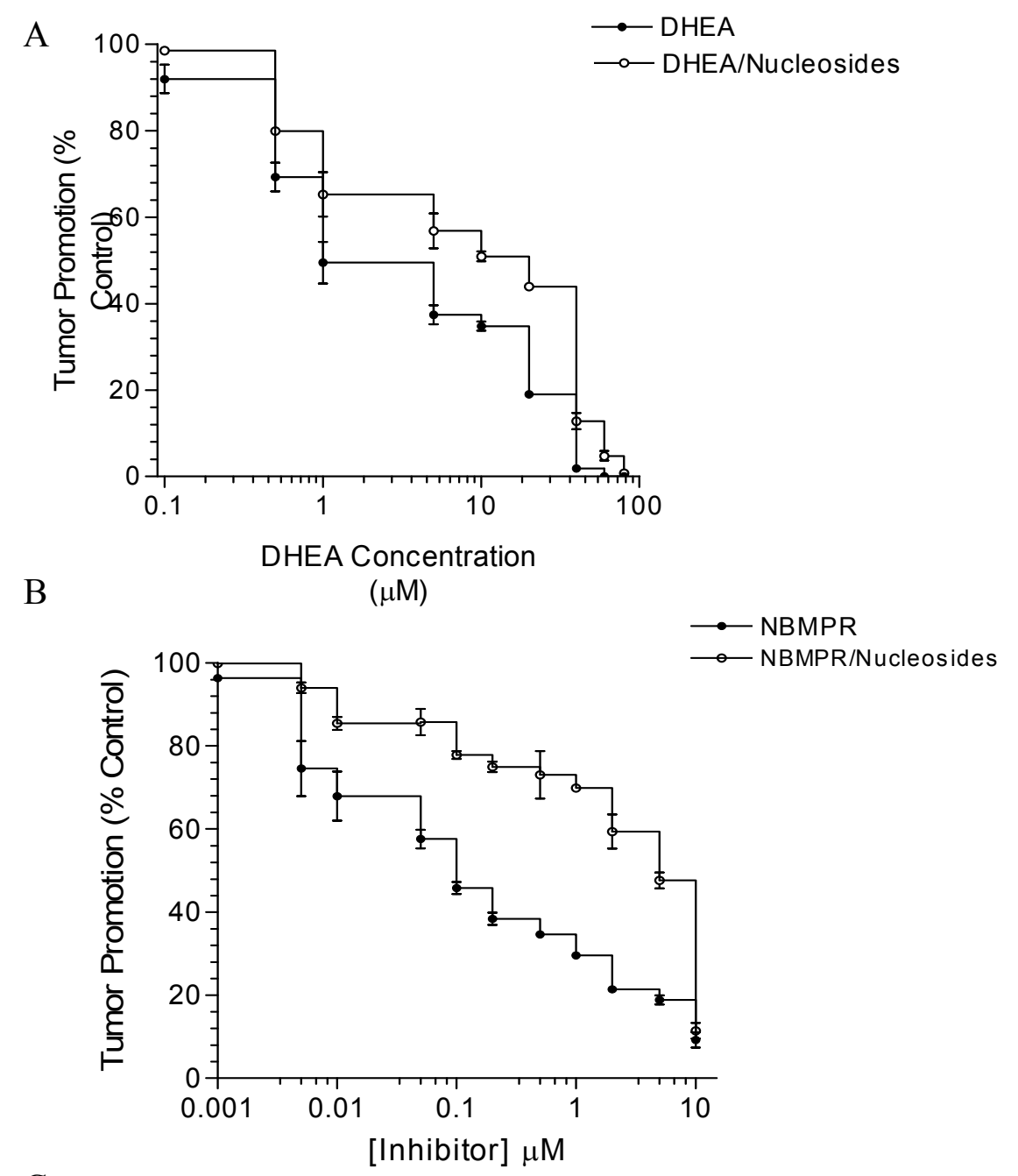

$\mathrm{C}$

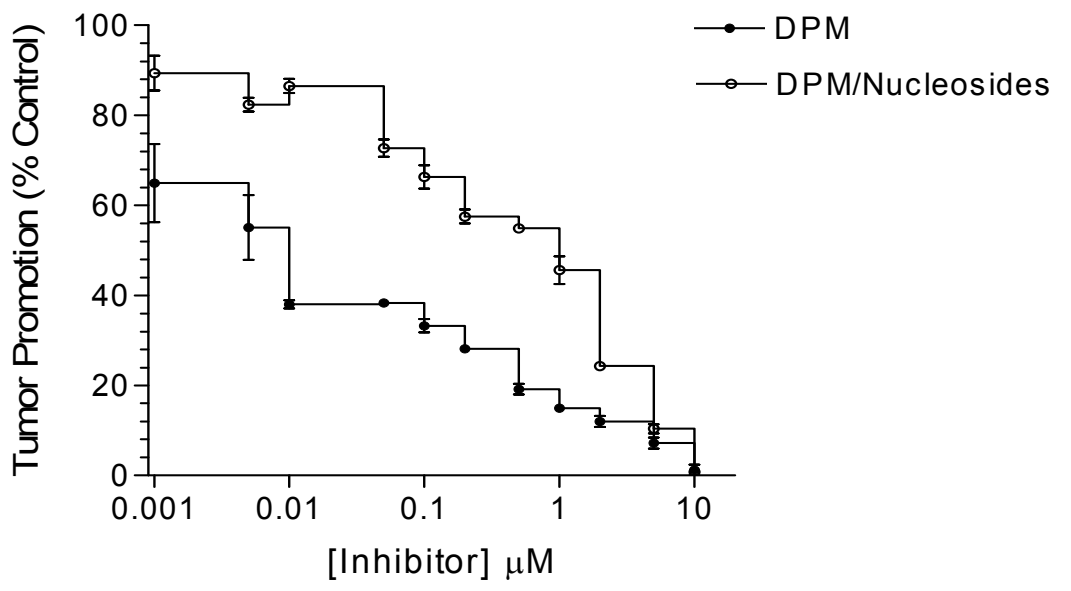

Figure 3.2. Dose-response effects of nucleosides and (A) DHEA, (B) NBMPR, and (C) DPM on tumor promotion. 
Based on these assays of functional NTs, JB6 $\mathrm{P}^{+}$cells showed predominantly an ENT1 transport phenotype, which may explain the higher capacity of nucleoside transport by the $\mathrm{P}^{+}$cell line than the $\mathrm{P}^{-}$variant (data not shown).

Real time PCR analysis of NT mRNA expression confirmed the results of the functional assays of nucleoside uptake showing ENT1 as the predominant transporter, with very little ENT2 or CNT1/2 expression (data not shown). For further characterization, real time PCR analysis of relative ENT1 expression between JB6 $\mathrm{P}^{+}$ (promotion sensitive) and JB6 $\mathrm{P}^{-}$(promotion resistant) variants (Figure 3.3). Expression profiles between the two variants indicates that the tumor promotion sensitive $\left(\mathrm{P}^{+}\right)$cell line has nearly twice the levels of ENT1 transporter mRNA than the tumor promotion resistance $\left(\mathrm{P}^{-}\right)$cell line.

\section{Differential Effects of TPA on NT expression}

Since the JB6 model of TPA-induced tumor promotion was used, the effects of TPA treatment on NT expression were determined for the JB6 $\mathrm{P}^{+}$(promotion-sensitive) and $\mathrm{P}^{-}$(promotion-resistant) variants. These data, summarized in Figure 3.4, show that in both variants, ENT1 predominates over ENT2 with TPA treatment producing increased expression of both ENT1 and ENT2. The observed TPA-induced NT expression was more pronounced in the $\mathrm{P}^{+}$cells. This suggests a possible role of NT overexpression in the TPA-induced tumor promotion of JB6 $\mathrm{P}^{+}$cells.

\section{Summary of Preliminary Data}

Exogenous nucleosides inhibit the antitumor promotion activity of DHEA and nucleoside transport inhibitors. Nucleoside transporter inhibitors show significant antitumor promotion activity. JB6 $\mathrm{P}^{+}$cells which are sensitive to tumor promotion have higher levels of NT expression than JB6 $\mathrm{P}^{-}$which are resistant to promotion. Taken together, these preliminary results support the hypothesis that nucleoside transporters may be a target in chemoprevention.

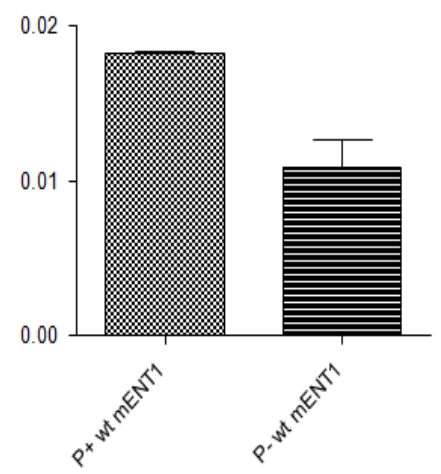

Figure 3.3. Real time PCR analysis of ENT1 gene expression in $\mathrm{JB} 6 \mathrm{P}^{+}$versus JB6 $\mathrm{P}^{-}$cells. 
Effects of $8 \mathrm{hr}$ TPA treatment on expression of ENT1 RNA in JB6 $\mathrm{P}^{-}$and JB6 $\mathrm{P}^{+}$cells

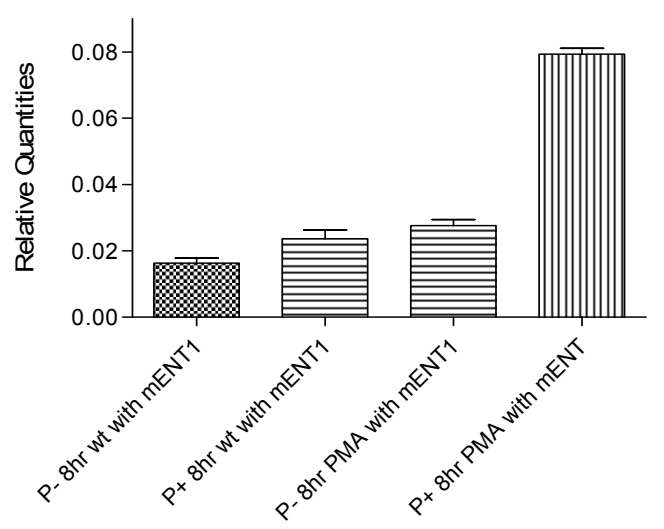

Effects of $8 \mathrm{hr}$ TPA treatment on expression of ENT2 RNA in JB6 $\mathrm{P}^{-}$and JB6 $\mathrm{P}^{+}$cells

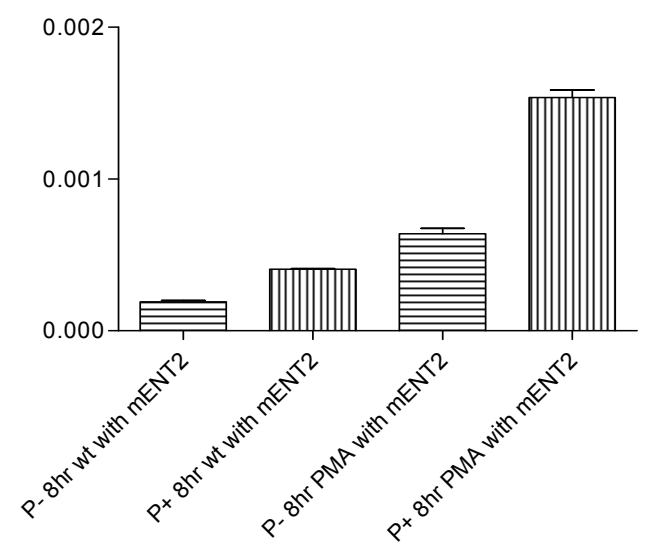

Figure 3.4. Real-time PCR analysis of ENT1 and ENT2 gene expression in JB6 $\mathrm{P}^{+}$and JB6 $\mathrm{P}^{-}$cells and the effect of TPA (PMA) treatment. 


\section{CHAPTER 4: THE ANTITUMOR PROMOTION EFFECTS OF DIPYRIDAMOLE AND ANALOGUES}

\section{Introduction}

Previous studies in our lab focused on exploring what roles nucleosides and nucleoside transport inhibitors (NTIs) might play in carcinogenesis. From that work, nucleoside transport inhibitors were found to have significant antitumor promotion activity in the JB6 mouse epidermal cell carcinogenesis model. Of the nucleoside transport inhibitors studied, dipyridamole appeared to have the best antitumor promotion activity at the concentrations tested. In an independent study, with the aim to identify more potent nucleoside transport inhibitors, an extensive and structurally diverse series of dipyridamole analogues was synthesized and tested for NTI activity (164).

With such a large library of DPM analogues at hand, it presented an opportunity to explore those compounds for antitumor promotion activity and subsequent structure activity relationships. This chapter details the antitumor promotion effects and SAR of dipyridamole and 64 of its analogues. The compounds were numbered for these studies as 101-164 by structural groups. Compound 164 does not follow the sequential numbering by structural group because it was the last compound added to the study after the other analogues had been numbered.

\section{The soft agar colony formation assay}

The soft-agar colony formation assay was utilized to determine the ability of DPM and its analogues to prevent tumor promotion. This assay has its basis in the promotion phase of carcinogenesis. JB6 cells are preneoplastic cells that respond to tumor promoters by irreversible induction of anchorage-independent growth. Anchorageindependent growth is one of the hallmarks of transformation which allows in vitro detection of malignant transformation of cells (20). Transformed cells proliferate uncontrollably and form clusters of transformed cells (or colonies). Cells were treated in the presence of the TPA and DPM analogues and allowed to grow under normal culture conditions for 14 days in the soft-agar media. Colonies were counted to calculate the percent of colony formation based on TPA treatment alone. Untreated (non-transformed) cells do not form these colonies in the soft-agar media (Figure 4.1)

\section{Overview of DPM analogues structural modifications}

All of the dipyridamole analogues maintained the core structure of 2,4,6,8tetrasubstituted-pyrimido $[5,4,-d]$ pyrimidine structure as well as the symmetry of dipyridamole. There were two main regions of substituent variations, designated as Regions 1 and 2 in Figure 4.2. The series of 64 DPM analogues was divided into four structural groups. Compounds in Group 1 had ring substituents at the 4- and 8-position 

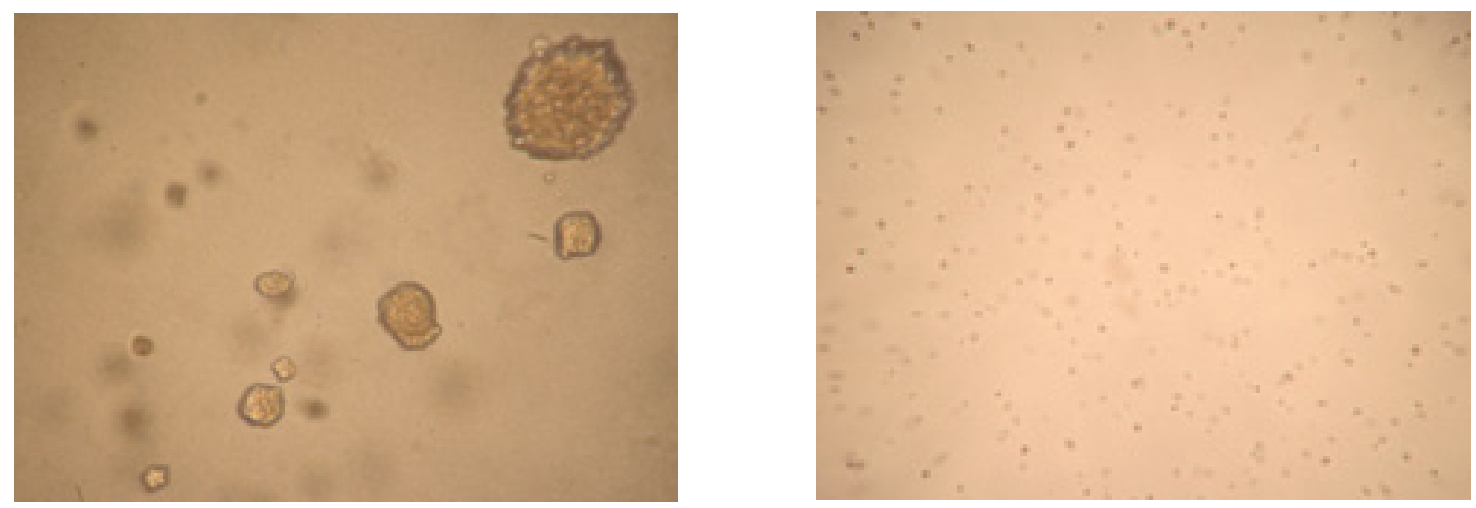

Figure 4.1. TPA-induced colony formation in JB6 $\mathrm{P}^{+}$cells.

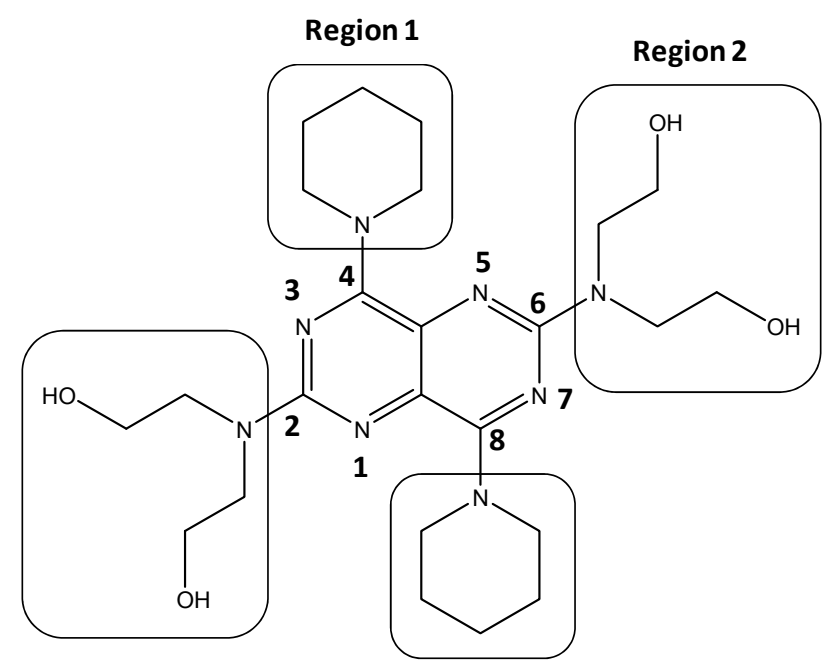

Figure 4.2. Structure of dipyridamole and regions of structural modifications. 
(Figure 4.3). In Group 2 compounds, the 4- and 8-position piperidine rings were substituted by acyclic tertiary amine moieties (Figure 4.4). In Group 3 compounds, 4-,8position tertiary amine was replaced by secondary amine groups (Figure 4.5). Compounds in Group 4 were modified at the hydroxyl groups to give ether compounds with the exception of Compound 158, which has locked the bis-ethanolamine into a morpholino ring (Figure 4.6). Within Groups 1-3 were two subgroups to explore the SAR effects of bis- versus monoethanolamine at positions 2 and 6 (Type A or Type B, Figures 4.3-4.6). The original series of compounds contained Type A and B of each 4-,8position variant. However, only compounds that were readily available were tested, therefore some DPM analogues had only one subtype represented.

\section{Results and Discussion}

To test compounds, JB6 $\mathrm{P}^{+}$cells $\left(3 \times 10^{3}\right)$ were exposed to $10 \mathrm{ng} / \mathrm{ml}$ TPA in soft agar in the presence or absence of $10 \mu \mathrm{M}$ DPM, compounds 101-164, or vehicle (DMSO) for 14 days. TPA-induced cell transformation was significantly inhibited by DPM ( $\sim 80 \%)$. The inhibitory effects of compounds 101-164 are compared to DPM and summarized in Tables 4.1 - 4.4. Approximately $20 \%$ of the screened analogues showed more than $95 \%$ inhibition of TPA-induced transformation with representation from each structural group. The inhibitory activities compounds range from $12-100 \%$ inhibition of TPA-induced transformation. Bar graphs of these data with error bars are located in Figures $4.7-4.8$.

Group 1 consisted of 14 compounds with various 5- to 10-membered ring substitutions in the place of the piperidine ring of DPM (Table 4.1). Only a few compounds had both Type A and Type B substitutions (103-104, 164-109, 112-113), but of those tested, there was a notable difference between the percent inhibitions of each subtype (Table 4.1). There were also several compounds showing complete inhibition of 127). No significant trend was observed for the activities of the Type A versus Type B ethanolamine substitutions (Table 4.2). The activities ranged from 30 to near $100 \%$ inhibition of colony formation.

Group 3 contained 30 compounds, which is the largest number of analogues among the four groups. In this group, the 4-, 8- position tertiary amine was replaced by a secondary amine to explore the SAR effects of the resulting free hydrogen (Figure 4.5). Substitutions ranged from monoalkyl (128-146), cycloalkyl (147-153), to aromatic rings (154-157). These compounds showed a wide range of activities from $12-100 \%$ inhibition of colony formation. Approximately $40 \%$ of the compounds screened had better activity than DPM. Within this group, there was a prominent trend of higher activity for the bis- versus the monoethanolamine containing compounds (Table 4.3).

The smallest number of analogues was in Group 4, which presented the most closely related to DPM itself. Modifications at the hydroxyl groups afforded activities ranging from $20-100 \%$ inhibition of tumor promotion of the 6 compounds tested. 

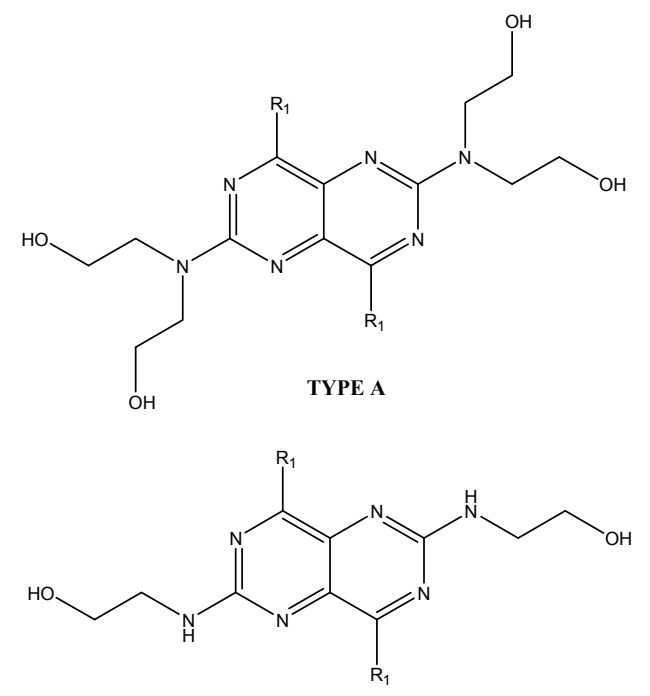

TYPE B

Figure 4.3. Core structures of Group 1 DPM analogues.
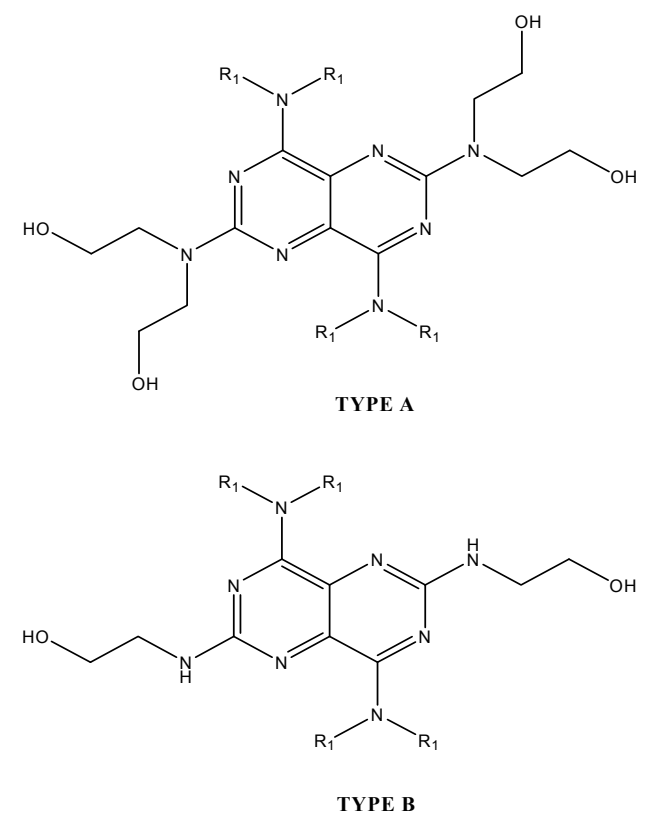

Figure 4.4. Core structures of Group 2 DPM analogues. 

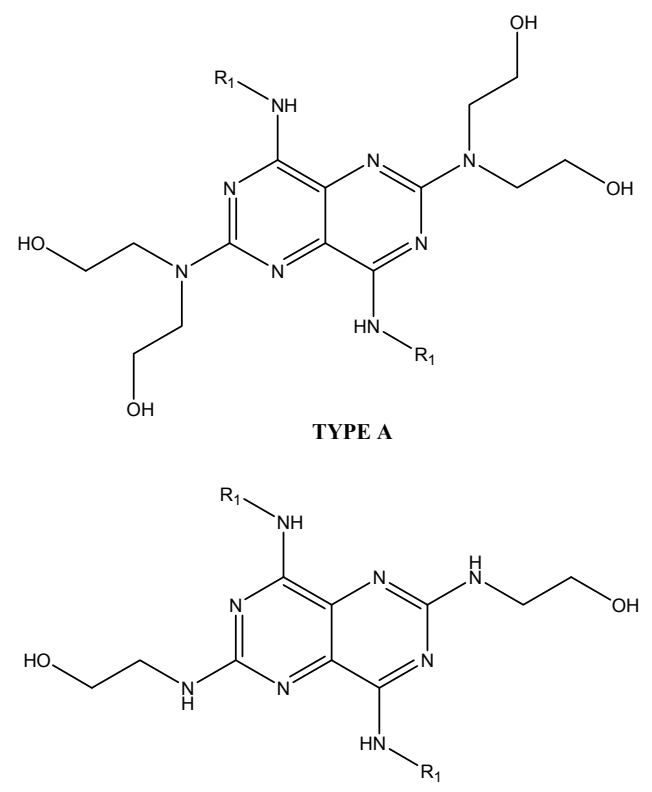

TYPE B

Figure 4.5. Core structures of Group 3 DPM analogues.

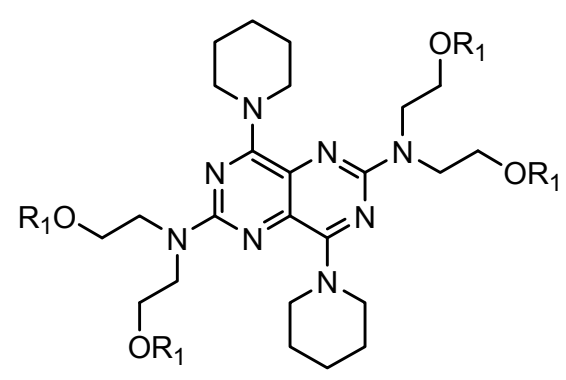

General Structure

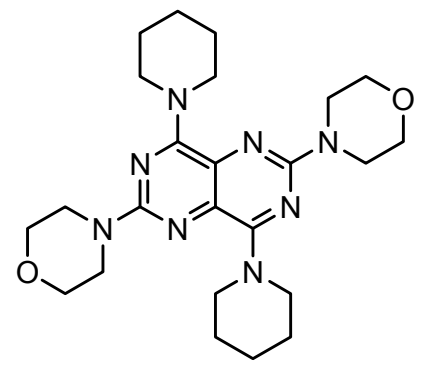

Compound 158

Figure 4.6. Core structures of Group 4 DPM analogues. 


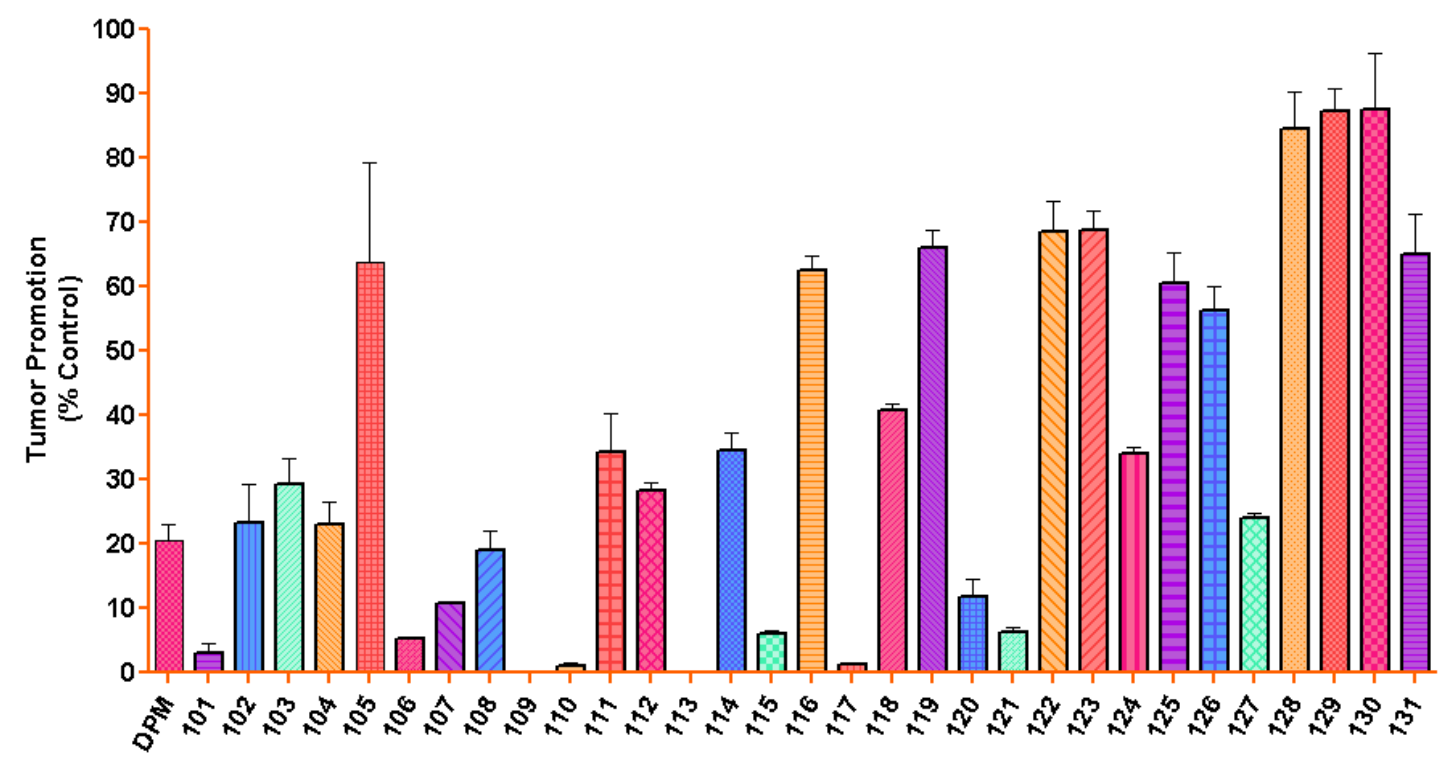

Figure 4.7. Effects of DPM and analogues $(\mathbf{1 0 1}-\mathbf{1 3 1})$ on TPA-induced tumor promotion.

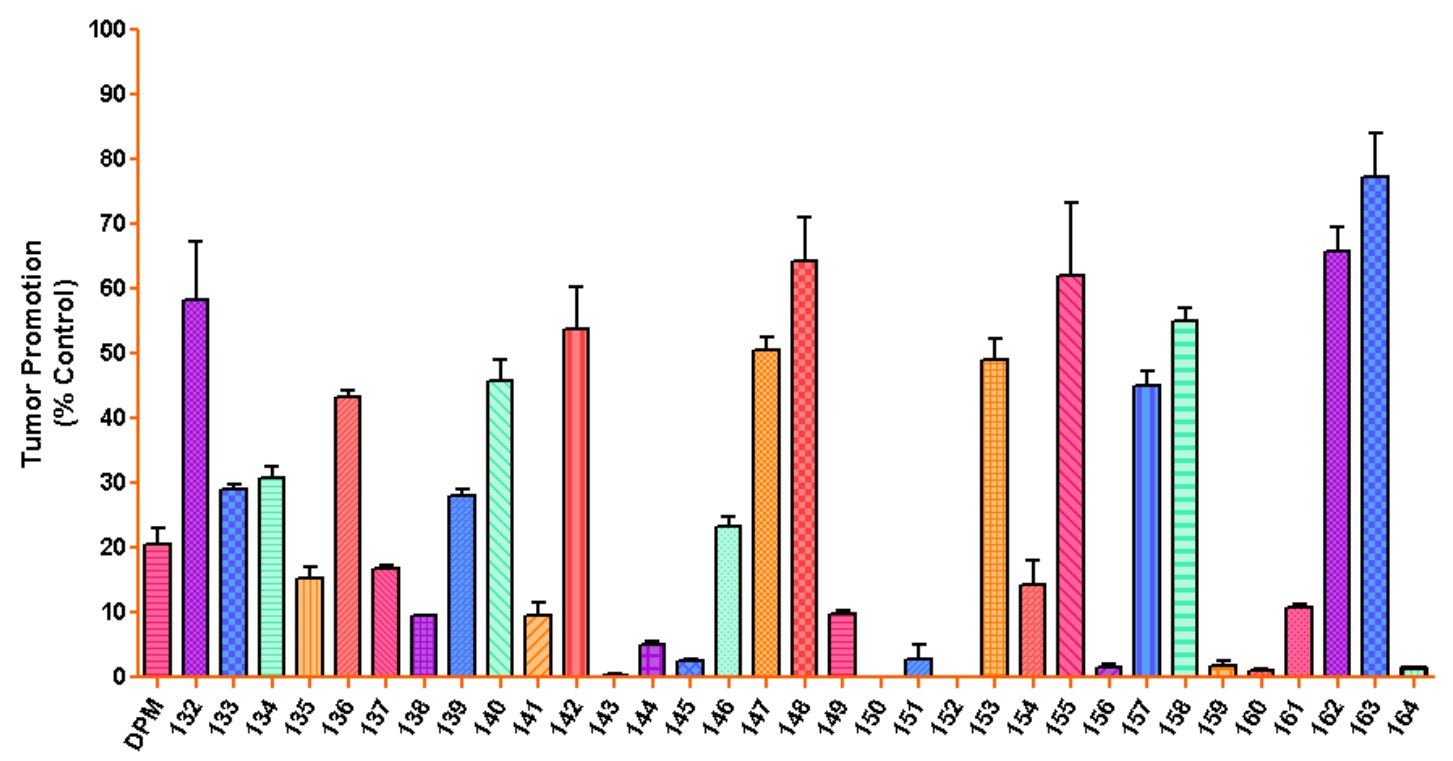

Figure 4.8. Effects of DPM and analogues $(\mathbf{1 3 2}-\mathbf{1 6 4})$ on TPA-induced tumor promotion. 
Table 4.1. Antitumor promotion activities of Group 1 DPM analogues.

\begin{tabular}{|c|c|c|c|}
\hline Compound & Type & $\mathbf{R}^{1}$ & $\begin{array}{c}\text { Percent } \\
\text { Inhibition }\end{array}$ \\
\hline DPM & A & & 79.5 \\
\hline 101 & B & & 97.0 \\
\hline 102 & B & & 76.7 \\
\hline 103 & $\mathrm{~A}$ & & 70.6 \\
\hline 104 & $\mathrm{~B}$ & & 76.9 \\
\hline 105 & A & & 51.3 \\
\hline 106 & A & & 94.7 \\
\hline 107 & A & & 89.2 \\
\hline 108 & B & & 80.9 \\
\hline 164 & A & & 100 \\
\hline 109 & B & & 100 \\
\hline 110 & B & & 99 \\
\hline 111 & B & & 65.6 \\
\hline 112 & A & & 71.6 \\
\hline 113 & B & & 100 \\
\hline
\end{tabular}


Table 4.2. Antitumor promotion activities of Group 2 DPM analogues.

\begin{tabular}{|c|c|c|c|}
\hline Compound & Type & $\mathrm{R}^{1}$ & $\begin{array}{c}\text { Percent } \\
\text { Inhibition }\end{array}$ \\
\hline DPM & & & 79.5 \\
\hline 114 & A & $\mathrm{CH}_{3}$ & 65.6 \\
\hline 115 & $\mathrm{~A}$ & \multirow{2}{*}{$\mathrm{C}_{2} \mathrm{H}_{5}$} & 94 \\
\hline 116 & B & & 37.4 \\
\hline 117 & A & \multirow{2}{*}{${ }^{n} \mathrm{C}_{3} \mathrm{H}_{7}$} & 98.7 \\
\hline 118 & $\mathrm{~B}$ & & 59.3 \\
\hline 119 & B & ${ }^{n} \mathrm{C}_{4} \mathrm{H}_{9}$ & 33.9 \\
\hline 120 & A & \multirow{2}{*}{${ }^{i s o} \mathrm{C}_{4} \mathrm{H}_{9}$} & 88.2 \\
\hline 121 & B & & 93.7 \\
\hline 122 & A & ${ }^{n} \mathrm{C}_{5} \mathrm{H}_{11}$ & 31.4 \\
\hline 123 & A & ${ }^{i s o} \mathrm{C}_{5} \mathrm{H}_{11}$ & 31.3 \\
\hline 124 & $\mathrm{~A}$ & \multirow{4}{*}{$\mathrm{CH}_{3} \mathrm{O}\left(\mathrm{CH}_{2}\right)_{2}$} & 66 \\
\hline 125 & B & & 39.6 \\
\hline 126 & A & & 43.7 \\
\hline 127 & B & & 76 \\
\hline
\end{tabular}

Table 4.3. Antitumor promotion activities of Group 3 DPM analogues $(128-144)$.

\begin{tabular}{|c|c|c|c|}
\hline Compound & Type & $\mathbf{R}^{1}$ & $\begin{array}{c}\text { Percent } \\
\text { Inhibition }\end{array}$ \\
\hline DPM & & & 79.5 \\
\hline 128 & A & $\mathrm{H}$ & 15.6 \\
\hline 129 & $\mathrm{~A}$ & \multirow{2}{*}{$\mathrm{CH}_{3}$} & 12.8 \\
\hline 130 & B & & 12.4 \\
\hline 131 & A & \multirow{2}{*}{$\mathrm{C}_{2} \mathrm{H}_{5}$} & 34.8 \\
\hline 132 & B & & 41.7 \\
\hline 133 & A & \multirow{2}{*}{${ }^{n} \mathrm{C}_{3} \mathrm{H}_{7}$} & 70.9 \\
\hline 134 & B & & 69.3 \\
\hline 135 & A & \multirow{2}{*}{${ }^{i s o} \mathrm{C}_{3} \mathrm{H}_{7}$} & 84.8 \\
\hline 136 & B & & 56.7 \\
\hline 137 & A & ${ }^{n} \mathrm{C}_{4} \mathrm{H}_{9}$ & 83.2 \\
\hline 138 & $\mathrm{~A}$ & ${ }^{i s o} \mathrm{C}_{4} \mathrm{H}_{9}$ & 90.6 \\
\hline 139 & $\mathrm{~A}$ & \multirow{2}{*}{${ }^{\text {tert }} \mathrm{C}_{4} \mathrm{H}_{9}$} & 72.0 \\
\hline 140 & B & & 54.3 \\
\hline 141 & A & \multirow{2}{*}{${ }^{n} \mathrm{C}_{5} \mathrm{H}_{11}$} & 90.3 \\
\hline 142 & B & & 46.3 \\
\hline 143 & A & \multirow{2}{*}{${ }^{\text {iso }} \mathrm{C}_{5} \mathrm{H}_{11}$} & 99.7 \\
\hline 144 & B & & 95.1 \\
\hline
\end{tabular}


Table 4.4. Antitumor promotion activities of Group 3 DPM analogues (145 - 157).

\begin{tabular}{|c|c|c|c|}
\hline Compound & Type & $\mathbf{R}^{1}$ & $\begin{array}{c}\text { Percent } \\
\text { Inhibition }\end{array}$ \\
\hline DPM & & & 79.5 \\
\hline 145 & A & \multirow{2}{*}{${ }^{t e r t} \mathrm{C}_{5} \mathrm{H}_{11}$} & 97.6 \\
\hline 146 & $\mathrm{~B}$ & & 76.8 \\
\hline 147 & A & \multirow{2}{*}{${ }^{c y c l o} \mathrm{C}_{3} \mathrm{H}_{5}$} & 49.6 \\
\hline 148 & $\mathrm{~B}$ & & 35.6 \\
\hline 149 & $\mathrm{~A}$ & ${ }^{\text {cyclo }} \mathrm{C}_{4} \mathrm{H}_{7}$ & 90.2 \\
\hline 150 & $\mathrm{~A}$ & \multirow{2}{*}{${ }^{c y c l o} \mathrm{C}_{5} \mathrm{H}_{9}$} & 100.0 \\
\hline 151 & $\mathrm{~B}$ & & 97.2 \\
\hline 152 & $\mathrm{~A}$ & \multirow{2}{*}{${ }^{c y c l o} \mathrm{C}_{6} \mathrm{H}_{11}$} & 100.0 \\
\hline 153 & $\mathrm{~B}$ & & 50.9 \\
\hline 154 & $\mathrm{~A}$ & & 85.7 \\
\hline 155 & B & & 37.9 \\
\hline 156 & $\mathrm{~A}$ & & 98.4 \\
\hline 157 & B & & 55.0 \\
\hline
\end{tabular}

Table 4.5. Antitumor promotion activities of Group 4 DPM analogues.

\begin{tabular}{lcc}
\hline Compound & $\mathbf{R}^{\mathbf{1}}$ & $\begin{array}{c}\text { Percent } \\
\text { Inhibition }\end{array}$ \\
\hline $\mathbf{D P M}$ & & 79.5 \\
$\mathbf{1 5 8}$ & - & 45.0 \\
$\mathbf{1 5 9}$ & $\mathrm{CHO}$ & 98.1 \\
$\mathbf{1 6 0}$ & $\mathrm{COCH}_{3}$ & 99.1 \\
$\mathbf{1 6 1}$ & $\mathrm{CH}_{3}$ & 89.1 \\
$\mathbf{1 6 2}$ & $\mathrm{C}_{2} \mathrm{H}_{5}$ & 34.2 \\
$\mathbf{1 6 3}$ & ${ }^{n} \mathrm{C}_{3} \mathrm{H}_{7}$ & 22.7 \\
\hline
\end{tabular}




\section{Cytotoxicity screening}

Once the series of DPM analogues was screened at $10 \mu \mathrm{M}$ for their antitumor promotion effects, the data showed some compounds were able to completely inhibit TPA-induced transformation. The alternative to this concept is that some of the compounds may be killing the cells and in turn, the antitumor promotion effects that we noted may have been a result of cytotoxicity. JB6 cells are otherwise normal cells until treated with tumor promoters such as TPA. Since the purpose of the soft colony agar assay was to determine the antitumor promotion effects of DPM and its analogues, it was necessary to assess if the observed antitumor promotion activities were real or just a mere representation of cell killing. To ensure more accurate analysis of the data from the colony assay, the MTT assay of cell viability was performed to determine the effects on JB6 $\mathrm{P}^{+}$cell viability. Cytotoxic effects were quantified as percent viability of untreated JB6 $\mathrm{P}^{+}$cell after treatment with $10 \mu \mathrm{M}$ of each compound (Figures $4.9-4.10$ ). Camptothecin, a cytotoxic alkaloid, and Ara-A, a nucleoside analog inhibitor of DNA polymerase, were used as positive controls for cytotoxicity. The MTT assay of cell viability showed that many of the compounds were cytotoxic ( $<80 \%$ viability), including a significant number of the analogues that showed $>90 \%$ inhibition of tumor promotion in the screening.

\section{Nucleoside transport inhibition: A mechanism of antitumor promotion}

As previously discussed, the DPM analogues tested in this study were originally designed and screened as nucleoside transport inhibitors. The preliminary studies on nucleoside transport inhibitors as potential chemopreventive agents spurred from the concept that neoplastic or preneoplastic cells have a higher demand for nucleic acid synthesis which may be prevented or delayed by the use of nucleoside transport inhibitors. In a first round effort to test the nucleoside transport inhibition as a mechanism in the antitumor promotion activity of the DPM analogues, a correlation analysis of the previously collected nucleoside transport inhibition data and the antitumor promotion data was done by linear regression analysis. After eliminated the cytotoxic compounds, there were 29 analogues remaining that were used for the regression analysis (Table 4.6). The nucleoside transport inhibition assay was done using PK15 nucleoside transport deficient cells transfected to express ENT1 or ENT2. Inhibition of nucleoside transport was measured using the standard ${ }^{3} \mathrm{H}$ [uridine] uptake assay. The correlation between antitumor promotion and nucleoside transport inhibition was higher for ENT1 $\left(\mathrm{R}^{2}=0.4286\right)$ than ENT2 $\left(\mathrm{R}^{2}=0.2097\right)$ (Figure $\left.4.11-4.12\right)$. This result suggests that ENT1 is more likely to be involved in the antitumor promotion activity of these compounds than ENT2. Based on the clustering of the compounds in the ENT1 correlation, it is would be a reasonable prediction that compounds with greater than $60 \%$ inhibition of ENT1 transport will be potent inhibitors of tumor promotion (Figure 4.11). The clustering of the compounds in the ENT2 correlation shows that even poor inhibitors of ENT2 are potent inhibitors of tumor promotion (Figure 4.12). Tables containing cell viability, nucleoside transport, and tumor promotion activity data for all the analogues are in Appendix A (Tables A.1 - A.4). 


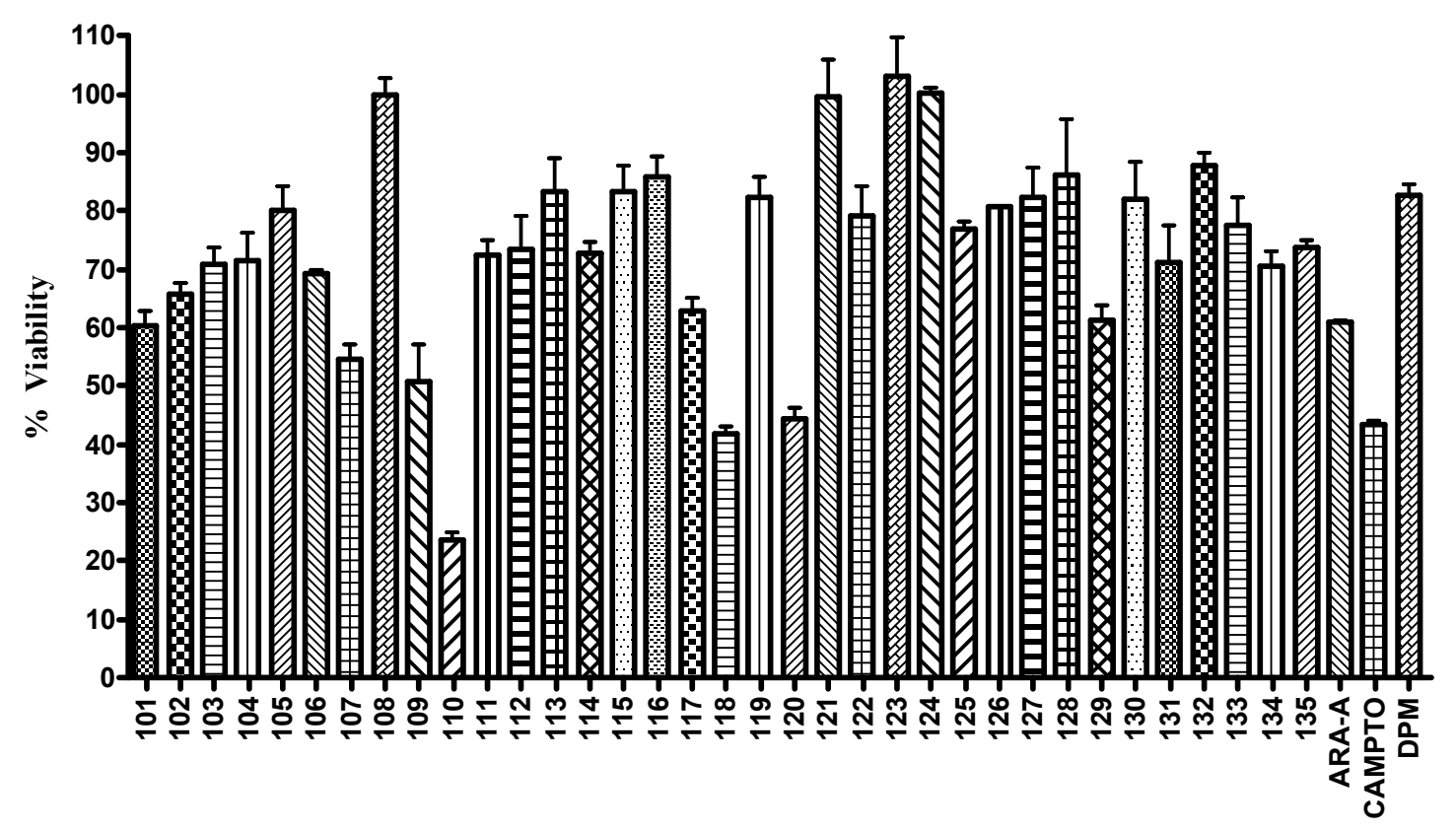

Figure 4.9. Effect of DPM and analogues $(\mathbf{1 0 1}-\mathbf{1 3 5})$ on $\mathrm{JB} 6 \mathrm{P}^{+}$viability

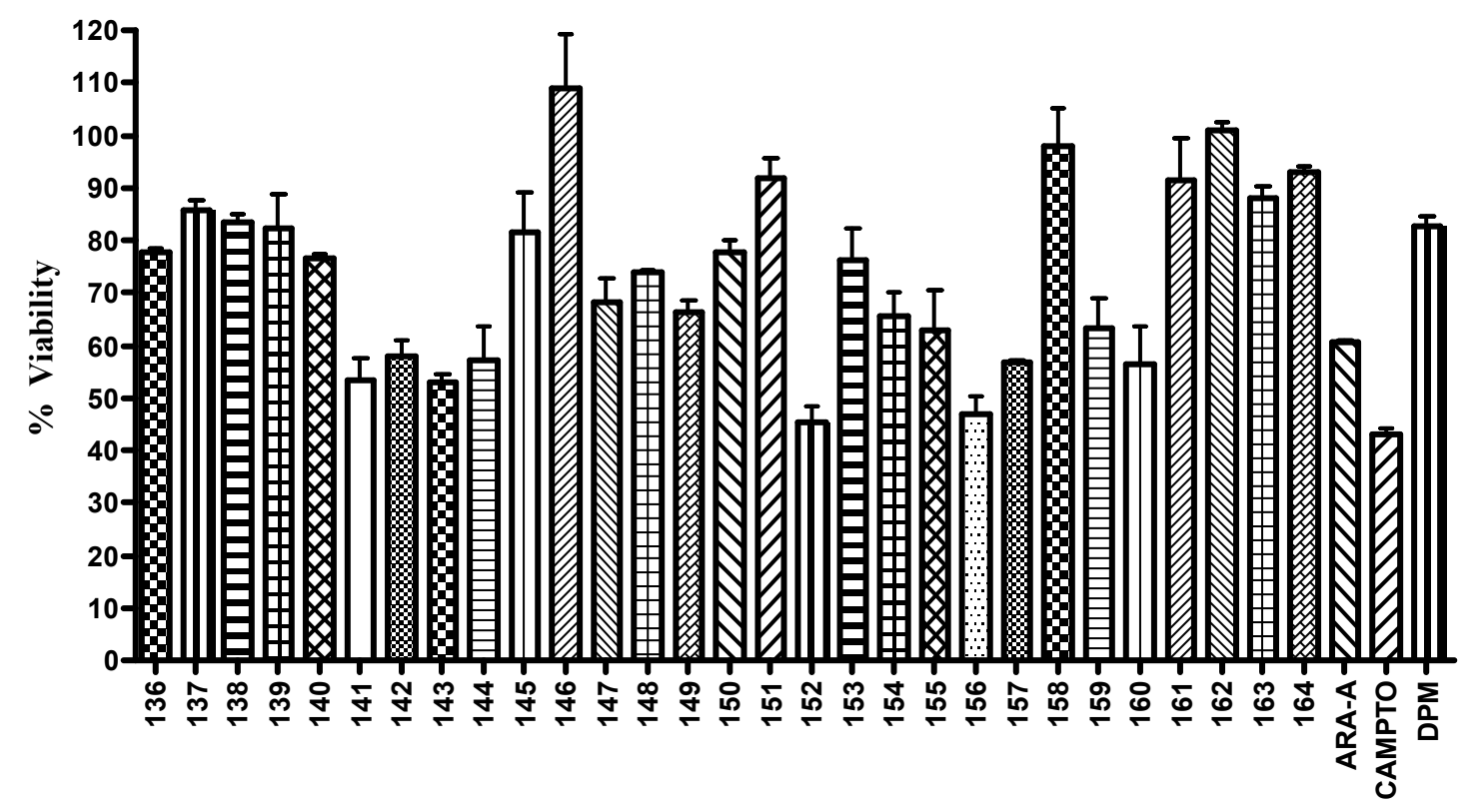

Figure 4.10. Effect of DPM and analogues $(\mathbf{1 3 6}-\mathbf{1 6 4})$ on $\mathrm{JB} 6 \mathrm{P}^{+}$viability. 
Table 4.6. Summary of the nucleoside transport inhibition and antitumor promotion activities of DPM and noncytotoxic analogues.

\begin{tabular}{|c|c|c|c|c|}
\hline \multirow[b]{2}{*}{ Compound \# } & \multirow[b]{2}{*}{ \% Viability } & \multicolumn{3}{|c|}{ \% Inhbition } \\
\hline & & $\begin{array}{c}\text { ENT1 } \\
\text { Uptake }\end{array}$ & $\begin{array}{c}\text { ENT2 } \\
\text { Uptake }\end{array}$ & $\begin{array}{c}\text { Tumor } \\
\text { Promotion }\end{array}$ \\
\hline 104 & 71.4 & 58.7 & 33.0 & 76.9 \\
\hline 105 & 80.0 & 28.9 & 18.3 & 51.3 \\
\hline 108 & 99.9 & 83.4 & 33.4 & 80.9 \\
\hline 113 & 83.4 & 74.5 & 3.7 & 100.0 \\
\hline 115 & 83.3 & 88.4 & 75.1 & 94.0 \\
\hline 116 & 85.9 & 77.4 & 84.0 & 37.4 \\
\hline 119 & 82.3 & 31.8 & 84.6 & 33.9 \\
\hline 121 & 99.5 & 58.8 & 92.6 & 93.7 \\
\hline 122 & 79.0 & 19.4 & 5.7 & 31.4 \\
\hline 123 & 103.1 & 31.3 & 11.8 & 31.3 \\
\hline 124 & 100.0 & 68.0 & 77.2 & 66.0 \\
\hline 126 & 80.6 & 53.2 & 21.0 & 43.7 \\
\hline 127 & 82.5 & 7.5 & 5.3 & 76.0 \\
\hline 128 & 86.0 & 7.3 & 3.2 & 15.6 \\
\hline 130 & 81.9 & 30.6 & -0.3 & 12.4 \\
\hline 132 & 87.8 & 25.0 & 1.0 & 41.7 \\
\hline 137 & 85.8 & 92.6 & 68.7 & 83.2 \\
\hline 138 & 83.6 & 95.4 & 89.2 & 90.6 \\
\hline 139 & 82.3 & 86.7 & 17.5 & 72.0 \\
\hline 145 & 81.7 & 85.5 & 37.4 & 97.6 \\
\hline 146 & 109.0 & 67.8 & 24.4 & 76.8 \\
\hline 149 & 66.2 & 89.1 & 89.3 & 90.2 \\
\hline 151 & 92.0 & 27.8 & 21.4 & 97.2 \\
\hline 158 & 97.8 & 71.0 & 25.7 & 45.0 \\
\hline 161 & 91.3 & 89.8 & 86.8 & 89.1 \\
\hline 162 & 101.0 & 60.8 & 0.0 & 34.2 \\
\hline 163 & 88.0 & 21.1 & 1.8 & 22.7 \\
\hline 164 & 93.1 & 94.1 & 79.5 & 100.0 \\
\hline DPM & 82.8 & 97.4 & 98.2 & 79.5 \\
\hline
\end{tabular}




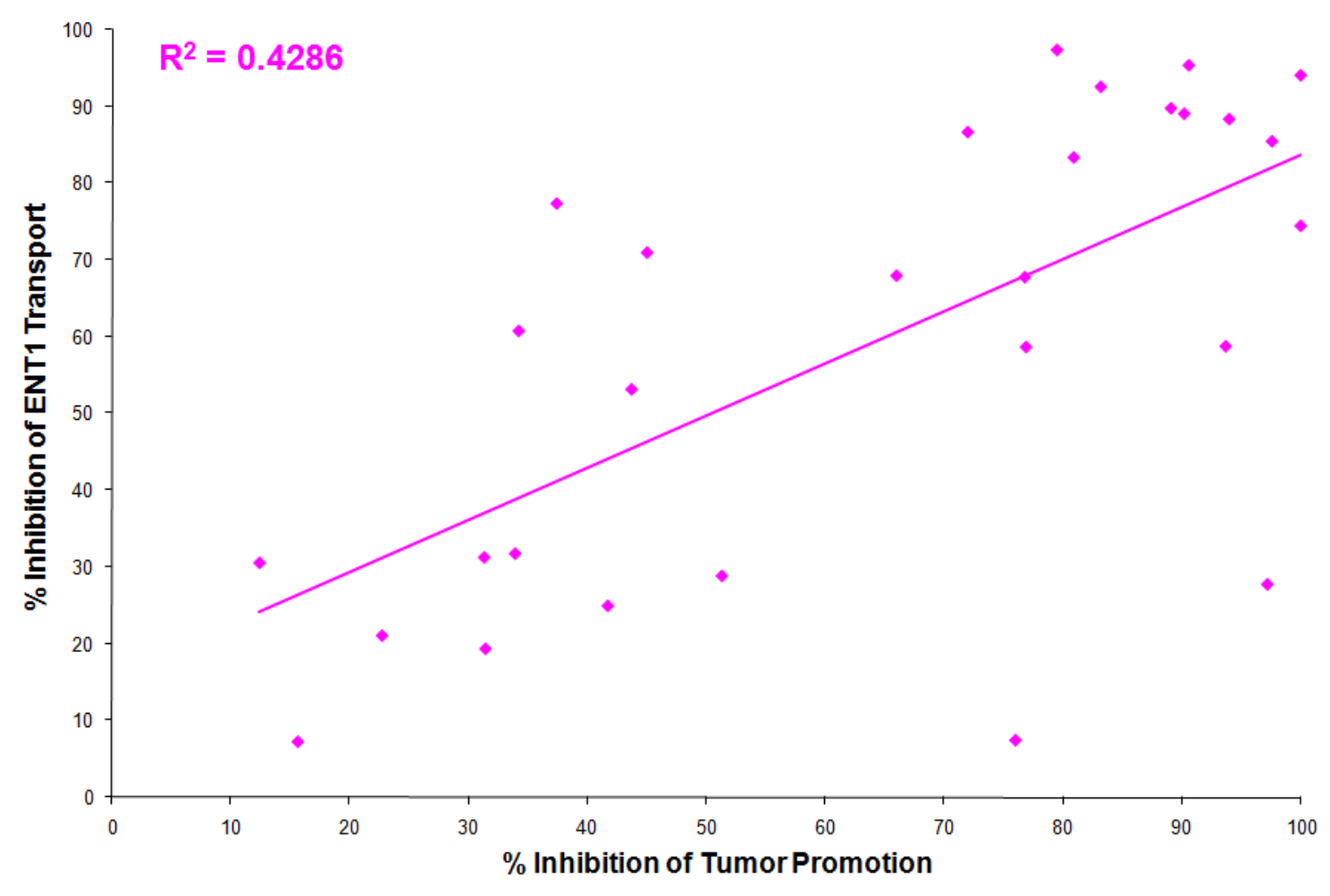

Figure 4.11. Linear regression of percent inhibition of ENT1 transport and percent inhibition of tumor promotion by DPM and analogues 


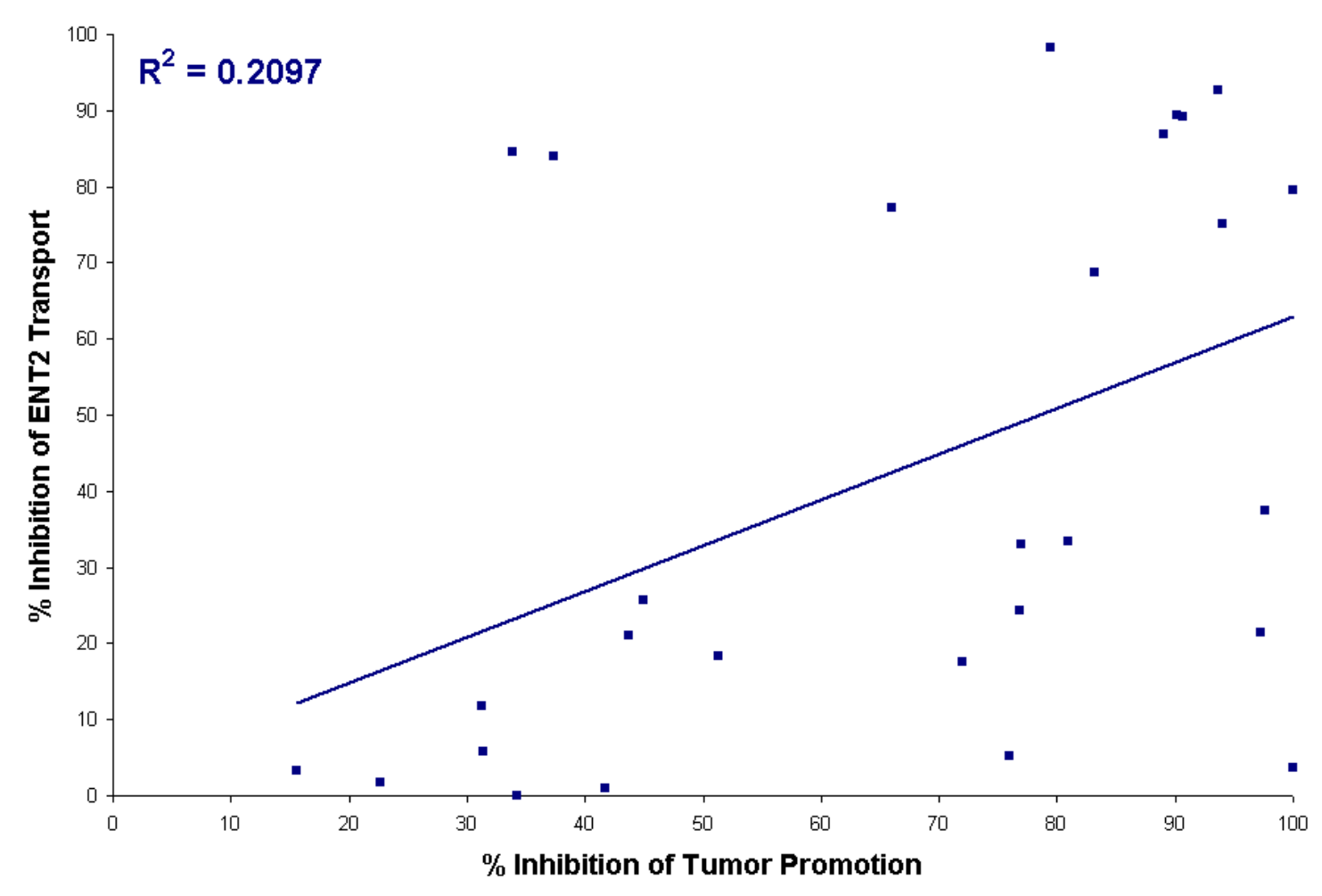

Figure 4.12. Linear regression of percent inhibition of ENT2 transport and percent inhibition of tumor promotion by DPM and analogues 


\section{Selection of compounds for dose-response study}

For the next phase of the study, the objective was to determine the $\mathrm{IC}_{50}$ values of the noncytotoxic analogues. From the original sample of 64 DPM analogues, compounds with less than $80 \%$ viability were eliminated. From the remaining compounds, those with \% inhibition of tumor promotion greater than that of DPM (79.5\%) were selected. The thirteen compounds selected for the dose-response study are shown in Table 4.7 which includes the MTT and antitumor promotion activity data. As in the correlation analysis from the previous section, a few compounds that did not quite pass the viability and/or antitumor activity screening limits for selection $(\mathbf{1 0 4 , 1 4 6 , 1 4 9 )}$ that were kept to broaden the range of activity data for SAR analysis.

\section{Anti-tumor promotion dose response of DPM and analogues}

The soft agar colony assay was repeated in the same manner as for the $10 \mu \mathrm{M}$ screening, but this time we using a range of concentrations $(0.01,0.1,1.0,5.0,10$, and 25 $\mu \mathrm{M})$ for each compound. The colonies were counted manually using inverted microscopy and percent inhibition values were calculated. Soft agar colonies of the control and DPM treatments were stained and digital images were taken (Figure 4.134.14) to represent the visible differences of dose on colony formation.

Dose-response curves were plotted in GraphPad Prism 4 using the calculated percent inhibition of tumor promotion. $\mathrm{IC}_{50}$ values were obtained by selecting the regression analysis that gave the best fit of the data (summarized in Table 4.8) and used to interpret structural activity relationships of these compounds. The structures and calculated $\mathrm{IC}_{50}$ and $\operatorname{LogP}$ data for tested compounds are presented based on the structural group to which they belong in Figures $4.15-4.20$. Structures of the 13 compounds along with $\mathrm{IC}_{50}$ data and dose curves are presented in Appendix B (Figures B.1 - B.5).

\section{SAR analysis}

The 13 compounds selected for $\mathrm{IC}_{50}$ analysis were representative of the various structural groups in the original data set of 64 compounds. Using DPM as the point of reference, a collection of structure activity relationship has been noted for DPM analogues using the antitumor promotion assay (summarized in Figure 4.21). Across all four structural groups, the bisethanolamine substituted analogues were more potent than the monoethanolamine substituted analogues (Type A > Type B). The most potent of all of the analogues, 145 (Type $\mathrm{A}, \mathrm{IC}_{50}=0.12 \mu \mathrm{M}$ ) contained a tert-pentyl secondary amine at the 4- and 8- positions followed in rank by the butyl counterparts $\mathbf{1 3 7}$ (n-butyl, $\mathrm{IC}_{50}=$ $0.55 \mu \mathrm{M}$ ) and 138 (isobutyl, $\mathrm{IC}_{50}=1.41 \mu \mathrm{M}$ ). There was a notable 20 fold decrease in activity between 145 (Type A) and its monoethanolamine counterpart (146, Type B). However, 146 still showed enhanced potency compared to DPM $(145>>146>$ DPM $)$ which suggests the tert-pentyl substitution confers enhanced activity compared to the pyrimidine in DPM. Larger, flexible rings are well tolerated as substitutes for the pyrimidine of DPM $(\mathbf{1 4 9}<$ DPM $<\mathbf{1 6 4})$. Bisethanolamine containing DPM analogues 
Table 4.7. Summary of MTT and antitumor promotion data for selected DPM analogues.

\begin{tabular}{ccc}
\hline Compound & \% Viability & $\begin{array}{c}\text { \% Inhibition of } \\
\text { Tumor Promotion }\end{array}$ \\
\hline 104 & 71.4 & 76.9 \\
108 & 99.9 & 80.9 \\
164 & 93.1 & 100.0 \\
113 & 83.4 & 100.0 \\
115 & 83.3 & 94.0 \\
121 & 99.5 & 93.7 \\
137 & 85.8 & 83.2 \\
138 & 83.6 & 90.6 \\
145 & 81.7 & 97.6 \\
146 & 109.0 & 76.8 \\
149 & 66.2 & 90.2 \\
151 & 92.0 & 97.2 \\
161 & 91.3 & 89.1 \\
\hline DPM & 82.8 & 79.5 \\
\hline
\end{tabular}

Note: Highlight signifies data for DPM 


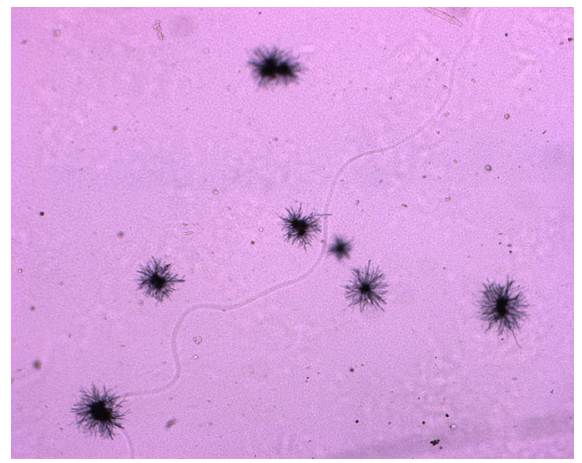

Figure 4.13. Soft agar colony control (16 nM TPA only).
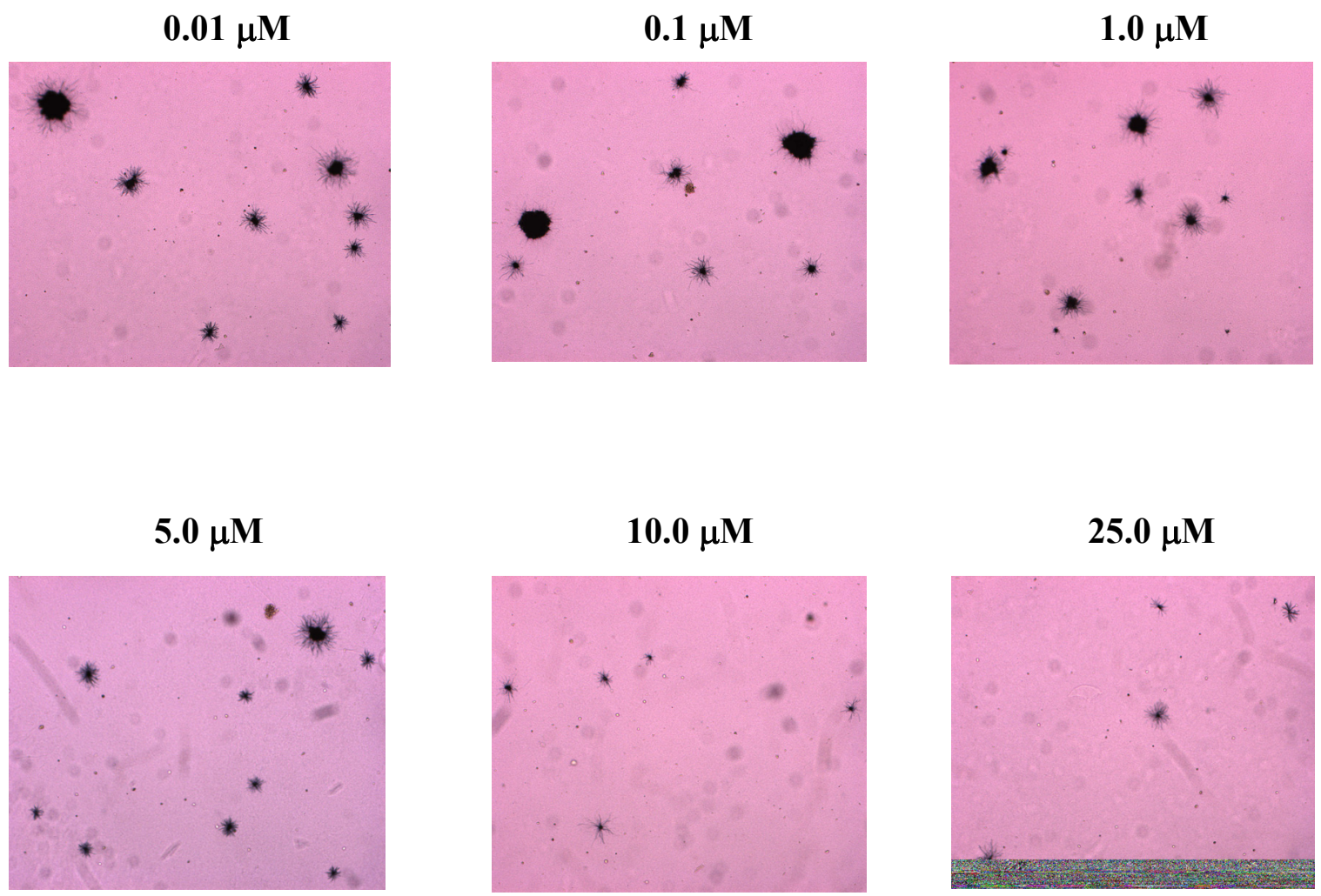

Figure 4.14. DPM dose-response in the soft agar colony assay. 
Table 4.8. Regression equations and calculated antitumor promotion $\mathrm{IC}_{50}$ for $\mathrm{DPM}$ and analogues. (Data presented as the mean \pm standard error of the mean).

\begin{tabular}{llc}
\hline & \multicolumn{1}{c}{ Regression Equation } & ${\text { Calculated } \mathbf{I C}_{\mathbf{5 0}}(\boldsymbol{\mu M})}$ \\
\hline $\mathbf{1 0 4}$ & Sigmoidal-Dose Response & $17.00 \pm 0.54$ \\
$\mathbf{1 0 8}$ & Sigmoidal-Dose Response (Variable Slope) & $4.86 \pm 0.44$ \\
$\mathbf{1 6 4}$ & Sigmoidal-Dose Response & $1.76 \pm 0.57$ \\
$\mathbf{1 1 3}$ & Sigmoidal-Dose Response (Variable Slope) & $5.10 \pm 0.48$ \\
$\mathbf{1 1 5}$ & Sigmoidal-Dose Response & $2.36 \pm 0.48$ \\
$\mathbf{1 2 1}$ & Sigmoidal-Dose Response (Variable Slope) & $3.88 \pm \mathrm{ND}$ \\
$\mathbf{1 3 7}$ & Sigmoidal-Dose Response (Variable Slope) & $0.55 \pm 0.471$ \\
$\mathbf{1 3 8}$ & Sigmoidal-Dose Response (Variable Slope) & $1.41 \pm 0.184$ \\
$\mathbf{1 4 5}$ & Sigmoidal-Dose Response & $0.12 \pm 0.459$ \\
$\mathbf{1 4 6}$ & Sigmoidal-Dose Response (Variable Slope) & $2.83 \pm 0.407$ \\
$\mathbf{1 4 9}$ & Sigmoidal-Dose Response (Variable Slope) & $4.11 \pm 0.103$ \\
$\mathbf{1 5 1}$ & Sigmoidal-Dose Response (Variable Slope) & $2.77 \pm 0.093$ \\
$\mathbf{1 6 1}$ & Sigmoidal-Dose Response (Variable Slope) & $4.90 \pm 0.107$ \\
$\mathbf{D P M}$ & Sigmoidal-Dose Response (Variable Slope) & $3.07 \pm 0.273$ \\
\hline
\end{tabular}

Note: Highlight signifies data for DPM

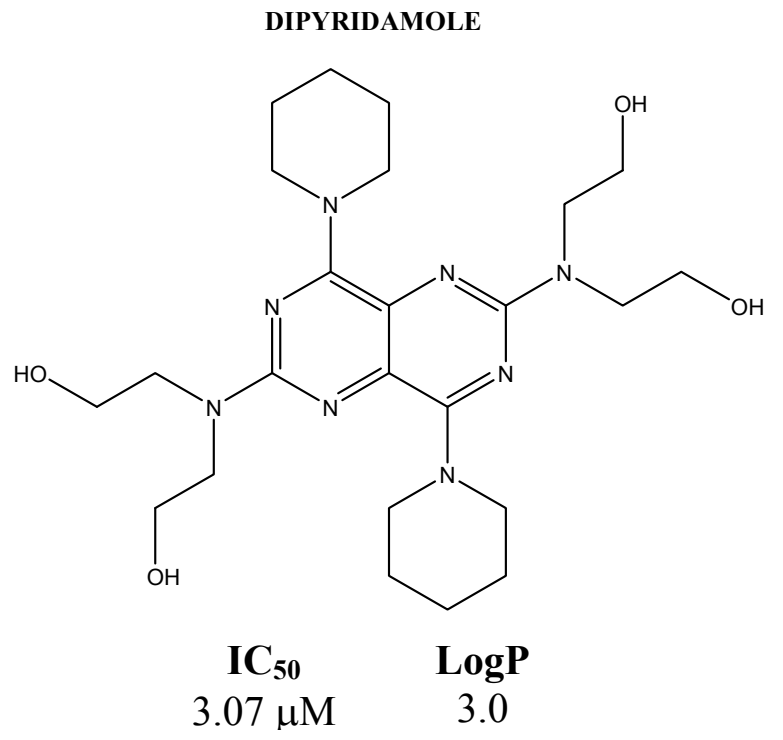

Figure 4.15. $\mathrm{IC}_{50}$ and $\log \mathrm{P}$ data for $\mathrm{DPM}$ 

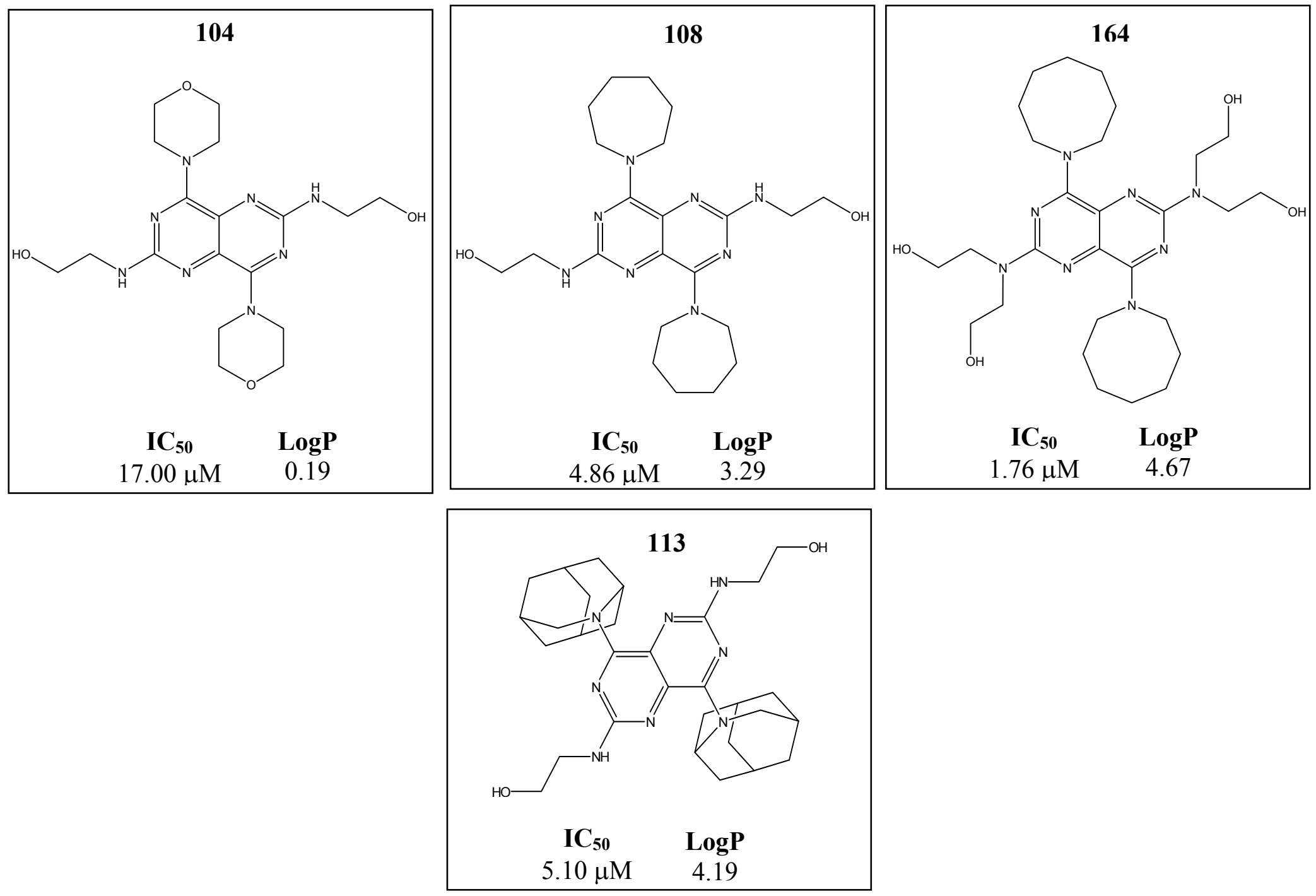

Figure 4.16. $\mathrm{IC}_{50}$ and $\log \mathrm{P}$ data for $\mathrm{DPM}$ Analogues from Group 1. 

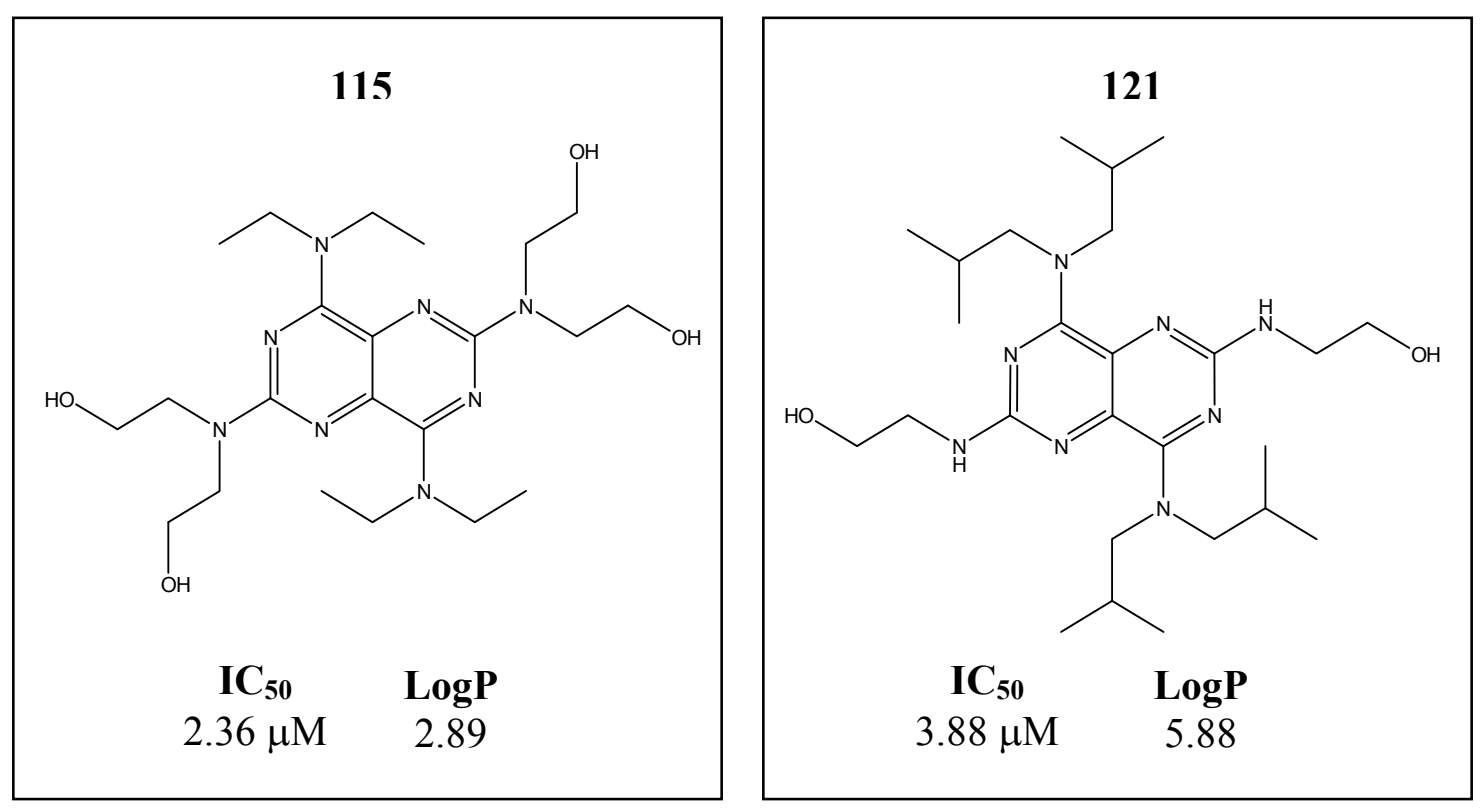

Figure 4.17. $\mathrm{IC}_{50}$ and $\log \mathrm{P}$ data for $\mathrm{DPM}$ analogues from Group 2. 

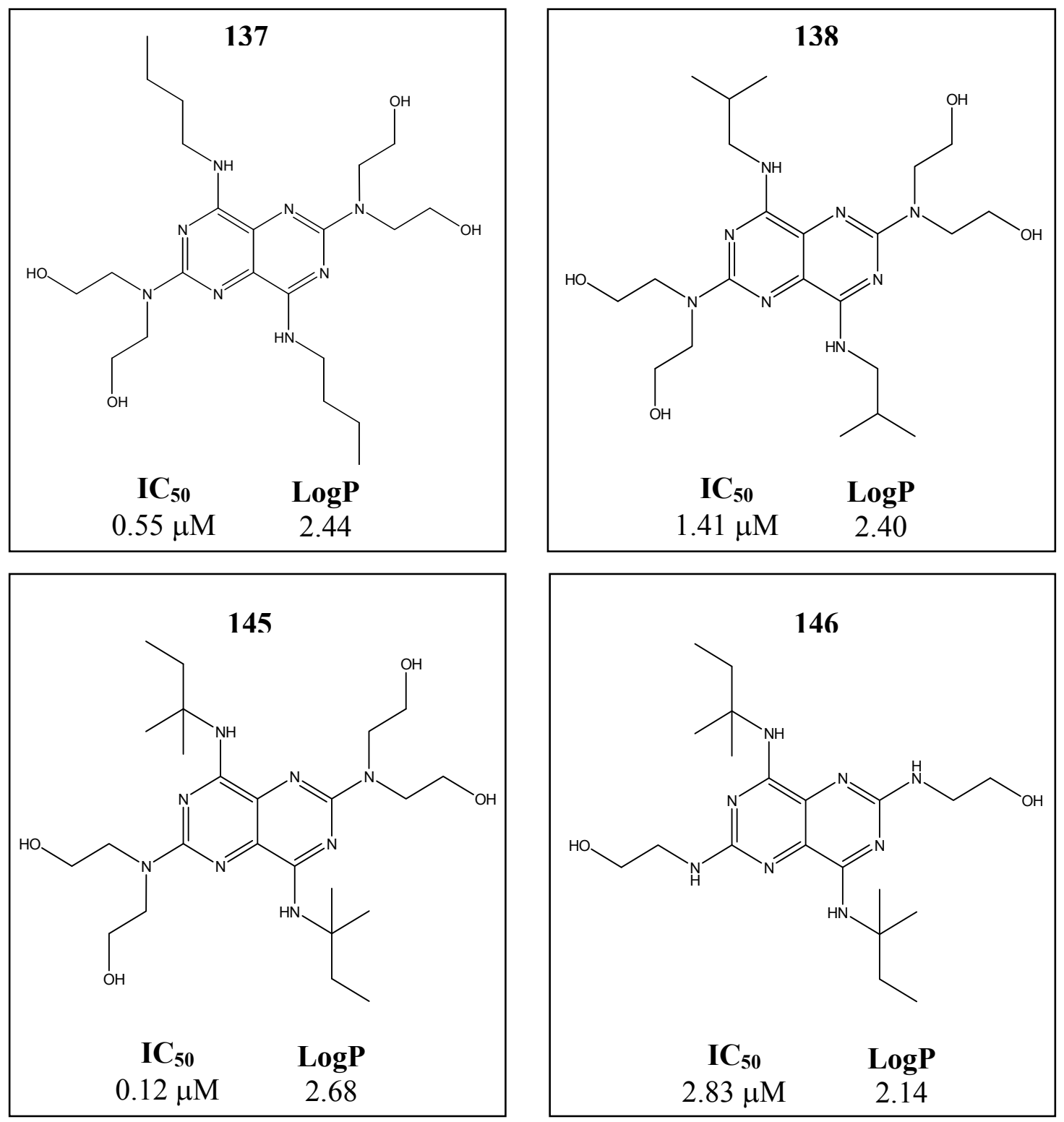

Figure 4.18. $\mathrm{IC}_{50}$ and $\log \mathrm{P}$ data for $\mathrm{DPM}$ analogues from Group 3. 

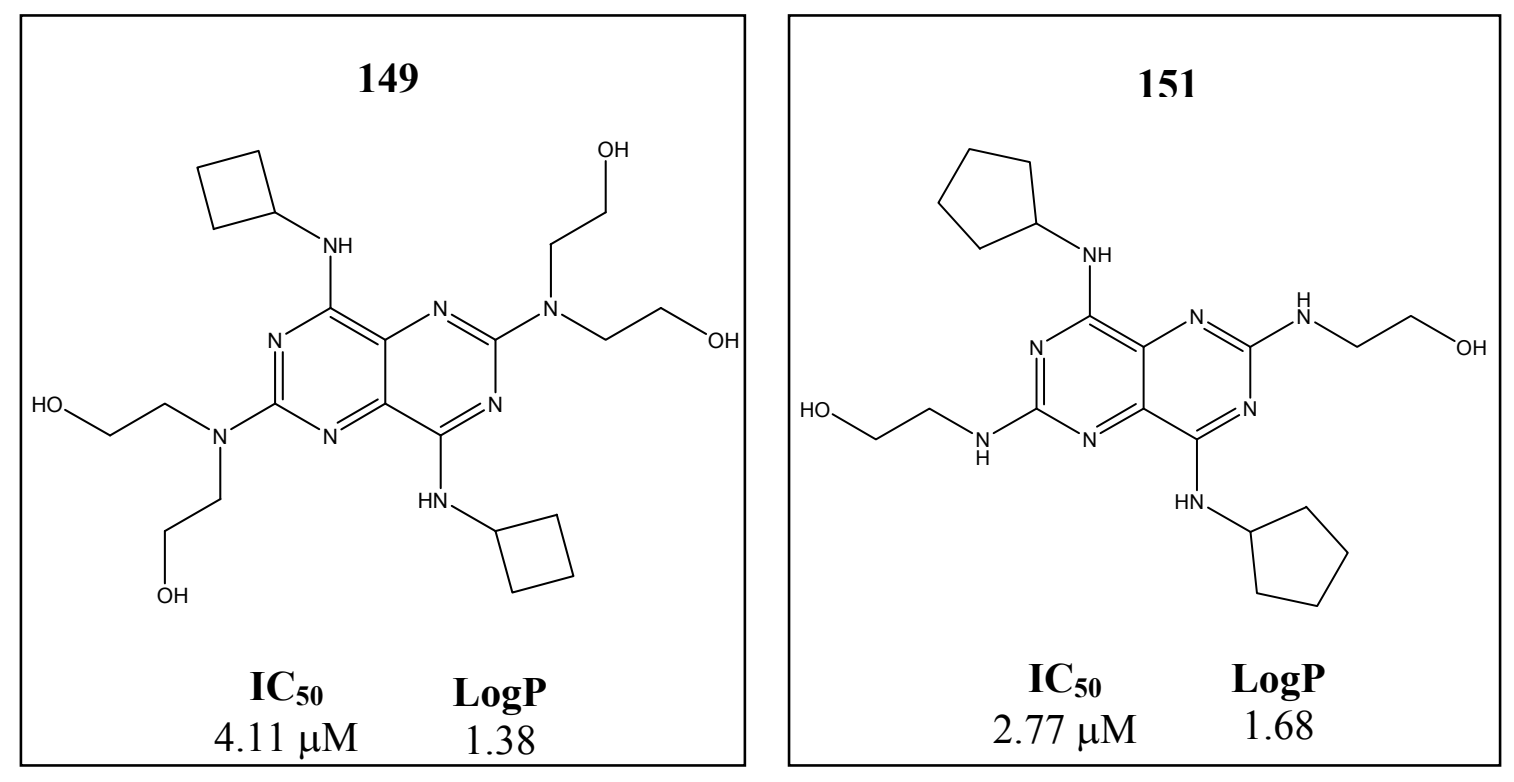

Figure 4.19. $\mathrm{IC}_{50}$ and $\log \mathrm{P}$ data for $\mathrm{DPM}$ analogues from Group 3.

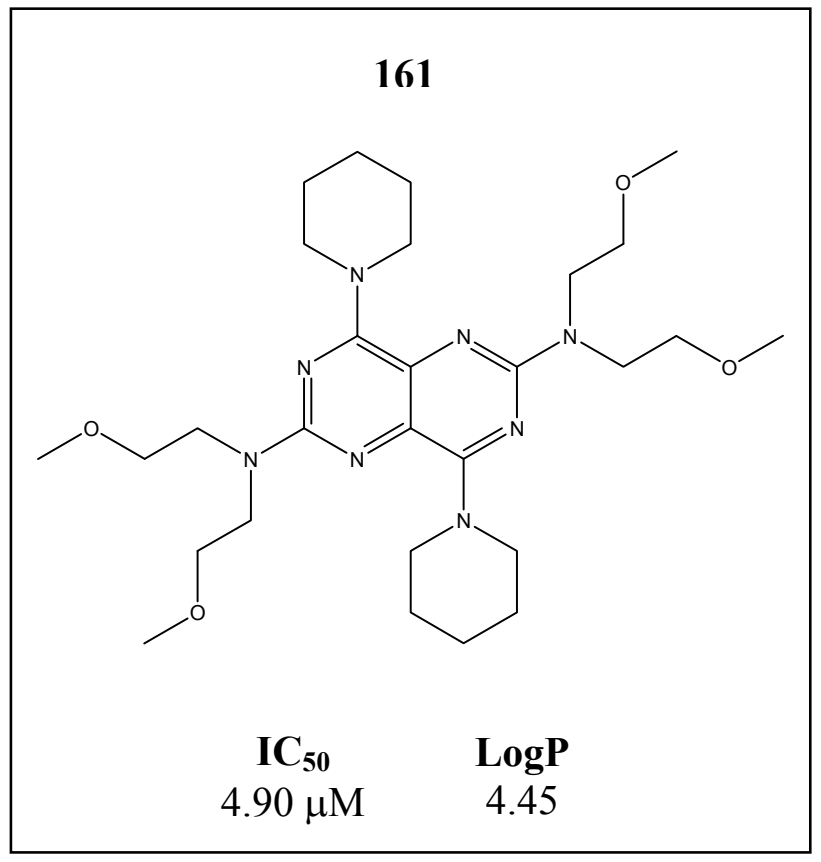

Figure 4.20. $\mathrm{IC}_{50}$ and $\log \mathrm{P}$ data for DPM analogues from Group 4. 


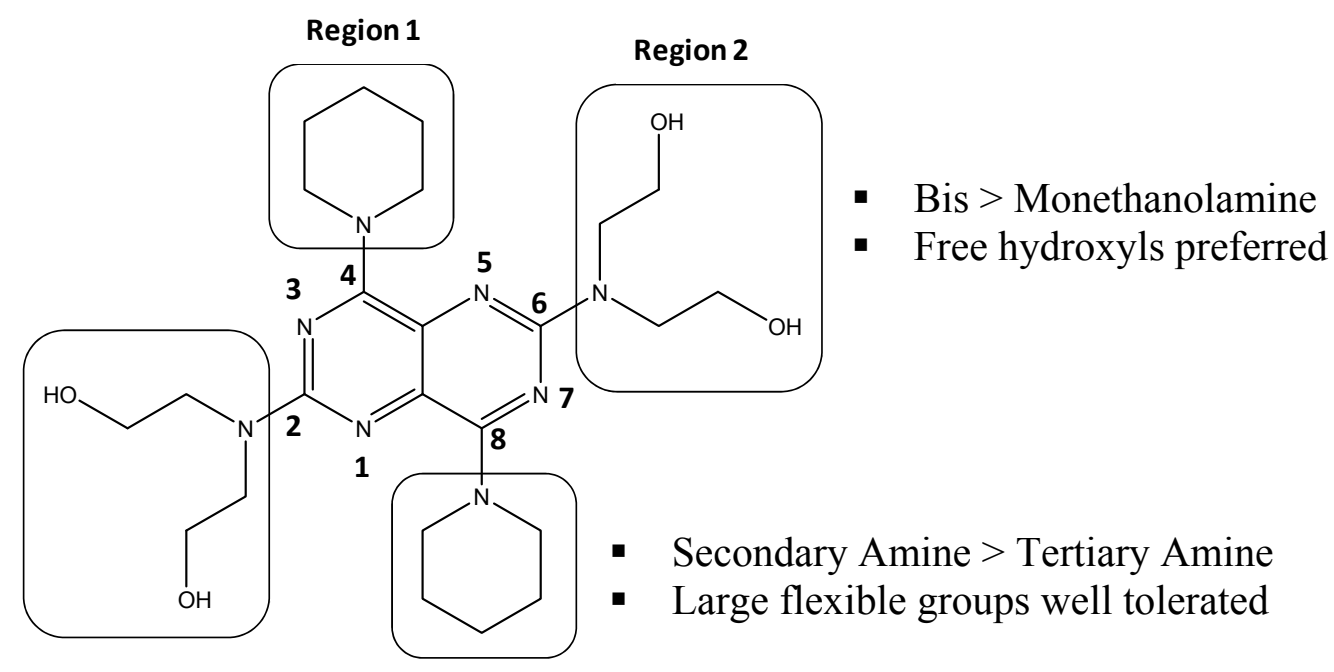

Figure 4.21. Summary of DPM and analogues antitumor promotion SAR.

also show preference for more flexible rings at the 4- and 8-positions $(108>113)$. There is a similar preference for flexible substituents on the 4- and 8-position secondary amines $(145>149)$. With the exception of the rigid cyclobutyl substitution (149), acyclic secondary amines at the 4- and 8-position were more potent than DPM. Replacing the free hydroxyls of DPM with methyl groups decreased the potency nearly 2 fold (DPM > 161).

\section{Conclusions}

Based on the regression analysis of inhibition of tumor promotion and inhibition of nucleoside transport, potent ENT1 inhibitors appear to be predictive of potent antitumor promotion activity. It is unlikely that inhibition of nucleoside transport is the only mechanism behind the antitumor promotion activity of these compounds. However, inhibition of ENT1 seems to have some significance in the chemopreventive activity of these compounds. The cytotoxicity and nucleoside transport data for all of the DPM analogues is summarized in Appendix A.

The dose-response analysis of the antitumor promotion activities of DPM and its analogues afforded a series of structure activity relationships which are summarized in Figure 4.18. The free hydroxyls of DPM are required for optimal activity and may offer insight to the mechanism of these compounds upon further analysis. The secondary amines at the 4- and 8-position also have free hydrogens that may be involved in hydrogen bonding that influences the antitumor promotion activity. Compound 145 was the most potent of the noncytotoxic DPM analogues with an $\mathrm{IC}_{50}$ of $0.12 \mu \mathrm{M}$, which is 25 fold more potent than the parent compound DPM $\left(\mathrm{IC}_{50}=3.07 \mu \mathrm{M}\right)$. Compound 145 is also potent inhibitor of ENT1 nucleoside transport $\left(K_{\mathrm{i}}=14.7 \mathrm{nM}\right)$, which may be involved in the mechanism of antitumor promotion of this compound. Compound $\mathbf{1 4 5}$ is a novel DPM analogue with potential use as a chemopreventive agent. Overall, this SAR 
data will aid in the next phase of drug design in search for even more potent chemopreventive agents.

\section{Limitations of the Present Study}

In the soft agar colony assay set-up, the treatments with the compounds were done in duplicate, which does not provide strong statistical basis for the data. However, to account for this limitation, colonies were counted twice for several of the samples to verify the consistency of the counting technique.

JB6 cells were treated with DPM and analogues for 48 hours in the cytotoxicity studies. However, in the soft-agar colony assay, the cells are incubated with compounds in the presence of TPA for 14 days. Therefore, cytotoxic effects that occur after 48 hours were not considered in this study and should be considered in future assay design.

\section{Materials and Methods}

\section{Reagents}

Dipyridamole (DPM), 12-O-tetradecanoyl-phorbol-13-acetate (TPA), dimethyl sulfoxide (DMSO), heat-inactivated fetal bovine serum (HI-FBS), and Trypsin-EDTA $(0.25 \%)$ solution were obtained from Sigma. Phosphate buffered saline (PBS) was diluted from a 10 X PBS ( $\mathrm{pH} 7.4$, GIBCO) stock to a 1 X PBS solution for cell culture. Minimum essential medium (MEM) powder (containing Earle's salts and L-glutamine), and gentamicin were purchased from GIBCO. For cell culture, $1 \mathrm{~L}$ of $1 \mathrm{X}$ MEM was prepared by diluting MEM powder in deionized (dI) $\mathrm{H}_{2} \mathrm{O}$ following the manufacturer's protocol. All cell culture materials were either pre-sterilized by the manufacture or autoclaved prior to use. Cell culture media was sterile-filtered using $0.22 \mu \mathrm{m}$ cellulose acetate bottle top filter. Low-melt agarose powder was purchased from American Bioanalytical. The JB6 $\mathrm{P}^{+}$mouse epidermal cell line, C141, was purchased from American Type Culture Collection (ATCC). DPM analogues (101-164) were prepared previously (198) and $10 \mathrm{mM}$ stock solutions in DMSO were used for all studies.

\section{Cell culture}

The JB6 $\mathrm{P}^{+}$mouse epidermal cell line, $\mathrm{C} 141$ was cultured at $37{ }^{\circ} \mathrm{C}, 5 \% \mathrm{CO}_{2}$ in MEM containing 5 or $10 \%$ FBS, $2 \mathrm{mM} \mathrm{L-glutamine} \mathrm{and} 25 \mu \mathrm{g} / \mathrm{ml}$ gentamicin. Cells were cultured in monolayer in T25, T75, or T150 flasks and passaged at $70-80 \%$ confluence. First, cells were washed with $10 \mathrm{ml}$ of $1 \mathrm{X}$ PBS followed by vacuum aspiration. To detach the cells for passaging (or for soft-agar colony assay), 1-2 $\mathrm{ml}$ of trypsin-EDTA $(0.25 \%)$ was added to the monolayer cells and placed at $37{ }^{\circ} \mathrm{C}, 5 \% \mathrm{CO}_{2}$ for 5-10 min. After incubation, 8-9 $\mathrm{ml}$ fresh culture media was added and the detached cells were collected and centrifuged $\left(20^{\circ} \mathrm{C}, 5-10 \mathrm{~min}, 1000 \mathrm{rpm}\right)$. The resulting cell pellet was homogenized in fresh culture media and split into new culture flasks. 


\section{Soft agar colony formation assay}

A concentrated solution of JB6 $\mathrm{P}^{+}$cell culture media ( $2 \mathrm{X}$ MEM) was prepared by diluting MEM powder in deionized $\mathrm{H}_{2} \mathrm{O}$ supplemented with 10 or $20 \%$ heat inactivated FBS and $25 \mu \mathrm{g} / \mathrm{ml}$ gentamicin to a volume of to $500 \mathrm{ml}$. A $1.6 \%$ agar was prepared by adding $1.6 \mathrm{~g}$ low-melt agarose powder to $100 \mathrm{ml}$ deionized $\mathrm{H}_{2} \mathrm{O}$ with subsequent sterilization by autoclave. All solutions and reagents were kept at $37^{\circ} \mathrm{C}$ while setting up the agar plates.

A solution of 2 X MEM media containing $32 \mathrm{nM}$ TPA with or without 2 times the final concentrations of the compounds was prepared (designated as $2 \mathrm{X}$ Sample Medium). The bottom layer was prepared by mixing $2 \mathrm{X}$ MEM with $1.6 \%$ agar (1:1). In 6-well plates, $1 \mathrm{ml}$ of this solution was added to each well and allowed to gel at $4{ }^{\circ} \mathrm{C}$ for 20-30 min. Plates were warmed at $37^{\circ} \mathrm{C}$ for 15 minutes before adding the top layer. The top layer solution ( $10 \mathrm{ml}$ ) consisted of $1.6 \%$ Agar, $2 \mathrm{X}$ Sample Medium, and $\mathrm{dI}_{2} \mathrm{O}$ (1:2:1). This solution was kept warm at $37^{\circ} \mathrm{C}$ while preparing the JB6 $\mathrm{P}^{+}$cells. Cells were trypsinized, pelleted, and resuspended to a concentration of $3 \times 10^{5}$ cells $/ \mathrm{ml}$ in $1 \mathrm{X}$ MEM. $100 \mu \mathrm{l}$ of this dilution of cells was added to the top layer solution and mixed well. $1 \mathrm{ml}$ of this top layer solution with cells was added to the pre-warmed bottom layer and allowed to gel at $4{ }^{\circ} \mathrm{C}$ for $15-20 \mathrm{~min}$.

The final working concentrations were: Top Layer $-3 \times 10^{3}$ cells in $1 \mathrm{ml}$ of $0.4 \%$ agar medium containing 5 or $10 \%$ FBS, $16 \mathrm{nM}$ TPA, and $0.01-25 \mu \mathrm{M}$ DPM analogues; Bottom Layer - $1.5 \mathrm{ml}$ of $0.8 \%$ agar medium. The DPM analogues were tested in duplicate. Soft-agar colony plates were incubated at $37{ }^{\circ} \mathrm{C}, 5 \% \mathrm{CO}_{2}$ for 14 days, and the anchorage-independent colonies were counted manually under an inverted microscope. Colonies with more than 8 cells were scored. Some plates were stained with MTT $(0.5 \mathrm{mg} / \mathrm{ml}$ in PBS $)$ after manual counting for visual enhancement of the digital images. The efficiency of DPM and analogues inhibition of TPA-induced cell transformation is expressed as a percentage of the transformation frequency when the cells were treated with TPA alone.

\section{MTT assay of cell viability}

JB6 $\mathrm{P}^{+}$cells were trypsinized, pelleted, and resuspended in $1 \mathrm{X}$ MEM. In 96-well plates, $100 \mu \mathrm{l} 1 \mathrm{X}$ MEM containing $5 \times 10^{3}$ cells were seeded in each well. Cells were incubated for 12-16 hrs and then treated with $10 \mu \mathrm{M}$ of DPM and analogues or vehicle, DMSO, in $100 \mu \mathrm{L}$ of $1 \mathrm{X}$ MEM for 48 hours. Subsequently, $10 \mu \mathrm{l}$ of $5 \mathrm{mg} / \mathrm{ml}$ methylthiazolyldiphenyl-tetrazolium bromide (MTT) in PBS was added to each well, and then incubated for $4 \mathrm{hrs}$ at $37^{\circ} \mathrm{C}$. The yellow MTT is reduced to purple formazan in the mitochondria of living cells (cell viability). The media/MTT solution was removed by blotting and the formazan crystals were dissolved in $100 \mu 1$ DMSO. The absorbance was quantified at $570 \mathrm{~nm}$ using a microplate reader (SpectraMax M2, Molecular Devices). 


\section{$\mathrm{IC}_{50}$ calculations}

$\mathrm{IC}_{50}$ values were determined using the GraphPad Prism 4 software. Data were input as concentration (nM) and percent inhibition. The software transform feature was used to convert the concentration to $\log$ (concentration) $[\mathrm{X}=\log (\mathrm{X})]$. These transformed data were then subjected to the software's built-in nonlinear regression (curve fit) analysis. Within the analysis, several equations were tried to provide the "best-fit" curves for the data. These curves were plotted and the equations that gave curves most representative of the data were selected and the respective calculations to compute the $\mathrm{IC}_{50}$ and standard error values. 


\section{CHAPTER 5: THE EFFECTS OF DIPYRIDAMOLE ON MAP KINASES}

\section{Introduction}

A large number of dietary factors, the most commonly studied agents in chemoprevention, are reported to have inhibitory effects on tumor-promoter inducedMAP kinase activation. For example, anthocyanidins, found in red cabbage, red grapes, purple sweet potatoes, and berries, inhibit tumorigenesis by inhibition of Erk and Jnk MAPKs (199). Green and black tea polyphenols such as epigallocatechin-3-gallate (EGCG) and theaflavins inhibit Jnk but not Erk activation (200). A number of chemopreventive agents, including the above mentioned, subsequently modulate the downstream transcription factor, AP-1. For instance, the anti-tumor promotion effect of equol, a soybean metabolite, is a result of inhibition of AP-1 via the MAPK pathway (201).

In previous studies, an AP-1-SEAP reporter stable transfectant JB6 cell line was established. Using this reporter cell line, DPM was found to inhibit AP-1 activity in a dose-dependent manner (Figure 5.1). Therefore, MAPKs were a feasible upstream signal potentially involved in the mechanism of DPM antitumor promotion. The studies in this section assessed the roles of p38 and Erk MAPKs in the observed AP-1 inhibition. Transcriptional activation of Elk-1 requires phosphorylation by MAPKs (52). Therefore, the role of Elk-1 was also studied.

\section{Results and Discussion}

\section{Time kinetics of TPA-induced MAPK signaling in JB6 $\mathbf{P}^{+}$}

The time course of TPA-induced MAPK activation was first analyzed to determine what time period of TPA treatment would afford significant induction of MAPK activity so as to analyze the effects of DPM. JB6 cells were first serum-starved $(0.1 \% \mathrm{FBS})$ for 48 hours. Fetal bovine serum (FBS) supplemented in the cell culture media contains growth factors, cytokines, and hormones, which can induce MAPK signaling. Growing the cells in minimal sera conditions minimizes the background MAPK activation from these components.

After starving, $16 \mathrm{nM}$ TPA was added at times ranging from 5 minutes to 24 hours, and the resultant induction of MAPKs was assessed by Western blotting analysis. For all of the MAPK studies, the negative control samples were treated with vehicle (DMSO) while the positive control was treated with TPA. ImageJ Analysis (NIH software) was used to quantify and normalize the protein bands. Based on the results from the time-course analysis (Fig 5.2), 1 hour TPA treatment gave the highest MAPK inductions. However, significant induction was also observed as early as 5 min for all proteins except $\mathrm{p} 38$. For the studies with DPM, cells were treated 1 hour to minimize technical errors. 


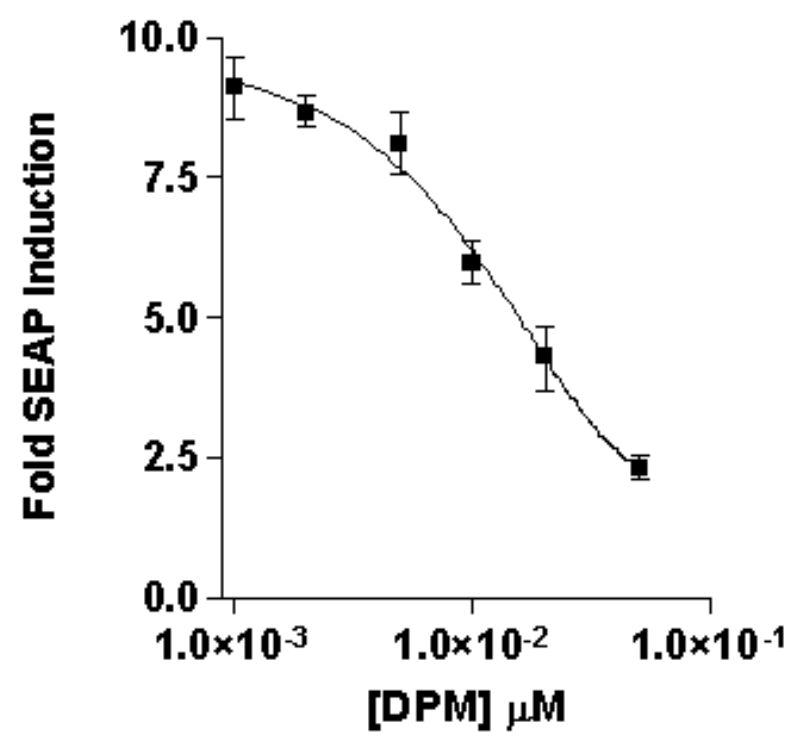

Figure 5.1. DPM dose-dependent inhibition of AP-1 transactivation.

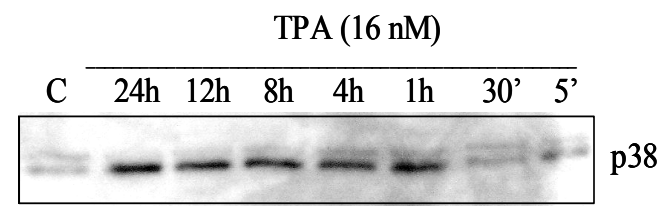

$\begin{array}{llllllll}1.0 & 2.2 & 2.2 & 2.5 & 3.1 & 3.1 & 2.3 & 1.3\end{array}$
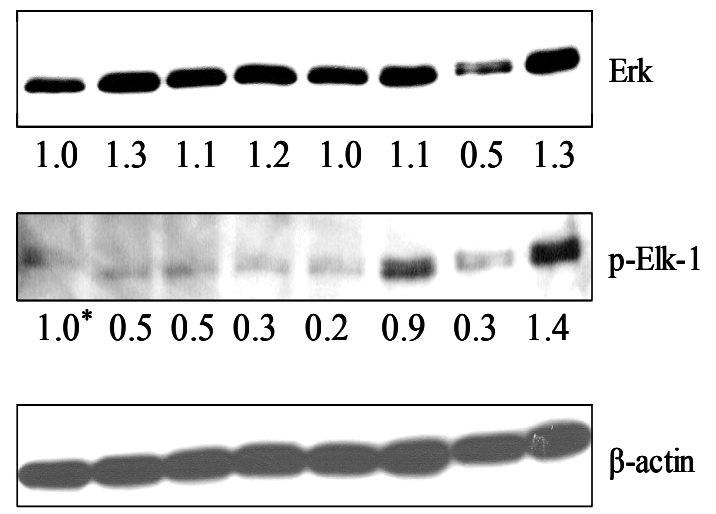
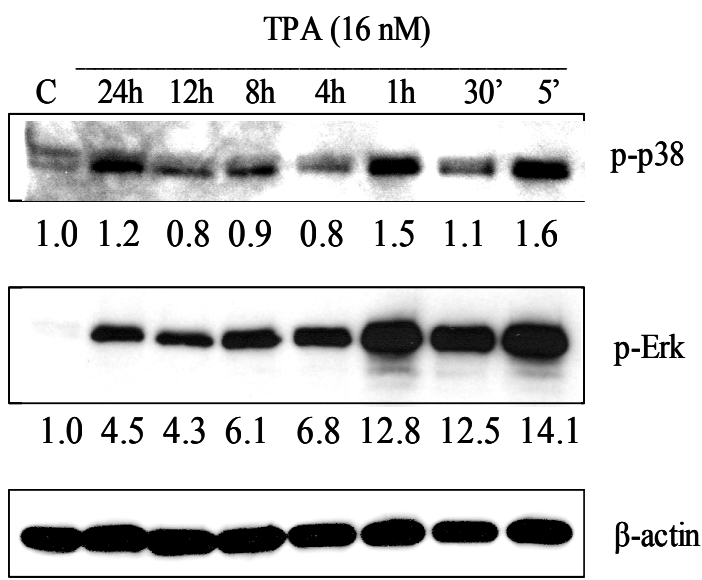

$\beta$-actin

* This value is slightly higher because of the background signal detected in ImageJ band analysis

Figure 5.2. Time course of TPA-induced MAPKs. 


\section{Effect of DPM pretreatment on TPA-induced MAPKs}

The purpose of the dose-response study was to determine the effects of varying concentrations of DPM $(0.01-25 \mu \mathrm{M})$ on MAPK signaling. JB6 $\mathrm{P}^{+}$cells were pretreated with DPM for 1 hour. Cells were subsequently stimulated with TPA for 1 hour as determined from the time-course analysis (Figure 5.3).

The negative control samples were not treated with TPA or DPM while the positive control was treated with TPA. The positive control served as the reference point to analyze the effects of DPM pretreated samples. Compared to the cells treated with TPA, DPM treatments showed decrease induction of Erk except for the $1 \mu \mathrm{M}$ treatment. There was no clear trend in this inhibitory effect as shown by the line graph of the fold induction values (Figure 5.4). The most significant inhibition of Erk was at 0.1 and 10.0 $\mu \mathrm{M}$ at which Erk induction was returned to its basal untreated levels.

All of the DPM concentrations augmented the activation of Erk, measured by phosphorylation of Erk (p-Erk) giving protein levels much higher than TPA stimulation. The highest activation was observed with 0.01 and $1.0 \mu \mathrm{M}$ DPM pretreatment (Figure 5.5). Taken alone, DPM induction of Erk does not correlate to inhibition of MAPK signaling. The level of Erk induction was a reference point to ensure the level of phosphorylated proteins is not just a consequence of protein levels. Normalized data showed that activation of p-Erk was independent of Erk induction (Figure 5.3).

Therefore, the DPM is clearly not an inhibitor of TPA-induced Erk induction based on the 1 hour pretreatment set-up. To the contrary, DPM showed a dose-dependent activation of $\mathrm{p}$-Erk, with the lowest concentration giving the most activation. There was a dose-dependent inhibition of p38 activation with $25 \mu \mathrm{M}$ DPM treatment giving a return to basal levels (Figure 5.6).

\section{Effect of DPM pretreatment on TPA-induced ENT1}

The PCR analysis of ENT1 in Chapter 3 showed that TPA stimulates the expression of ENT1 mRNA. In this study, ENT1 expression was analyzed in response to DPM and TPA stimulation. Cells were pretreated with DPM followed by 1 hour of TPAstimulation. JB6 $\mathrm{P}^{+}$cells stimulated for $1 \mathrm{hr}$ resulted in induction of ENT1, while pretreatment with various concentrations of DPM did not show any significant changes in ENT1 levels (Figure 5.7).

\section{Dose effects of DPM on MAPK signaling}

Based on the findings from the DPM dose-response study, it seemed that DPM was activating Erk independent of TPA. To determine the MAPK stimulation of DPM itself, JB6 $\mathrm{P}^{+}$cells were pretreated with or without $10 \mu \mathrm{M}$ DPM followed by stimulation with $16 \mathrm{nM}$ TPA (Figure 5.8). Erk induction by DPM alone was equivalent to that with TPA stimulation. DPM pretreatment followed by TPA stimulation resulted in increased Erk induction. Phosphorylation (activation) of Erk by DPM alone was much lower than 

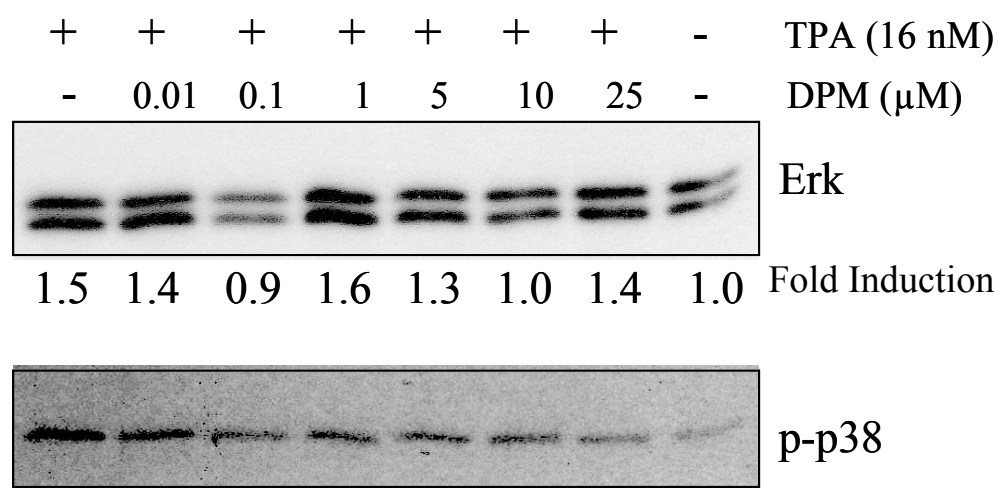

p-p38

$\begin{array}{llllllll}1.9 & 1.6 & 1.5 & 1.3 & 1.2 & 1.1 & 1.0 & 1.0\end{array}$ Fold Induction
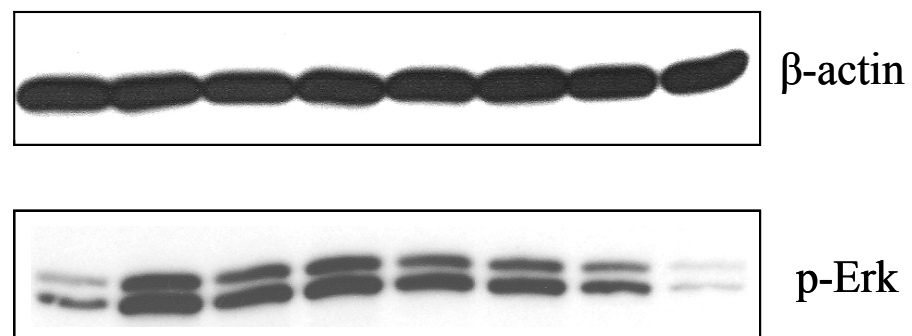

$\begin{array}{llllllll}4.5 & 12.4 & 11.7 & 12.3 & 11.7 & 10.0 & 6.2 & 1.0\end{array}$ Fold Induction

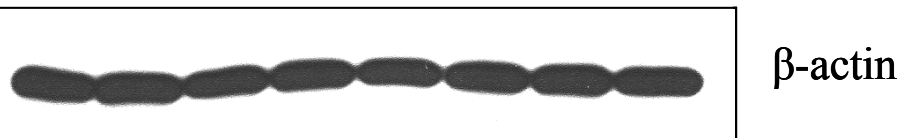

Figure 5.3. DPM dose effects on TPA-induced MAPKs. 


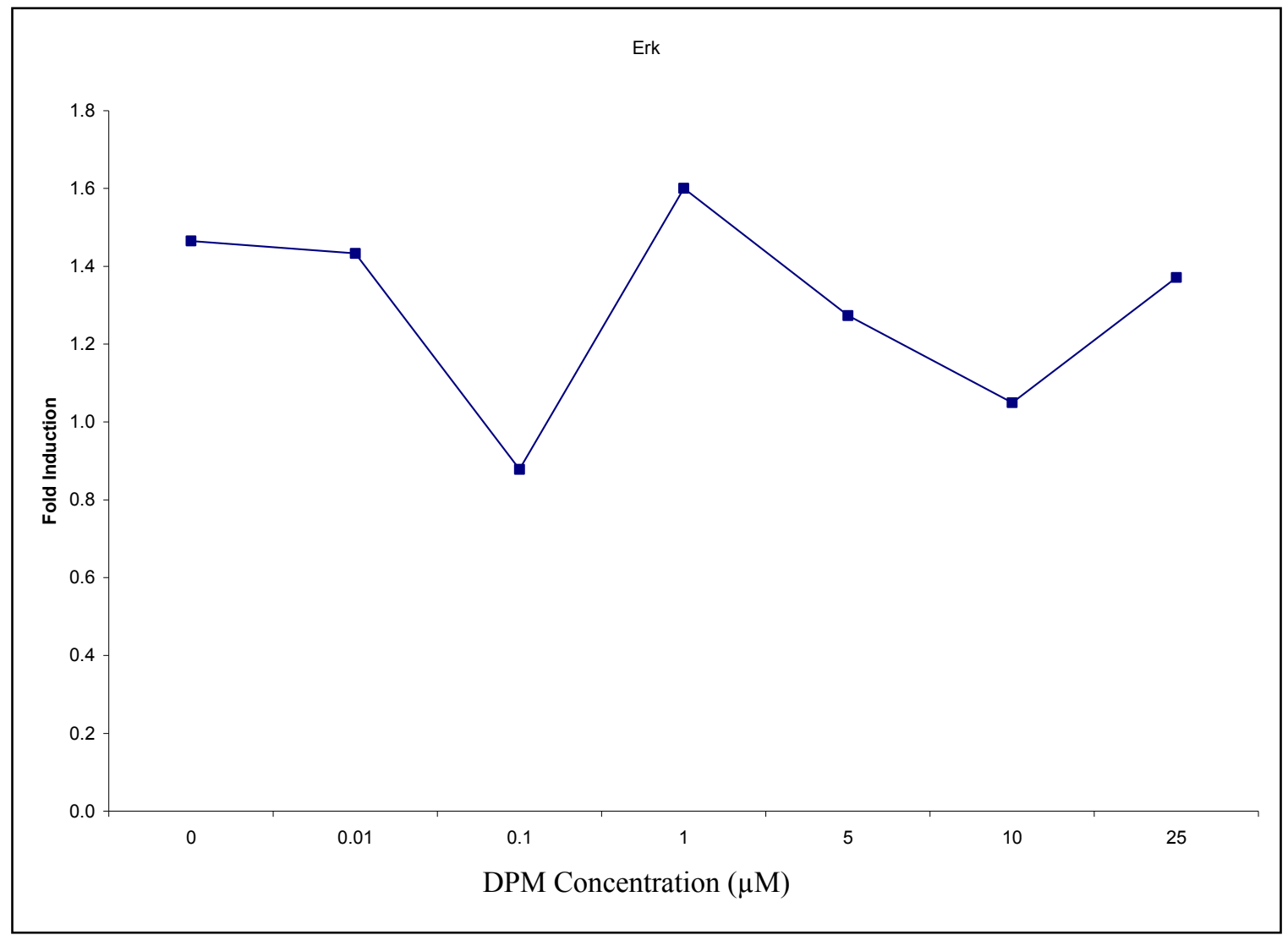

Figure 5.4. DPM dose effects on TPA-induced Erk. 


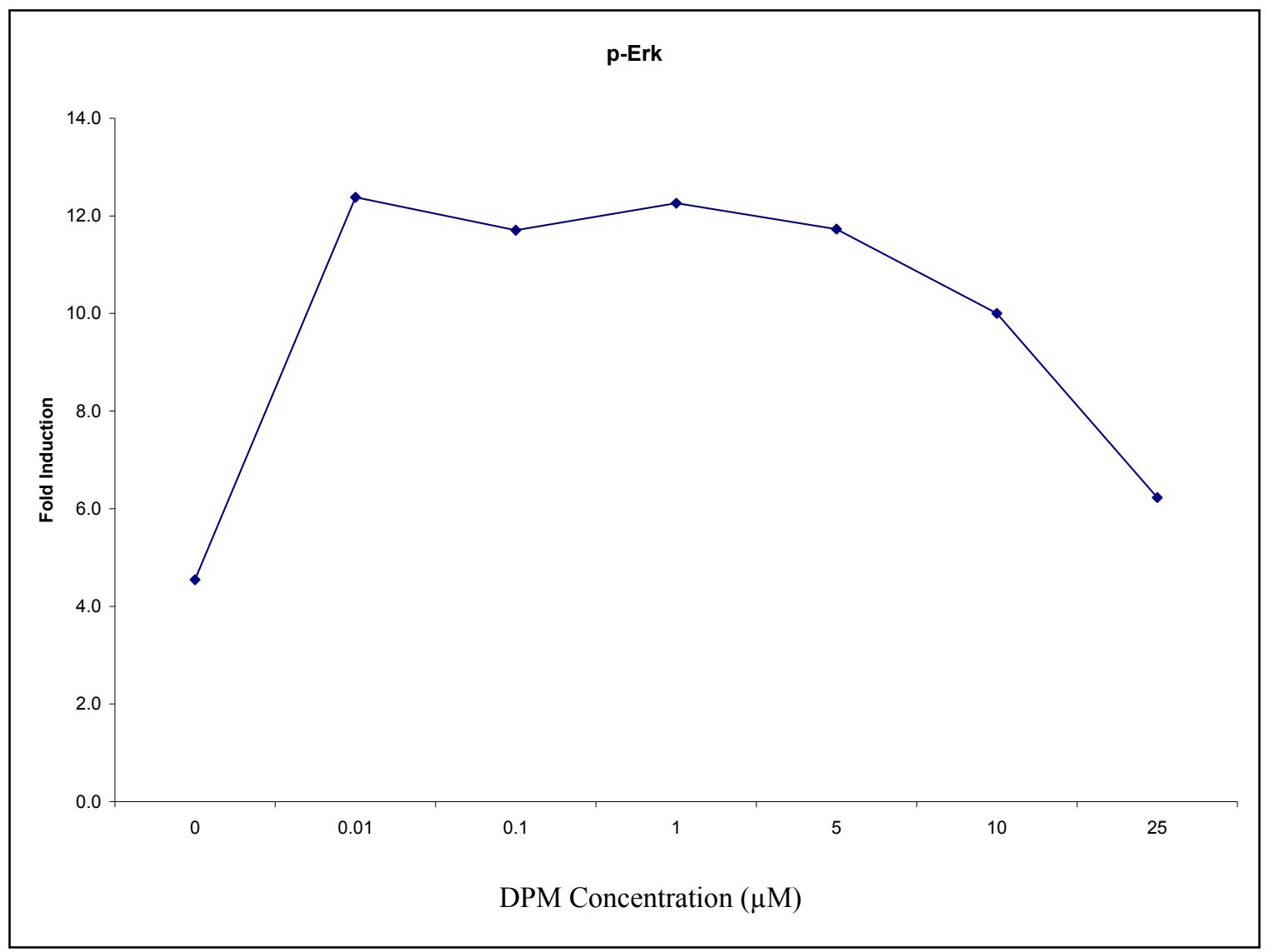

Figure 5.5. DPM dose effects on TPA-induced Erk activiation. 


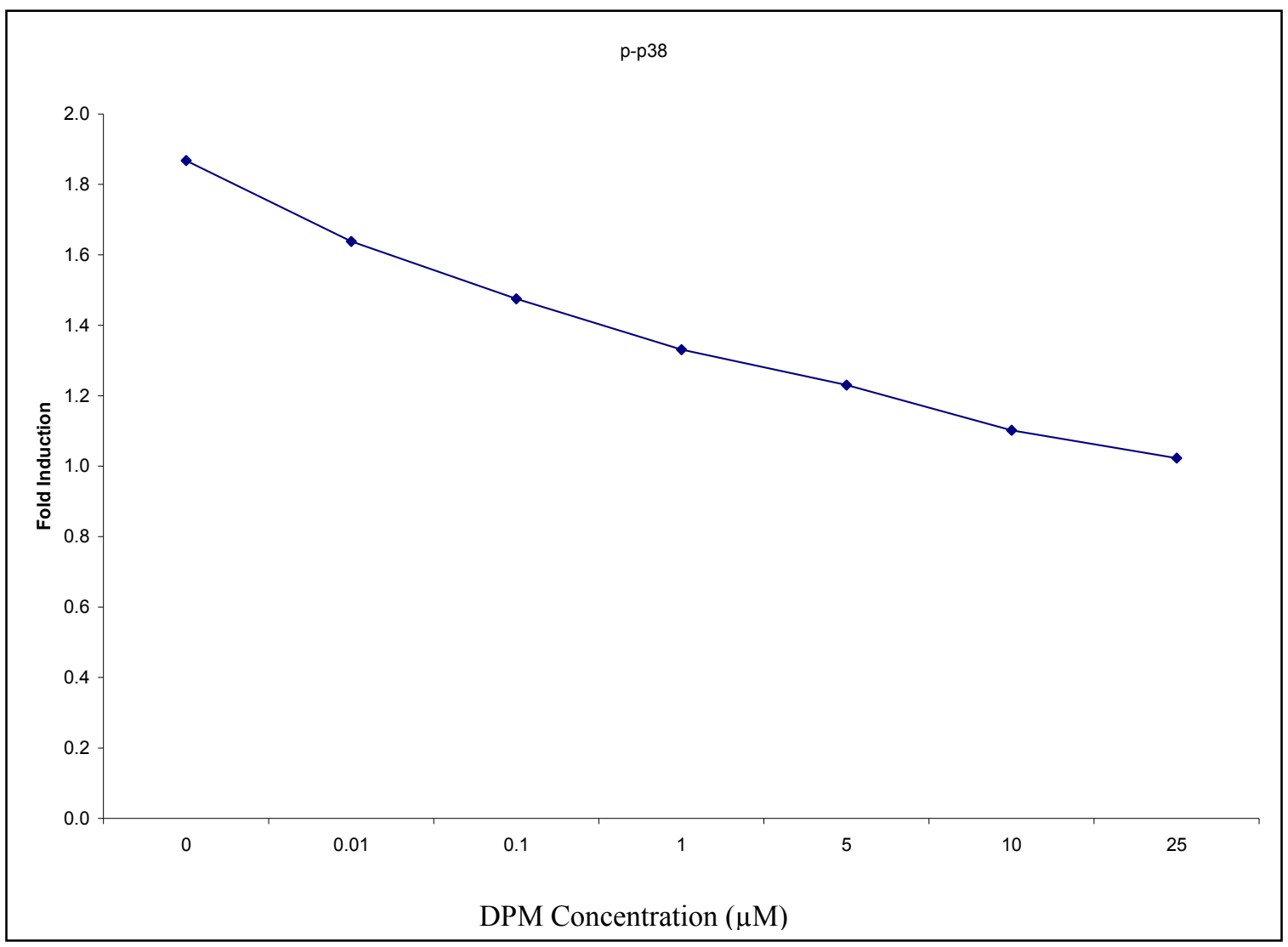

Figure 5.6. DPM dose effects on TPA-induced p38 activation. 


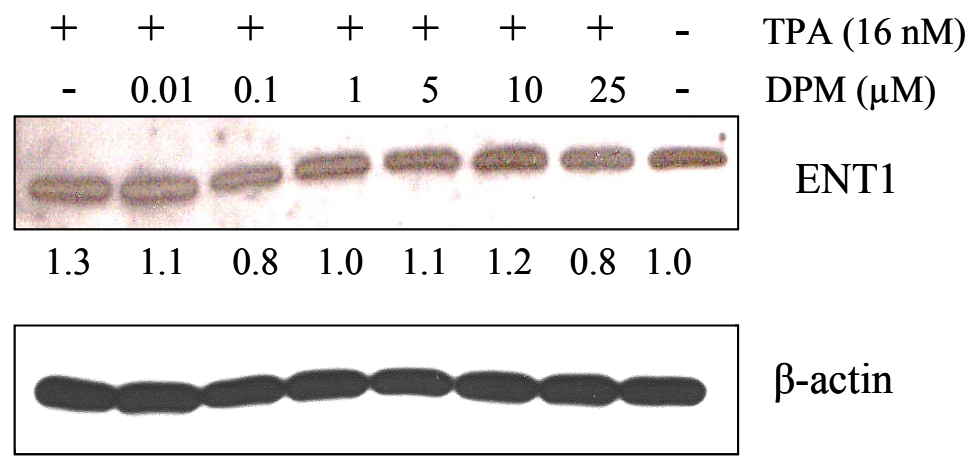

Figure 5.7. DPM dose effects on TPA-induced ENT1.

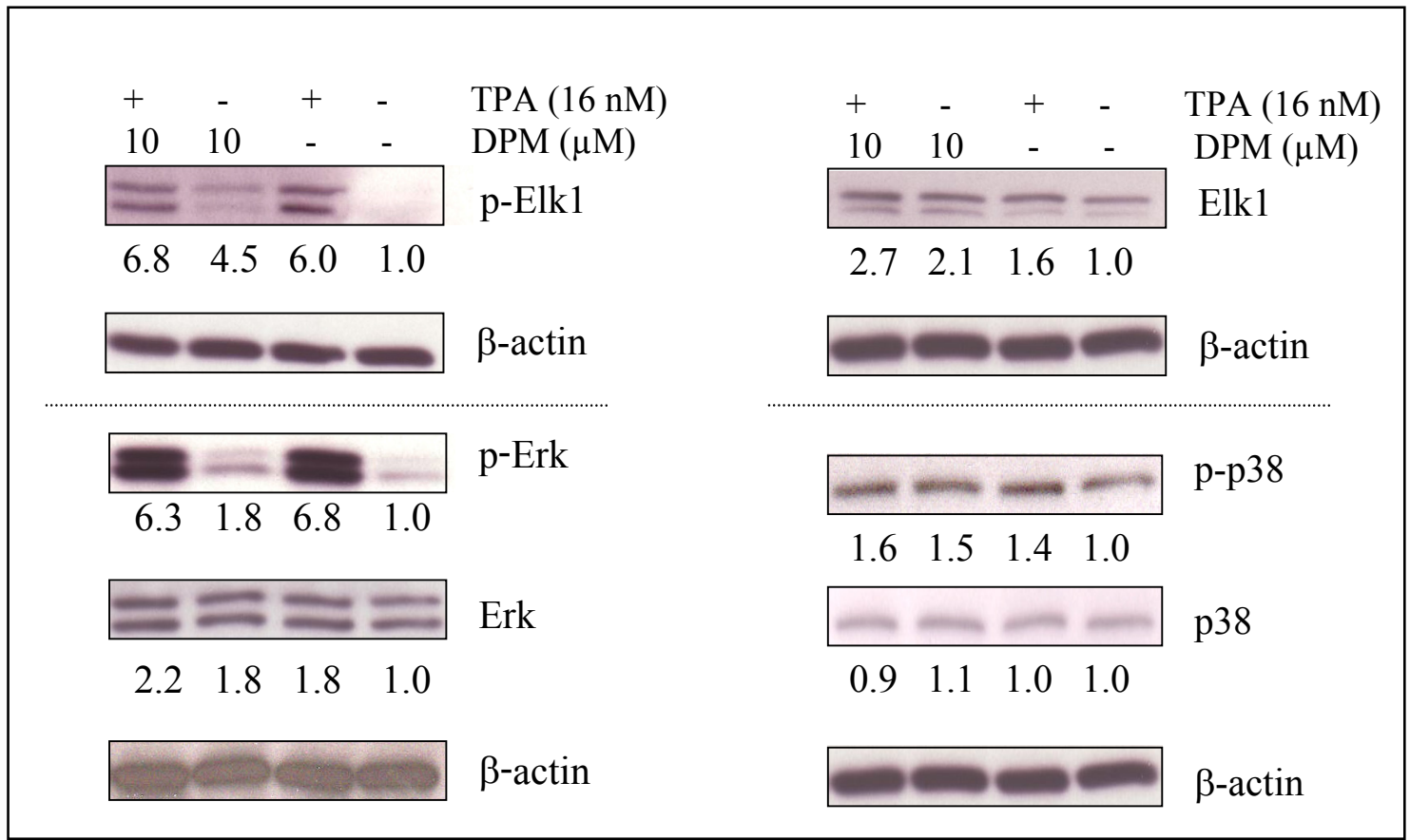

Figure 5.8. Effects of DPM and TPA on MAPKs. 
that of TPA. Pretreatment with DPM showed no significant difference between DPM and TPA-induced p-Erk (Figure 5.8).

The effect of DPM on Elk-1, a downstream target of Erk, was also studied. JB6 $\mathrm{P}^{+}$treated with DPM alone showed a similar induction of Elk-1 protein compared to TPA alone. As seen with Erk, pretreatment with DPM followed by TPA stimulation increased this induction. DPM alone stimulated Elk-1 activation, but less than TPA. There was an additive effect on Elk activation when cells were treated with both TPA and DPM. This activation was independent of Elk-1 protein levels (Figure 5.9). The effects on p38 were also determined. DPM alone or combined with TPA showed similar activation of $\mathrm{p} 38$, which was independent of p38 protein induction (Figures 5.8-5.9). This result differs from that in the previous dose-response study in which DPM inhibited p-p38 activation. This is likely a due to the difference in the experimental protocol. In the first doseresponse analysis DPM was added to the cells in a premixed media solution and incubated for $1 \mathrm{hr}$. This solution was removed prior to adding a premixed media solution with TPA. In this study looking at the effects of DPM itself on MAPKs, TPA was added directly to the premixed solution containing DPM. Therefore, the cells were exposed to DPM for an additional hour and the observed p-p38 activation likely reflects the time effects of DPM incubation on MAPKs.

\section{Discussion}

\section{DPM and nucleoside transport inhibition}

To begin with, DPM is a nucleoside transport inhibitor. In previous work, the tumor promoter, TPA induced expression of ENT1 mRNA (Figure 3.4). The hypothesis was that preneoplastic cells require higher amounts of nucleosides based on the demand to produce RNA and DNA. The observed increase in ENT1 mRNA expression in response to TPA suggests that this transformation signaling induces NT expression to meet this demand. Therefore, by inhibition of nucleoside transport, DPM can inhibit or prevent the preneoplastic-to-neoplastic transformation.

Tamoxifen, an anti-estrogen cancer drug and chemopreventive agent, has been reported to influence NT expression. ENT1 protein expression is downregulated in tamoxifen treated MCF-7 human breast cancer cells and can be reversed by treatment with estradiol (197). Tamoxifen treatment also inhibits ENT1 function in MCF-7 cells (202). Tamoxifen has exhibited chemopreventive activities in clinical trials as well. The Breast Cancer Prevention Trial (BCPT) assessed the effects of tamoxifen on women at high risk for developing breast cancer. The study was terminated upon recognizing nearly all the women receiving tamoxifen showed 50\% fewer invasive breast cancer diagnoses compared to those receiving placebo. The Food and Drug Administration (FDA) has approved tamoxifen for breast cancer prevention, however, side effects including endometrial cancer, pulmonary embolism, and deep vein thrombosis preclude tamoxifen use in certain populations $(203,204)$. 


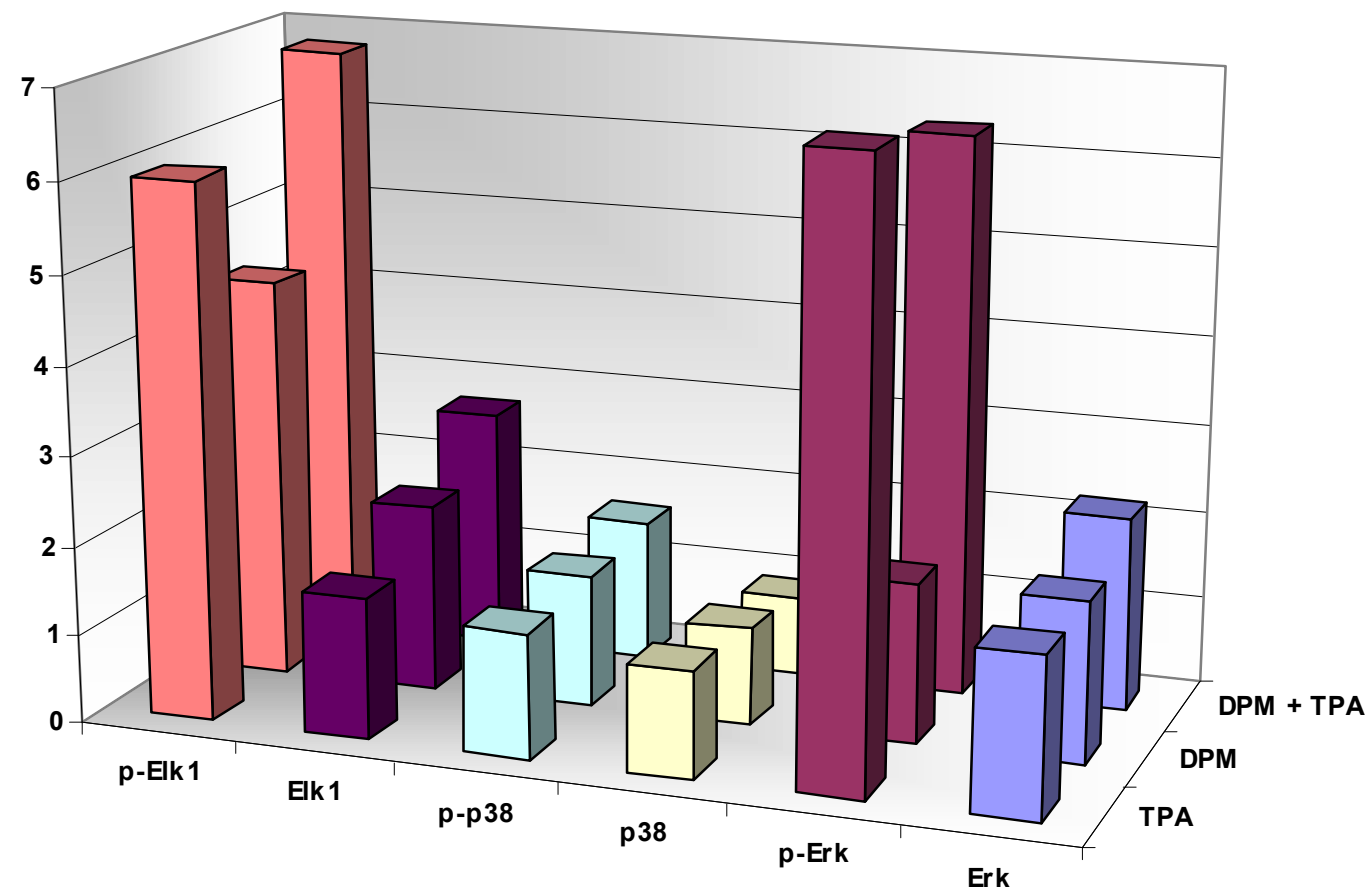

Figure 5.9. Comparison of MAPK induction versus activation by DPM and TPA. 
The chemopreventive activity of tamoxifen may be a attributed to regulation of ENT1. By downregulating ENT1 protein and function, it mimics the action of NTIs in that it decreases the ability of preneoplastic cells to use salvage pathways to produce the nucleotides needed for aberrant growth and proliferation. Tamoxifen is also a PKC inhibitor which may underlie the regulation of ENT1 by tamoxifen.

A common factor in the TPA and tamoxifen mediated regulation of NTs is PKC. As it relates to NTs, acute stimulation of PKC has been shown to cause rapid elevation of hENT1 in cultured human cancer cell lines, MCF-7 and HeLa. In this same report downregulation of PKC resulted in decreased hENT1 transport (136). Inhibitors of PKC have shown inhibition of nucleoside transport in K562 human erythroleukemia cells (152). All three of these cell lines have predominantly equilibrative nucleoside transporters with ENT1 dominating, which may be the link between PKC inhibition and antitumor promotion $(202,205,206)$.

TPA-induced tumor promotion involves binding to and activation of its intracellular receptor PKC. Taken together with the previous reports, TPA-induced NT expression observed in our study is likely mediated by TPA activation of PKC. Also, the ability of DPM to inhibit this is similar to that observed with the chemopreventive agent, tamoxifen. This suggests that inhibition of PKC and its regulatory effects on NTs may be a potential target for the design of chemopreventive agents. The involvement of PKC was not analyzed in this study, but this should be considered. In terms of targeting NTs, their regulation by $\mathrm{PKC}$ adds to their potential as targets for chemoprevention.

Finally, it is noteworthy to mention that a few chemopreventive dietary factors have shown inhibition of nucleoside transport activity. Green tea polyphenols have shown potent inhibition of nucleoside transport and TPA-induced tumor promotion (207209) One particular tea polyphenol, EGCG, also inhibited the activation of PKC by teleocidin.

\section{DPM and MAPKs}

MAP kinases are important signaling molecules known to mediate AP-1 function (210). Inhibition of MAPKs is responsible for inhibition of cell transformation via inhibition of AP-1 transactivation (211). The purpose of this study was to determine if MAPKs are involved in the antitumor effects of DPM in the JB6 model. Based the data from previous studies, DPM inhibits AP-1 transactivation. Since MAPKs mediate AP-1, the postulate was that DPM inhibits MAPKs. In this study, we found that DPM itself was actually an activator of Erk and Elk MAPKs. Pretreatment of the JB6 $\mathrm{P}^{+}$cells with DPM did not inhibit TPA induced Erk or Elk-1, but adds to this activation. Therefore, DPM pretreatment does not inhibit AP-1 via Erk or Elk-1 within the observed times of this study.

We did, however, observe a dose-dependent inhibition of p-p38. Recent studies in RAW 264.7 cells report DPM to activate MAPK phosphatase (MKP-1). MKP-1 is a potent inhibitor of $\mathrm{p} 38$ MAPK function. Our results from 1 hour pretreatment with DPM 
agree with this finding. p38 MAPK is a key player in EGF-induced promotion in JB6 cells, as well as a regulator of AP-1 binding and NF- $\mathrm{kB}$ signaling (NF- $\kappa \mathrm{B}$ discussed in the next section) (30). Therefore, the inhibition of AP-1 and possibly NF-kB is likely one mechanism of antitumor promotion by DPM.

\section{DPM and inhibition of ROS}

All aerobic organisms form and degrade reactive oxygen species (ROS) (212). Oxidative metabolism in the mitochondria, metabolic processes, and inflammation are sources of endogenous ROS (213). Detoxification and metabolism of drugs, hormones, and other xenobiotics are exogenous sources of ROS $(214,215)$. ROS produced by these processes include the superoxide anion radical, hydrogen peroxide, and the hydroxyl radical, all of which contain unpaired electrons. Cellular defense and redox systems are responsible for the regulation of ROS levels. At homeostatic levels, ROS has beneficial physiologic uses including intracellular signaling and redox regulation (212). However, if these regulatory antioxidant systems are overcome by excessive ROS, it may result in damage to critical macromolecules such as DNA, proteins, carbohydrates and lipids (215).

TPA treatment in JB6 $\mathrm{P}^{+}$cells leads to the generation of ROS, which stimulates cell growth in soft agar or in monolayer (216). TPA-induced tumor promotion requires elevated levels of superoxide anion $(216,217)$. DPM and analogues have been shown to inhibit lipid peroxdiation in mitochondria (218). DPM has been reported to act as a ROS scavenger of superoxide and hydroxical radicals in vitro $(219,220)$. Other antioxidant mechanisms of DPM include breaking free radical chain reactions and electron transfer reactions $(221,222)$. ROS is a major regulator of NF- $\mathrm{KB}$ and in turn, tumor promoter induced transformation (223). Therefore, based on the antioxidant properties of DPM, inhibition of ROS may be a key mechanism of its antitumor promotion activity in the JB6 model.

\section{DPM and inhibition of NF-KB}

Nuclear factor kappa B (NF- $\mathrm{kB})$ is a downstream target of AP-1 transactivation the JB6 model. NF- $\mathrm{kB}$ plays a key role in tumor promoter induced transformation response (224). Using the JB6 model, it was determined that the JB6 $\mathrm{P}^{-}$tumor promotion resistant phenotypes was due to failure to activate $\mathrm{p} 65$, a member of the NF- $\mathrm{kB}$ family of transcription factors(225). Therefore $\mathrm{p} 65$ is essential for TPA-induced transformation in $\mathrm{P}^{+}$cells.

In a study aimed to probe the anti-inflammatory mechanisms of DPM, it was

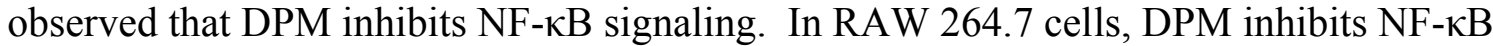
specific DNA binding as well as LPS-induced NF- $\kappa B$ activation. This is attributed to the ability of DPM to inhibit the translocation of $\mathrm{p} 65$ from the cytosol to the nucleus. 
Another report claims DPM can be used in combination with corticosteroids as treatment for inflammatory disorders such as rheumatoid arthritis. This effect is attributed to the inhibition of TNF- $\alpha$, an inflammatory cytokine, by DPM (226). TNF- $\alpha$ is a tumor promoter used in the JB6 model and required NF- $\kappa \mathrm{B}$ for the transformation response (225). Although these studies were not done in the JB6 with TPA-induced transformation, this shows the possible involvement of $\mathrm{NF}-\kappa \mathrm{B}$ in the antitumor promotion activity of DPM.

\section{Conclusions}

AP-1 transactivation is pivotal in TPA-induced tumor promotion. The nucleoside transport inhibitor, dipyridamole, inhibits AP-1 transactivation in a dose-response manner. Mechanistic studies have revealed that inhibition of the p38 MAPK activation is one mechanism by which DPM inhibits AP-1. Erk and Elk-1 MAPKs did not show any correlation with DPM inhibition of AP-1. This study and others show connections between DPM and three major mediators in TPA-induced tumor promotion: AP-1, NF$\kappa \mathrm{B}$, and ROS. We have shown inhibition of AP-1 activity in the JB6 tumor promotion model directly. Others have shown inhibitory effects of DPM on NF- $\kappa$ B and ROS, which warrants future investigation in the JB6 model. Inhibition of nucleoside transport shows potential as a novel target in chemoprevention as evidenced by the ability of DPM and other nucleoside transport inhibitors to hinder tumor promotion. However, it should be noted that the expression profile and function of nucleoside transporters must be determined in each model in which these proteins are intended chemoprevention targets. Overall, these data provide mechanistic insights into the potent chemopreventive activity of DPM (Figure 5.10).

In regards to the therapeutic potential of DPM in chemopreventive therapy, a few factors must be considered. DPM has multiple targets (nucleoside transporters, phosphodiesterase, prostacyclin, etc) and the long term effects of these interactions may prove to negate the chemopreventive benefits upon clinical studies. In addition to the broad pharmacologic effects of DPM, it also has high serum binding giving it a poor pharmacologic profile. Therefore, the pursuit of more potent chemopreventive DPM analogues such as Compound 145 will allow the design of agents with more mechanistic selectivity and increased pharmacologic efficacy.

\section{Future Directions}

\section{Time course of DPM chemoprevention}

In this study of the chemoprevention mechanism of DPM, JB6 $\mathrm{P}^{+}$cells were pretreated with DPM for $1 \mathrm{hr}$ followed by induction with TPA. It is clear that DPM in the presence of TPA was able to inhibit transformation in the 14 day colony assay. However, the time effects of DPM on MAPK activation are not known. To study this, JB6 $\mathrm{P}^{+}$cells will be treated with selected concentrations of DPM at set times before, simultaneously, or after induction with TPA. This analysis will help elucidate at what 


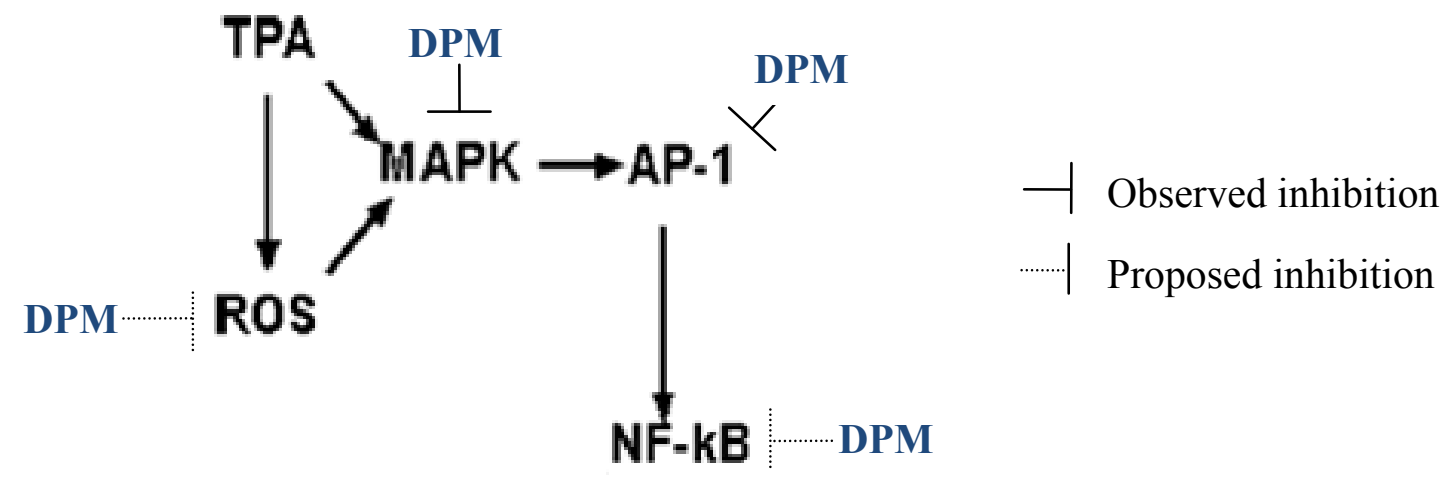

Figure 5.10. Potential mechanisms of DPM in chemoprevention.

time DPM maximally inhibits tumor promotion and may offer further insight into its mechanism.

\section{DPM effects on AP-1 DNA binding}

Inhibition of AP-1 transactivation by DPM may be a result of inhibitory effects on AP-1 DNA binding. This can be analyzed by electrophoretic mobility shift assay (EMSA). JB6 $\mathrm{P}^{+}$cells will be pretreated with various concentrations of DPM at set times prior to stimulation with TPA. Following TPA stimulation, collected nuclear protein extracts will be analyzed for AP-1 DNA binding. DPM effects on AP-1 binding will offer further mechanistic insight.

\section{DPM effects on TPA-induced NF-אB activity and DNA binding}

There are several literature reports suggesting DPM inhibits NF- $\kappa B$. Since NF$\kappa \mathrm{B}$ is important in tumor promotion, it is a reasonable target to investigate. DPM effects on NF- $\kappa \mathrm{B}$ transactivation and binding can be done in the same manner as done for AP-1.

\section{DPM effects on ROS}

TPA induction of ROS is important of tumor promotion and DPM has reported antioxidant properties. ROS can be measured after pretreatment of JB6 $\mathrm{P}^{+}$cells with DPM followed by TPA stimulation using the fluorescent probe dichlorofluorescein diacetate (DCFDA). DCFDA becomes trapped in cells after passive diffusion. In the presence of intracellular ROS, DCFDA is oxidized to a fluorescent product that can be monitored using a fluorescence detection method of choice. 


\section{DPM effects on EGF, TNF- $\alpha$, and UV-induced transformation}

EGF, TNF- $\alpha$, and UV-induced tumor promotion are more representative of the causative agents of cancer in humans than TPA. They each also elicit different signaling mechanisms (some of which are common between them), but each signaling cascade offers insight into the particular aspects of carcinogenesis within certain cancer populations. For instance, UV is a causative agent in skin cancer development. Evaluating the effect of DPM under different tumor-promoter induced signaling will further the understanding of the chemopreventive effects of DPM and also help determine its potential in clinical settings.

\section{DPM chemoprevention in vivo}

To study the effects of DPM in vivo, SENCAR (sensitivity to carcinogenesis) mice can be used. These mice are bred for sensitive to DMBA-initiation-TPA-promotion carcinogenesis model. In this setting, a single dose of carcinogen (DMBA) is applied topically, followed by repeated application of promoter (TPA). This treatment protocol results in visible tumors on the mouse skin. To test DPM in chemoprevention, it should be added during the promotion phase. Any chemopreventive effects (measured by skin papilloma incidence) of DPM would suggest its potential in the prevention of skin cancer.

\section{Mechanism studies on the novel DPM analogue, compound 145}

From the SAR studies presented in Chapter 4, compound 145 shows more potent antitumor promotion activity than DPM. This warrants further investigation into the mechanism of this compound. All of the studies done with DPM should be done with 145 to compare the resulting mechanisms.

\section{Materials and Methods}

\section{Reagents}

Dipyridamole (DPM), 12-O-tetradecanoyl-phorbol-13-acetate (TPA), dimethyl sulfoxide (DMSO), heat-inactivated fetal bovine serum (HI-FBS), Trypsin-EDTA $(0.25 \%)$ solution, and bovine serum albumin (BSA) were obtained from Sigma. Phosphate buffered saline (PBS) was diluted from a $10 \mathrm{X}$ PBS (pH 7.4, GIBCO) stock to a 1 X PBS solution for cell culture. Minimum essential medium (MEM) powder (containing Earle's salts and L-glutamine), and gentamicin were purchased from GIBCO. For cell culture, $1 \mathrm{~L}$ of $1 \mathrm{X}$ MEM was prepared by diluting MEM powder in deionized $\mathrm{H}_{2} \mathrm{O}$ following the manufacturer's protocol. All cell culture materials were either presterilized by the manufacture or autoclaved prior to use. Cell culture media was sterilefiltered using $0.22 \mu \mathrm{m}$ cellulose acetate bottle top filter. The JB6 $\mathrm{P}^{+}$mouse epidermal cell line, C141, was purchased from American Type Culture Collection (ATCC). Erk, pErk, p38, p-p38, Elk-1, and p-Elk-1 antibodies were obtained from Cell Signaling. RIPA 
lysis buffer with protease inhibitors was purchased from Santa Cruz. BCA protein assay buffers were purchased from Pierce. Protein gels, Tris-buffered saline (TBS), and Laemmli sample buffer were purchased from Bio-Rad. Enhanced chemiluminescence detection solution (ECL) was purchased from GE-Amersham.

\section{Cell culture}

The JB6 $\mathrm{P}^{+}$mouse epidermal cell line, $\mathrm{C} 141$ was cultured at $37{ }^{\circ} \mathrm{C}, 5 \% \mathrm{CO}_{2}$ in MEM containing 5 or $10 \%$ FBS, $2 \mathrm{mM} \mathrm{L-glutamine} \mathrm{and} 25 \mu \mathrm{g} / \mathrm{ml}$ gentamicin. Cells were cultured in monolayer in T25, T75, or T150 flasks and passaged at 70-80\% confluence. First, cells were washed with $10 \mathrm{ml}$ of $1 \mathrm{X}$ PBS followed by vacuum aspiration. To detach the cells for passaging (or for soft-agar colony assay), $1-2 \mathrm{ml}$ of trypsin-EDTA $(0.25 \%)$ was added to the monolayer cells and placed at $37{ }^{\circ} \mathrm{C}, 5 \% \mathrm{CO}_{2}$ for 5-10 min. After incubation, 8-9 $\mathrm{ml}$ fresh culture media was added and the detached cells were collected and centrifuged $\left(20^{\circ} \mathrm{C}, 5-10 \mathrm{~min}, 1000 \mathrm{rpm}\right)$. The resulting cell pellet was homogenized in fresh culture media and split into new culture flasks.

\section{Preparation of cytosolic extracts}

JB6 $\mathrm{P}^{+}$cells were cultured in 6-well dishes $\left(1.5 \times 10^{5}\right.$ cells per well) for $24 \mathrm{~h}$. After which, the cells were starved in $0.1 \%$ FBS-MEM for $48 \mathrm{~h}$ to eliminate the influence of FBS on MAPK activation. The cells were then treated in triplicate with or without DPM for $1 \mathrm{~h}$ and then treated with TPA $(10 \mathrm{ng} / \mathrm{ml})$ at designated times. The cells were scraped and lysed using RIPA lysis buffer with protease inhibitors followed by sonication at $4{ }^{\circ} \mathrm{C}$. Homogenates were centrifuged at $10,000 \mathrm{x}$ g for $20 \mathrm{~min}$ at $4{ }^{\circ} \mathrm{C}$. The resulting supernatant was collected as the cytosolic extract and protein was quantified using BCA analysis following the manufacturer's protocol.

\section{Immunoblotting}

For immunoblot analysis, $10 \mu \mathrm{g}$ of each protein lysate was denatured in Laemmeli sample buffer $(1: 1)$ by boiling for $5 \mathrm{~min}$. Denatured proteins were then loaded on $12 \%$ Tris-HCl gels for SDS-PAGE analysis. The gels were run for $1 \mathrm{hr}$ at $135 \mathrm{~V}$ (constant voltage). The separated proteins were transferred onto a PVDF membrane ( $100 \mathrm{~V}, 1 \mathrm{hr}, 4$ $\left.{ }^{\circ} \mathrm{C}\right)$. The membranes were then blocked with $5 \%$ nonfat milk powder $(\mathrm{w} / \mathrm{v})$ in TBS $/ 0.1 \%$ Tween-20 (TBST) for 1-2 $\mathrm{h}$ at room temperature. Following the block, membranes were washed 3 times for $10 \mathrm{~min}(3 \times 10 \mathrm{~min})$ in TBS/0.1\% Tween-20. Membranes were then probed with specific primary antibodies in antibody dilution buffer (TBST/ 5\% BSA) overnight at $4{ }^{\circ} \mathrm{C}$. After the primary antibody incubation period, membranes were washed in TBST ( $3 \times 20 \mathrm{~min}$ ) followed by incubation with the appropriate HRPconjugated secondary antibody in blocking buffer for $1 \mathrm{hr}$. Membranes were washed again $(3 \times 10 \mathrm{~min}, \mathrm{TBST})$ and incubated with $6 \mathrm{ml} \mathrm{ECL}$ solution for $5 \mathrm{~min}$. Protein bands were visualized by exposing the membranes to BioMax maximum sensitivity autodradiography film in an autoradiography cassette in the dark room. The film was developed in a film processor (Kodak X-OMAT 2000A). 


\section{ImageJ analysis}

The developed immunoblot films were scanned and the images uploaded to Image J (NIH software). Protein bands from immunoblotting were quantified following software instructions. For each protein band, the value obtained from ImageJ was divided by the value of the sample loading control ( $\beta$-actin) from the same lane on the protein gel to normalize the data. For the untreated control, this normalized value (Y) was then designated as $1.0(\mathrm{Y} / \mathrm{Y})$ and the remaining protein sample values $(\mathrm{Z})$ were divided by the value of the untreated control $(\mathrm{Z} / \mathrm{Y})$ to give the fold induction values. 


\section{LIST OF REFERENCES}

1. American Cancer Society. (2007) Cancer Facts \& Figures 2007, American Cancer Society, Atlanta.

2. Cunningham SC, Schulick, RD. (2007) Pallative management of gastric cancer. Surg Oncol 16, 267-275.

3. Wattenberg LW. (1966) Chemoprophylaxis of carcinogenesis: a review. Cancer Res 26, 1520-1526.

4. Sporn MB. (1976) Approaches to prevention of epithelial cancer during the preneoplastic period. Cancer Res 36, 2699-2702.

5. Surh YJ. (2003) Cancer chemoprevention with dietary phytochemicals. Nature Rev Cancer 3, 768-780.

6. Kwon KH, Barve A, Yu S, Huang M-T, Kong AT. (2007) Cancer chemoprevention by phytochemicals: potential molecular targets, biomarkers and animal models. Acta Pharmacol Sin 28, 1409-1421.

7. Greenwald P, Kelloff G, Burch-Whitman C, and Kramer BS. (1995) Chemoprevention. CA Cancer J Clin 45, 31-39.

8. Smith JJ, Tully P, and Padberg RM. (2005) Chemoprevention: a primary cancer prevention strategy. Semin Oncol Nurs 21, 243-251.

9. Burstein, HJ. (2000) Side effects of chemotherapy. J Clin Oncol 18, 693-698

10. Lippman S, Lee JL. (2006) Reducing the "Risk" of chemoprevention: defining and targeting high risk - 2005 AACR cancer research and prevention foundation award lecture. Cancer Res 66, 2893-2903.

11. Palmer LI, Martin RCG, and Hein DW. (2004) Chemopreventive drug treatments in subjects with predisposition to cancer: prescriber liability and health care disparities. Pharmacogenomics 5, 319-329.

12. Goodman LS, Wintrobe WM, Dameshek W, Goodman MJ, Gilman A, and McLennan MT. (1946) Nitrogen mustard therapy. Use of methyl-bis(betachloroethyl)amine hydrochloride and tris(beta-chloroethyl) amine hydrochloride for Hodgkin's disease, lymphosarcoma, leukemia, and certain allied and miscellaneous disorders. J Am Med Assoc 105, 475-476.

13. Armitage, P. (1985) Multistage carcinogenesis. Environ Health Perspect 63, 195201.

14. Loeb LA, Springgate, CF, and Battula N. (1974) Errors in DNA replication as a basis of malignant changes. Cancer Res 34, 2311-2321.

15. Young MR, Yang HS, and Colburn NH. (2003) Promising molecular targets for cancer prevention: AP-1, NF-kappaB and Pdcd4. Trends Mol Med 1, 36-41.

16. Bode AM, Dong Z. (2004) Cancer prevention by food factors through targeting signaling transduction pathways. Nutrition 20, 89-94.

17. Sporn MB, Liby KT. (2005) Cancer chemoprevention: scientific promise, clinical uncertainty. Nat Clin Pract Oncol 2, 518-525.

18. Slaga TJ, Fisher SM, Weeks CE, Klein-Szanto AJP, and Reiners J. (1982) Studies on the molecular mechanisms involved in multistage carcinogenesis in mouse skin. J Cell Biochem 18, 99-119. 
19. DiGiovanni J, Imamoto A, Naito M, Walker SE, Beltran L, Chenicek KJ, and Skow L. (1992) Further genetic analysis of skin tumor promoter susceptibility using inbred and recombinant inbred mice. Carcinogenesis 13, 525-531.

20. Colburn NH, Former BF, Nelson KA, and Yuspa SH. (1979) Tumour promoter induces anchorage independence irreversibly. Nature 281, 589-591.

21. De Benedetti F, Colburn NH, Oppenheim JJ, and Faltynek CR. (1990) Tumor necrosis factor induces anchorage independent growth of two murine nontransformed cell lines. In: Oppenheim JJ, Powanda MC, Kluger MJ, and Dinarello, CA (eds). Molecular and cellular biology of cytokines, Wiley-Liss, Inc, New York.

22. Colburn NH, Gindhart TD, Hegamyer GA, Blumberg PM, Delclos KB, Magun BE, and Lockyer J. (1982) Phorbol diester and epidermal growth factor receptors in 12-O-tetradecanoylphorbol-13-acetate-resistant and sensitvie mouse epidermal cells. Cancer Res 42, 3093-3097.

23. Colburn NH, Wendel E, and Srinivas L. (1982) Responses of preneoplastic epidermal cells to tumor promoters and growth factors: use of promoter resistant variance for mechanism studies. $J$ Cell Biochem 18, 261-270.

24. Dhar A, Young MR, and Colburn HN. (2002) The role of AP-1, NF-kB and ROS/NOS in skin carcinogenesis: the JB6 model is predictive. Mol Cell Biochem 234/235, 185-193.

25. Bernstein LR, Ben-Ari EF, Simek SL, and Colburn NH. (1991) Gene regulation and genetic susceptibility to neoplastic transformation: AP-1 and p80 in JB6 cells. Environ Health Perspect 93, 111-119.

26. Angel JM, DiGiovanni J. (1999) Genetics of skin tumor promotion. Prog Exp Tumor Res 35, 143-157.

27. Gindhart TD, Nakaura Y, Stevens LA, Hegameyer GA, West MW, Smith BM, and Colburn NH. (1985) Genes and Signal Transduction in tumor promotion: conclusions from studies with promotion resistant variants of JB6 mouse epidermal cells. In. Tumor Promotion and Enhancement in the Etiology of Human and Experimental Respiratory Tract Carcinogenesis, Raven Press, New York.

28. Cmarik JL, Min H, Hegamyer G, Zhan S, Kulesz-Martin M, Yoshinaga H, Matsuhashi S, and Colburn NH. (1999) Differentially expressed protein Pdcd4 inhibits tumor promoter-induced neoplastic transformation. Proc Natl Acad Sci USA 24, 14037-14042.

29. Chen N, Ma YW, She QB, Wu E, Liu G, Bode AM and Dong Z. (2001) Transactivation of the epidermal growth factor receptor is involved in 12-Otetradecanoyl-phorbol-13-acetate-induced signal transduction. J Biol Chem 276, $46722-46728$.

30. He Zhiwei, Cho YY, Liu G, Ma W-Y, Bode AM, and Dong Z. (2003) p38 mitogen-activated protein kinase regulation of JB6 C141 cell transformation promoted by epidermal growth factor. J Biol Chem 278, 26435-26442.

31. Ashendel, CL. (1985) The phorbol ester receptor: a phospholipid-regulated protein kinase. Biochim Biophys Acta 822, 219-242.

32. Castagna M, Takai Y, Kaibuchi K, Sano K, Kikkawa U, and Nishizuka Y. (1982) Direct activation of calcium-activated phospholipid-dependendent protein kinase by tumor-promoting phorbol ester. J Biol Chem 257, 7847-7851. 
33. Dong Z, Birrer MJ, Watts RG, Matrisian LM, Colburn NH (1994) Blocking of tumor promoter-induced AP-1 activity inhibits induced transformation in JB6 mouse epidermal cells. Proc Natl Acad Sci USA 91, 609-613.

34. Li JJ, Dong Z, Dawson MI, and Colburn NH. (1996) Inhibition of tumor promoter-induced transformation by retinoids that transrepress AP-1 withouth transactivating retinoic acid response element. Cancer Res 56, 483-489.

35. Schonwasser DC, M. R., Marshall CJ, and Parker PJ. (1998) Activation of the mitogen-activated protein kinase/extracellular signal-related kinase pathway by conventional, novel, and atypical protein kinase C isotypes. Mol Cell Biol 18, 790-798.

36. Young MR, Li JJ, Rincon M, Flavell RA, Sathyanarayana BK, Hunziker R, Colburn N. (1999) Transgenic mice demonstrate AP-1 (activator protein-1) transactivation is required for tumor promotion. Proc Natl Acad Sci USA 96, 9827-9832.

37. Hoshi M, Nishida E, and Sakai H. (1989) Characterization of a mitogen-activated, Ca2+-sensitive microtubule-associated protein-2 kinase. Eur J Biochem 184, 477486.

38. Young S, Parker PJ, Ullrich A, and Stabel S. (1987) Down-regulation of protein kinase $\mathrm{C}$ is due to an increased rate of degradation. Biochem J 244, 775-779.

39. Nishizuka, Y. (1988) The molecular heterogeneity of protein kinase $\mathrm{C}$ and its implications for cellular regulation. Nature 334, 661-665.

40. Lu Z, Hornia A, Jiang YW, Zang Q, Ohno S, and Foster DA. (1997) Tumor promotion by depleting cells of protein kinase C delta. Mol Cell Biol 17, 34183428.

41. Reddig PJ, Dreckschmidt NE, Ahrens H, Simsiman R, Tseng CP, Zou J, Oberley TD, and Verma AK. (1999) Transgenic mice overexpressing protein kinase C delta in the epidermis are resistant to skin tumor promotion by 12-Otetradecanoylphorbol-13-acetate. Cancer Res 59, 5710-5718.

42. Reddig PJ, Dreckschmidt NE, Zou J, Bourguignon SE, Oberley TD, and Verma AK. (2000) Transgenic mice overexpressing protein kinase C epsilon in their epidermis exhibit reduced papilloma burden but enhanced carcinoma formation after tumor promotion. Cancer Res 60, 595-602.

43. Kennard MD, Kang DC, Montgomery RL, and Butler AP. (1995) Expression of epidermal ornithine decarboxylase and nuclear proto-oncogenes in phorbol ester tumor promotion-sensitive and -resistant mice. Mol Carcinog 12, 14-22.

44. Bernstein LR, Colburn NH. (1989) AP1/jun function is differentially induced in promotion-sensitive and resistant JB6 cells. Science 244, 566-569.

45. Young MR, Nair R, Bucheimer N, Tulsian P, Chapp C, Hsu T-C, and Colburn NH. (2002) Trasactivation of Fra-1 and consequent activation of AP-1 occur extracellul signal-regulated kinase dependently. Mol Cell Biol 22, 587-598.

46. Li JJ, Rhim JS, Schlegel R, Vousden KH, and Colburn NH. (1998) Expression of dominant negative Jun inhibits elevated AP-1 and NF-kappaB transactivation and suppresses anchorage independent growth of HPV immortalized human keratinocytes. Oncogene 16, 2711-2721. 
47. Feng Z, Li L, Ng PY, and Porter AG. (2002) Neuronal differentiation and protection from nitric oxide-induced apoptosis require c-Jun-dependent expression of NCAM140. Mol Cell Biol 22, 5357-5366.

48. Curran T, Franza BF. (1988) Fos and Jun: the AP-1 connection. Cell 55, 395-397

49. Wagner EF. (2001) AP-1 articles. Oncogene 20, 2333-2497.

50. Angel P, Imagawa M, Chiu R, Stein B, Imbra RJ, Rahmsdorf HJ, Jonat C, Herrlich P, and Karin M. (1987) Phorbol ester-inducible genes contain a common cis element recognized by a TPA-modulating trans-acting factor. Cell 49, 729739.

51. Cavigelli M, Dolfi F, Claret FX, Karin M. (1995) Induction of c-fos expression through JNK-mediated TCF/Elk-1 phosphorylation. EMBO J 14, 5957-5964.

52. Janknecht R, Ernst WH, Pingoud V, Nordheim A. (1993) Activation of ternary complex factor Elk-1 by MAP kinases. EMBO J 12, 5097-5104.

53. Dong Z, Watts SG, Sun Y, and Colburn NH. (1995) Progressive elevation of AP1 activity during preneoplastic to neoplastic progression as modeled in mouse JB6 cell variants. Int $J$ Oncol 7, 359-364.

54. Barthelman M, Chen W, Gensler HL, Huang C, Dong Z, and Bowden GT. (1998) Inhibitory effects of perillyl alcohol on UVB-induced murine skin cancer and AP1 transactivation. Cancer Res 58, 711-716.

55. Huang C, Ma WY, and Dong Z. (1996) Inhibitory effects of ascorbic acid on AP1 activity and transformation of JB6 cells. Int J Oncol 8, 389-393.

56. Huang C, Ma WY, Dawson MI, Rincon M, Flavell RA and Dong Z. (1997) Blocking activator protein-1 activity, but not activating retinoic acid response element, is required for the antitumor promotion effect of retinoic acid. Proc Natl Acad Sci USA 94, 5826-5830.

57. Brown PH. (1993) Suppression of oncogene-induced transformation by a deletion mutant of c-Jun. Oncogene 8, 877-886.

58. Ballif BA, Blenis J. (2001) Molecular mechanisms mediating mammalian mitogen-activated protein kinase (MAPK) kinase (MEK)-MAPK cell survival signals. Cell Growth Differ 12, 397-408.

59. Kallunki T, Su B, Tsigelny I, Sluss HK, Derijard B, Moore G, Davis R, and Karin M. (1994) JNK2 contains a specificity-determining region responsible for efficient c-Jun binding and phosphorylation. Genes Dev 8, 2996-3007.

60. Harper SJ, LoGrasso P. (2001) Signalling for survival and death in neurones: the role of stress-activated kinases, JNK and p38. Cell Signal 13, 299-310.

61. Papatsoris AG, Papavassiliou A. (2001) Molecular 'palpation' of BPH: a tale of MAPK signalling?. Trends Mol Med 7, 288-292.

62. Herlaar E, Brown Z. (1999) p38 MAPK signalling cascades in inflammatory disease. Mol Med Today 5, 439-447.

63. Seger R, Krebs EG. (1995) The MAPK signaling cascade. FASEB J 9, 726-735.

64. Huang C, Ma WY, Young MR, Colburn N, and Dong Z. (1998) Shortage of mitogen-activated protein kinase is responsible for resistance to AP-1 transactivation and transformation in mouse JB6 cells. Proc Natl Acad Sci USA 95, 156-161. 
65. Watts RG, Huang C, Young MR, Li JJ, Dong Z, Pennie WD, and Colburn NH. (1998) Expression of dominant-negative Erk2 inhibits AP-1 trasactivation and neoplastic transformation. Oncogene 17, 3493-3498.

66. Huang C, Li J, Ma W, and Dong Z. (1999) JNK activation is required for JB6 cell transformation induced by tumor necrosis factor-alpha but not by $12-\mathrm{O}-$ Tetradecanoylphorbol-13-Acetate. J Biol Chem 274(42), 29672-29676.

67. Berg JM, Tymoczko JL, and Stryer L. (2002) Biochemistry, 5 Ed., W.H. Freeman and Company, New York.

68. Griffith DA, Jarvis SM. (1996) Nucleoside and nucleobase transport systems of mammalian cells. Biochim Biophys Acta 1286, 153-181.

69. King,AE, Ackley MA, Cass CE, Young JD, and Baldwin SA. (2006) Nucleoside transporters: from scavengers to novel therapeutic targets. TRENDS Pharmacol Sci 27, 416-425.

70. Baldwin SA, Mackey JR, Cass CE, and Young JD. (1999) Nucleoside transporters: molecular biology and implications for therapeutic development. Mol Med Today 5, 216-224.

71. Acimovic Y, and Coe I. (2002) Molecular evolution of the equilibrative nucleoside transporter family: identifcation of novel family members in prokaryotes and eukaryotes. Mol Biol Evol 19, 2199-2210.

72. Hyde JR, Cass CE, Young JD, and Baldwin SA. (2001) The ENT family of eukaryote nucleoside and nucleobase transporters: recent advances in the investigation of structure/function relationships and the identification of novel isoforms. Mol Membr Biol 18, 53-63.

73. Baldwin SA, Beal PR, Yao SYM, King AE, Cass CE, and Young JD. (2004) The equilibrative nucleoside transport family, SCL29. Pflugers Arch 447, 735-743

74. Damaraju VL, Damaraju S, Young JD, Baldwin SA, Mackey J, Sawyer MB, and Cass CE. (2003) Nucleoside anticancer drugs: the role of nucleoside transporters in resistance to cancer chemotherapy. Oncogene 22, 7524-7536.

75. Griffiths M, Beaumont N, Yao SYM, Sundaram M, Boumah CE, Davies A, Kwong FYP, Coe I, Cass CE, Young JD, and Baldwin SA. (1997) Cloning of a human nucleoside transporter implicated in the cellular uptake of adenosine and chemotherapeutic drugs. Nat Med 3, 89-93.

76. Yao SM, Ng AM, Muzyka WR, Griffiths M, Cass CE, Baldwin SA, and Young, JD. (1997) Molecular cloning and functional characterization of nitrobenzylthioinosine (NBMPR)-sensitive (es) and NBMPR-insensitive (ei) equilibrative nucleoside transporter proteins (rENT1 and rENT2) from rat tissues. J Biol Chem 272, 28423-28430.

77. Handa M, Choi DS, Caldeiro RM, Messing RO, Gordon AS, and Diamon I. (2001) Cloning of a novel isoform of the mouse NBMPR-sensitive equilibrative nucleoside transporter (ENT1) lacking a putative phosphorylation site. Gene 262, 301-307.

78. Griffiths M, Yao SYM, Abidi F, Phillips SEV, Cass CE, and Young JD. (1997) Molecular cloning and characterization of a nitrobenzylthioinosine-insensitive (ei) equilibrative nucleoside transporter from human placenta. Biochem $J$ 328, 739743. 
79. Kiss A, Farah K, Kim J, Garriock RJ, Drysdale TA, and Hammond JR. (2000)

Molecular cloning and functional characterization of inhibitor-sensitive (mENT1) and inhibitor-resistant (mENT2) equilibrative nucleoside transporters from mouse brain. Biochem J 352, 363-372.

80. Crawford CR, Patel DH, Naeve C, and Belt JA. (1998) Cloning of the human equilibrative, nitrobenzylmercaptopurine riboside (NBMPR)-insensitive nucleoside transporter ei by functional expression in a transport-deficient cell line. $J$ Biol Chem 273, 5288-5293.

81. Mangravite LM, Xiao G, and Giacomini KM. Localization of human equilibrative nucleoside transporters, hENT1 and hENT2, in renal epithelial cells. Am J Physiol Renal Physiol (2003) 284, F902-F910.

82. Acimovic Y, Coe I. (2002) Molecular evolution of the equilibrative nucleoside transporter family: identifcation of novel family members in prokaryotes and eukaryotes. Mol Biol Evol 19, 2199-2210.

83. Ritzel MWL, Yao SYM, Huang M-Y, Elliott JF, Cass CE, and Young JD. (1997) Molecular cloning and functional expression of cDNAs encoding a human $\mathrm{Na}+-$ nucleoside transporter (hCNT1). Am J Physiol 272, C707-C714.

84. Loewen SK, Ng AML, Yao SYM, Cass CE, Baldwin SA, and Young JD. (1999) Identification of amino acid residues responsible for the pyrimidine and purine nucleoside specificities of human concentrative $\mathrm{Na}+$ nucleoside cotransporters hCNT1 and hNCT2. J Biol Chem 274, 24475-24484.

85. Ritzel MWL, Ng AML, Yao SYM, Graham K, Loewen SK, Smith KM, Ritzel RG, Mowles DA, Carpenter P, Chen X-Z, Karpinski E, Hyde RJ, Baldwin SA, Cass CE, and Young, JD. (2002) Molecular identification and characterization of novel human and mouse concentrative $\mathrm{Na}+$-nucleoside cotransporter proteins (hCNT3 and mCNT3) broadly selective for purine and pyrimidine nucleosides (system cib). J Biol Chem 276, 2914-2927.

86. Sundaram M, Yao SYM, Ingram JC, Berry ZA, Abidi F, Cass CE, Baldwin SA, Young JD. (2001) Topology of a human equilibrative, nitrobenzylthioinosine (NBMPR)-sensitive nucleoside transporter (hENT1) implicated in the cellular uptake of adenosine and anti-cancer drugs. J Biol Chem 276, 45270-45275.

87. King AE, Ackley MA, Cass CE, Young JD, Baldwin SA. (2006) Nucleoside transporters: from scavengers to novel therapeutic targets. TRENDS Pharmacol Sci 27, 416-425.

88. Arastu-Kapur S, Arendt CS, Purnat T, Carter NS, and Ullman B. (2005) Secondsite suppression of a nonfunctional mutation within the leishmania donovani inosine-guanosine transporter. J Biol Chem 280, 2213-2219.

89. Endres CJ, Sengupta DJ, and Unadkat JD. (2004) Mutation of leucine-92 selectively reduces the apparent affinity of inosine, guanosine, NBMPR [S6-(4nitrobenzyl)-mercaptopurine riboside] and dilazep for the human equilibravie nucleoside transporter, hENT1. Biochem J 380, 131-137.

90. Sundaram M, Yao SYM, Ng AML, Griffiths M, Cass CE, Baldwin SA, and Young JD. (1998) Chimeric constructs between human and rat equilibrative nucleoside transporters (hENT1 and rENT1) reveal ENT1 structural domains interacting with coronary vasoactive drugs. J Biol Chem 273, 21519-21525. 
91. Young JD, Yao SYM, Cass CE, Baldwin SA. (2003) Equilibrative (ENT) nucleoside transport proteins. In: Bernhardt I, Ellory JC (eds). Red Cell Membrane Transport in Health and Disease, Springer-Verlag, Berlin.

92. Hamilton SR, Yao SYM, Ingram JC, Hadden DA, Ritzel MWL, Gallagher MP, Henderson PJF, Cass CE, Young JD, and Baldwin SA. (2001) Subcellular distribution and membrane topology of the mammalian concentrative $\mathrm{Na}+-$ nucleoside cotransporter rCNT1. J Biol Chem 276, 27981-27988.

93. Governo RJM, Deuchars J, Baldwin SA, and King AE. (2005) Localization of the NBMPR-sensitive equilibrative nucleoside transporter, ENT1, in the rat dorsal root ganglion and lumbar spinal cord. Brain Res 1059, 129-138.

94. Cass CE, Gati WP, Odegard R, and Paterson ARP. (1985) The effect of pH on the interaction of nitrobenzylthioinosine and hydroxynitrobenzylthioinosine with the nucleoside transporter of human erythrocyte membranes. Mol Pharmacol 27, 662665.

95. Musa H, Dobrzynski I, Berry Z, Abidi F, Cass CE, Young JD, Baldwin SA, and Boyett MR. (2002) Immuncytochemical demonstration of the equilibrative nucleoside transporter rENT1 in rat sinoatrial node. J Histochem Cytochem 50, 305-309.

96. Pennycooke M, Chaudary N, Shuralyova I, Zhang Y, and Coe IR. (2001) Differential expression of human nucleoside transporters in normal and human tissues. Biochem Biophys Res Comm 280, 951-959.

97. Cass CE, Young JD, Baldwin SA, Cabrita MA, Graham KA, Griffiths M, Jennings LL, Mackey JR, Ng AM, Ritzel MW, Vickers MF, and Yao SY. (1999) Nucleoside transporters of mammalian cells. Pharm Biotechnol 12, 313-352.

98. Mangravite LM, Xiao G, and Giacomini KM. (2003) Localization of human equilibrative nucleoside transporters, hENT1 and hENT2, in renal epithelial cells. Am J Physiol Renal Physiol 284, F902-F910.

99. Osses N, Pearson JD, Yudilevich DL, Jarvis SM. (1996) Hypoxanthine enters human vascular endothelial cells (ECV 304) via the nitrobenzylthioinosineinsensitive equilibrative nucleoside transporter. Biochem $J$ 317, 843-848.

100. Gray JH, Owen RP, and Giacomini KM. (2004) The concentrative nucleoside transport family, SLC28. Eur J Physiol 447, 728-734.

101. Ritzel MWL, Ng AML, Yao SYM, Graham K, Loewen SK, Smith KM, Ritzel RG, Mowles DA, Carpenter P, Chen X-Z, Karpinski E, Hyde RJ, Baldwin SA, Cass CE, and Young, JD. (2002) Molecular identification and characterization of novel human and mouse concentrative $\mathrm{Na}+$-nucleoside cotransporter proteins (hCNT3 and mCNT3) broadly selective for purine and pyrimidine nucleosides (system cib). J Biol Chem 276, 2914-2927.

102. Buolamwini JK. (1997) Nucleoside transport inhibitors: structure-activity relationships and potential therapeutic applications. Curr Med Chem 4, 35-66.

103. Galmarini CM, Mackey JR, and Dumontet C. (2002) Nucleoside analogues and nucleobases in cancer treatment. Lancet Oncol 3, 415-424.

104. Lang TT, Young JD, and Cass CE. (2004) Interactions of nucleoside analogs, caffeine, and nicotine with human concentrative nucleoside transporters 1 ad 2 stably produced in a transporter-defective human cell line. Mol Pharmacol 65, 925-933. 
105. Moline-Arcas M, Bellosillo B, Casado FJ, Montserrat E, Gil J, Colomer D, and Pastor-Anglada M. (2003) Fludarabine uptake mechanisms in B-cell chronic lymphocytic leukemia. Blood 101, 2328-2334.

106. Gati WP, Paterson AR, Belch AR, Chlumecky V, Laratt LM, Mant MJ, and Turner AR. (1998) Es nucleoside transporter content of acute leukemia cells: role in cell sensitivity to cytarabine (araC). Leuk Lymphoma 32, 45-54.

107. King KM, Damaraju VL, Vickers MF, Yao SY, Lang T, Tackaberry TE, Mowles DA, Ng AM, Young JD, and Cass CE. (2006) A comparison of the transportability, and its role in cytotoxicity, of clofarabine, cladribine, and fludarabine by recombinant human nucleoside transporters in three model expression systems. Mol Pharmacol 69, 345-353.

108. King KM, Cass CE. (1994) Membrane transport of 2-chloro-2'-deoxyadenosine and 2-chloro-2'-arabinofluro-2'-deoxyadenosine is required for cytotoxicity. Proc Am Assoc Cancer Res 35, A3436.

109. Schaner ME, Wang J, Zevin S, Gerstin KM, and Giacomini KM. (1997) Transient expression of a purine selective nucleoside transporter (SPNTint) in a human cell line (HeLa). Pharm Res 14, 1316-1321.

110. Mackey JR, Yao SY, Smith KM, Karpinski E, Baldwin SA, Cass CE, and Young JD. (1999) Gemcitabine transport in xenopus oocytes expressing recombinant plasma membrane mammalian nucleoside transporters. J Natl Cancer Inst 91, 1876-1881.

111. Graham KA, Leithoff J, Coe IR, Mowles D, Mackey JR, Young JD, and Cass CE. (2000) Differential transport of cytosine-containing nucleosides by recombinant human concentrative nucleoside transporter protien hCNT1. Nucleosides Nucleotides Nucleic Acids 19, 415-434.

112. Zhang J, Tackaberry T, Ritzel MW, Raborn T, Barron G, Baldwin SA, Young JD, and Cass CE. (2006) Cysteine-accesibility analysis of transmembrane domains 11-13 of human concentrative nucleoside transporter 3. Biochem J 394 (Pt 2), 389-398.

113. Clarke ML, Damaraju VL, Zhang J, Mowles D, Tackaberry T, Lang T, Smith KM, Young JD, Tomkinson B, and Cass CE. (2006) The role of human nucleoside transporters in cellular uptake of 4'-thio-beta-Darabinofuranosylcytosine and beta-D-arabinosylcytosine. Mol Pharmacol 70, 303310.

114. Yao SM, Ng AM, Sundaram M, Cass CE, Baldwin SA, and Young JD. (2001) Transport of antiviral 3'-deoxy-nucleoside drugs by recombinant human and rat equilibrative, nitrobenzylthioinosine (NBMPR)-insensitive (ENT2) nucleoside transporter proteins produced in Xenopus oocytes. Mol Membr Biol 18, 161-167.

115. Mackey JR, Baldwin SA, Young JD, and Cass CE. (1998) Nucleoside transport and its significance for anticancer drug resitance. Drug Resist Updat 1, 310-324.

116. Pennycooke M, Chaudary N, Shuralyova I, Zhang Y, and Coe IR. (2001) Differential expression of human nucleoside transporters in normal and human tissues. Biochem Biophys Res Comm 280, 951-959.

117. Muller MM, Kraupp M, Chiba P, and Rumpold H. (1983) Regulation of purine uptake in normal and neoplastic cells. Adv Enzyme Regul 21, 239-256. 
118. Ruiz-Montasell B, Maritnez-Ma JV, Enrich C, Casado FJ, Felipe A, PastorAnglada M. (1993) Early induction of $\mathrm{Na}(+)$-dependent uridine uptake in the regenerating rat liver. FEBS Lett 18, 85-88.

119. Clarke ML, Mackey JR, Baldwin SA, Young JD, and Cass CE. (2002) The role of membrane transporters in cellular resistance to anticancer nucleoside drugs. In: D, A. B. a. M. (ed). Clinically relevant resistance in cancer chemotherapy, Kluwer, Boston.

120. Mackey JR, Mani RS, Selner M. (1998) Nucleoside transport and its significance for anticancer drug resitance. Cancer Res 58, 4349-4357.

121. Spratlin J, Sangha R, Glubrecht D, Dabbagh L, Young JD, Dumontet C, Cass C, Lai R, and Mackey JR. (2004) The absence of human equilibrative nucleoside transporter 1 Is associated with reduced survival in patients with gemcitabinetreated pancreas adenocarcinoma. Clin Cancer Res 10, 6956-6961.

122. Galmarini CM, Thomas X, Calvo F, Rousselot P, El Jafaari A, Cros E, Dumontet C. (2002) Potential mechanims of resistance to cytarabine in AML patients. Leuk Res 26, 621-629.

123. Wiley JS, Woodfurr R, Jamieson GP, Firkin FC, and Sawyer WH. (1987) Cytosine araboniside in the treatment of T-cell acute lymphoblastic leukemia. Aus NZ J Med 17, 379-386.

124. Farre X, Guillen-Gomez E, Sanchez L, Hardisson D, Plaza Y, Lloberas J, Casado FJ, Palacios J, and Pastor-Anglada M. (2004) Expression of the nucleosidederived drug transporters hCNT1, hENT1 and hENT2 in gynecologic tumors. Int J Cancer 112, 959-966.

125. Damaraju S, Zhagn J, Visser F, Tackaberry T, Dufour J, Smith KM, Slugoski M, Ritzel, MWL, Baldwin SA, Young JD, and Cass CE. (2005) Identification and functional characterization of variants in human concentrative nucleoside transporter 3, hCNT3 (SLC28A3), arising from single nucleotide polymorphisms in coding regions of the hCNT3 gene. Pharmacogenet Genomics 15, 173-182.

126. Ramkumar V, Hallam DM, and Nie Z. (2001) Adenosine, oxidative stress, and cytoprotection. Jpn J Pharmacol 86, 265-274.

127. Fredholm BB, Abbrachio MP, Burnstock G, Daly JW, Harden TK, Jacobson KA, Leff P, and Williams M. (1994) Nomenclature and classification of purinoreceptors. Pharmacol Rev 46, 143-156.

128. Mailliard WS, and Diamond I. (2004) Recent advances in the neurobiology of alcoholism: the role of adenosine. Pharmacol Ther 101, 39-46.

129. Hack SP. (2003) Adaptations in adenosine signaling in drug dependence: therapeutic applications. Crit Rev Neurobiol 15, 235-274.

130. Nagy LE, Diamond I, Casso DJ, Franklin CF, and Gordon AS. (1990) Ethanol increases extracellular adenosine by inhibiting adenosine uptake via the nucleoside transporter. J Biol Chem 265(4), 1946-1951.

131. Sawynok J, and Liu XJ. (2003) Adenosine in the spinal cord and periphery: release and regulation of pain. Prog Neurobiol 69, 313-340.

132. Porkka-Heiskanen T, Alanko L, Kalinchuk A, and Stenberg D. (2002) Adenosine and sleep. Sleep Med Rev 6(4), 321-332.

133. Van Belle H. (1993) Nucleoside transport inhibition - a therapeutic approach to cardioprotection via adenosine?. Cardiovasc Res 27, 68-76. 
134. Delicado EG, Sen RP, and Miras-Portugal MT. (1991) Effects of phorbol esters and secretagogues on nitrobenzylthioinosine binding to nucleoside transporters and nucleoside uptake in cultured chromafin cells. Biochem J 279, 651-655.

135. Lee CW. (1994) Decrease in equilibrative uridine transport during monocytic differentiation of HL-60 leukaemia: involvement of protein kinase C. Biochem $J$ 300, 407-412.

136. Coe I, Zhang Y, McKenzie T, and Naydenova Z. (2002) PKC regulation of the human equilibrative nucleoside transporter, hENT1. FEBS Lett 517, 201-205.

137. Soler C, Felipe A, Mata JF, Casado FJ, Celada A, and Pastor-Anglada M. (1998) Regulation of nucleoside transport by lipopolysaccharide, phorbol esters, and tumor necrosis factor-alpha in human b-lymphocytes. J Biol Chem 273, 2693926945.

138. Soler C, Felipe A, Casado FJ, Celada A, and Pastor-Anglada M. (2000) Nitric oxide regulates nucleoside transport in activated B lymphocytes. J Leukoc Biol 67, 345-349.

139. Torres M, Baker MF, Aunis D, Miras-Portugal MT. (1987) Nerve growth factor effect on adenosine transport in cultured chromaffin cells. J Neurochem 48, 233235.

140. Mecklin-Gill KA, Guilbert L, Cass CD. (1993) CSF-1 stimulates nucleoside transport in S1 macrophages. J Cell Physiol 155, 530-538.

141. Pressacco J, Wiley JS, Jamieson GP, Erlichman C, and Hedley W. (1995) Modulation of the equilibrative nucleoside transporter by inhibitors of DNA synthesis. Br J Cancer 72, 939-942.

142. Del Santo B, Valdes R, Mata J, Felipe A, Casado FJ, Pastor-Anglada M. (1998) Differential expression and regulation of nucleoside transport systems in rat liver parenchymal and hepatoma cells. Hepatology 28, 1504-1511.

143. Gomez-Angelats M, Del Santo B, Mercader J, Ferrer-Martinez A, Felipe A, Casado J, Pastor-Anglada M. (1996) Hormonal regulation of concentrative nucleoside transport in liver: two isoforms from the same gene family are expressed in liver cells. Biochem J 330, 997-1001.

144. Valdes R, Casado FJ, Pastor-Anglada M. (2002) Cell-cycle dependent regulation of CNT1, a concentrative nucleoside transporter involved in the uptake of cellcycle dependent nucleoside-derived anticancer drugs. Biochem Biophys Res Commun 296, 575-579.

145. Elion G. (1967) The biochemistry and pharmacology of purine analogs. Fed Proc 26, 890-904.

146. Benedict WF, Baker MS, Haroun L, Choi E, and Ames BN. (1977) Mutagenicity of cancer chemotherapeutic agents in the Salmonella/microsome test. Cancer Res 37, 2209-2213.

147. Tatani K, Nonaka Y, Kikuchi N, inventors. (2006) Purinenucleoside derivatives modified in 8-position and medicinal use thereof.

148. Toan SV, To KK, Leung GP, de Souza MO, Ward JL, and Tse CM. (2003) Genomic organization and functional characterization of human concentrative nucleoside transporter-3 isoform (hCNT3) expressed in mammalian cells. Pflugers Arch 68, 195-204. 
149. Nonaka YTK, Hiratochi M, Kuramochi Y, and Isaji M, inventors. (2004) 5'modified nucleoside derivative and medicinal use thereof.

150. Kikuchi NNY, Tatani K, Hiratochi M, Kuramohi Y, Isaji M, Shimizu K, and Miyagi T, inventors. (2005) Preparation of ribofuranoside compounds having benzimidazole moiety as CNT2 inhibitors.

151. Huang M, Wang Y, Collins M, Gu JJ, and Mitchell, BS. (2002) Inhibition of nucleoside transport by p38 MAP kinase inhibitors. J Biol Chem 277, 2836428367.

152. Huang M, Wang Y, Cogut SB, Mitchell BS, and Graves LM. (2003) Inhibition of nucleoside transport by protein kinase inhibitors. $J$ Pharmacol Exper Ther 304, 753-760.

153. Masuda M, Chang-Chun C, Mollhoff T, Belle HV, and Flameng W. (1992) Effects of nucleoside transport inhibition on long-term ex-vivo preservatino of canine hearts. J Thorac Cardiovasc Surg 104, 1610-1617.

154. Ramkumar V, Hallam DM, and Nie Z. (2001) Adenosine, oxidative stress, and cytoprotection. Jpn J Pharmacol 86, 265-274.

155. Phillis JW, O'Regan MH. (1996) Effects of an inhibitor of adenosine deaminase, deoxycoformycin, and of nucleoside transport, propentofylline, on post-ischemic recovery of adenine nucleotides in rat brain. Neurochem Res 21, 347-353.

156. Fredholm BB, Lindstrom K, Wallman-Johansson A. (1994) Propentofylline and other adenosine transport inhibitors increase the efflux of adenosine following electrical or metabolic stimulation of rat hippocampal slices. $J$ Neurochem $\mathbf{6 2}$, 563-573.

157. Weber G. (1983) Biochemical strategy of cancer cells and the design of chemotherapy: G.H.A. Clowes Memorial Lecture. Cancer Res 43, 3466-3492.

158. Mackey JR, Baldwin SA, Young JD, and Cass CE. (1998) Nucleoside transport and its significance for anticancer drug resitance. Drug Resist Updat 1, 310-324.

159. Wright AM, Gati WP, Paterson AR. (2000) Enhancement of retention and cytotoxicity of 2-chlorodeoxyadenosine in cultured human leukemic lymphoblasts by nitrobenzylthioinosine, an inhibitor of equilibrative nucleoside transport.

Leukemia 14, 52-60.

160. de Koning HP, Bridges DJ, Burchmore RJS. (2005) Purine and pyrimidine transport in pathogenic protozoa: from biology to therapy. FEMS Micobiol Rev 29, 987-1020.

161. el Kouni, M. (2003) Potential chemotherapeutic targets in purine metabolism of parasites. Pharmacol Ther 99, 283-309.

162. Zhu Z, Furr J, and Buolamwini JK. (2003) Synthesis and flow cytometric evaluation of novel 1,2,3,4-tetrahydroisoquinoline conformationally constrained analogues of nitrobenzylmercaptopurine riboside (NBMPR) designed for probing its conformation when bound to the es nucleoside transporter. J Med Chem 46, 831-837.

163. Gupte A, Boulamwini JK. (2004) Novel halogenated nitrobenzylthioinosine analogs as es nucleoside transporter inhibitors. Bioorg Med Chem Lett 14, 22572260 . 
164. Lin W, Boulamwini JK. (2007) Synthesis, flow cytometric evaluation, and identification of highly potent dipyridamole analogues as equilibrative nucleoside transporter 1 inhibitors. J Med Chem 50, 3906-3920.

165. Zhu Z, Boulamwini JK. (2007) Constrained NBMPR analogue synthesis, pharmacaphore mapping and 3D-QSAR modeling of equilibrative nucleoside transporter 1 (ENT1) inhibitory activity. Bioorg Med Chem 16, 3848-3865.

166. Addo JK, Boulamwini JK. (2004) Design, synthesis, and evaluation of 5'-Saminoethyl-N(6)-azidobenzyl-5'-thioinosine biotin conjugate: a bifunctional photoaffinity probe for the es nucleoside transporter. Bioconjug Chem 15, 536540.

167. Remick SC, Grem JL, Fischer PH, Tutsch KD, Alberti DB, Nieting LM, Tombes MB, Bruggink J, Wilson JK, and Trump DL. (1990) Phase I trial of 5-fluorouracil and dipyridamole administered by seventy-two hour concurrent continuous infusion. Cancer Res 50, 2667-2672.

168. Bailey H, Wilding G, Tutsch KD, Arzoomanian RZ, Alberti D, Tombes MB, Grem JL, and Spriggs DR. (1992) A phase I trial of 5-fluorouracil, leucovorin, and dipyridamole given by concurrent 120 -h continuous infusions. Cancer Chemother Pharmacol 30, 297-302.

169. Grem JL. (1992) Biological modulation of 5-fluorouracil by dipyridamole: preclinical and clinical experience. Semin Oncol 19, 56-65.

170. Grem JL, Fisher PH. (1986) Alteration of fluorouracil metabolism in human colon cancer cells by dipyridamole with a selective increase in fluorodeoxyuridine monophosphate levels. Cancer Res 46, 6191-6199.

171. Van Mouwerik TJ, Pangallo CA, Wilson JK, and Fisher PH. (1987) Augmentation of methotrexate cytotoxicity in human colon cancer cells achieved through inhibition of thymidine salvage by dipyridamole. Biochem Pharmacol 36, 809-814.

172. Wilson JKV, Fisher PH, Remick SC, Tutsch KD, Grem JL, Nieting L, Alberti D, Bruggink J, and Trump DL (1989) Methotrexate and dipyridamole combination therapy based upon inhibition of nucleoside salvage in humans. Cancer Res. 49, 1866-1870.

173. Chakrabarti S, Freedman JE. (2008) Dipyridamole, cerebrovascular disease, and the vasculature. Vascul Pharmacol 48, 143-149.

174. Best LC, McGuire MB, Jones PB, Holland TK, Martin TJ, Preston EE, Segal DS, and Russel RG. (1979) Mode of action of dipyridamole on human platelets. Thromb Res 16, 367-379.

175. Dresse A, Chevolet C, Delapierre D, Masset H, Weisenberg H, Bozler G, and Heinzel G. (1982) Pharmacokinetics of oral diypriamole (Persantine) and its effect on platelet adenosine uptake in man. Eur J Clin Pharmacol 23, 229-234.

176. German DC, Kredich NM, and Bjornsson TD. (1989) Oral dipyridamole increases plasma adenosine levels in human beings. Clin Pharmacol Ther 45, 80-84.

177. Mills DC, Smith JB. (1971) The influence on platelet aggregation of drugs that affect the accumulation of adenosine 3':5'-cyclic monophosphate in platelets. Biochem J 121, 185-196.

178. Smith JB, Mills DC. (1970) Inhibition of adenosine 3',5'-cyclic monophophate phosphodiesterase. Biochem J 120, 20P. 
179. Blass KE, Block HU, Forster W, and Ponicke K. (1980) Dipyridamole: a potent stimulator of prostacyclin (PGI2) biosynthesis. Br J Pharmacol 68, 71-73.

180. Baron JF, Mundler O, Bertrand M, Vicaut E, Barre E, Godet G, Samama CM, Coriat P, Kieffer E, and Viars P. (1994) Dipyridamole-thallium scintigraphy and gated radionuclide angiography to assess cardiac risk before abdominal aortic surgery. N Engl J Med 330, 663-669.

181. Leppo JA, O'Brien J, Rothendler JA, getchell JD, and Lee VW. (1984) Dipyridam-ole-thallium-201 scintigraphy in the prediction of future cardiac events after myocardial infarction. N Engl J Med 310, 1014-1018.

182. Neumann F-J, Marx N, Gawaz M, Brand K, Ott I, Rokitta C, Sticherling C, Meinl C, May A, and Schomig A. (1997) Induction of cytokine expression in leukocytes by binding of thrombin-stimulated platelets. Circulation 95, 2387-2394.

183. Neumann F-J, Zohlnhofer D, Fakhoury L, Ott I, Gawaz M, and Schomg A. (1999) Effect of glycoprotein IIb/IIIa receptor blockade on platelet-leukocyte interaction and surface expression of the leukocyte integrin Mac-1 in acute myocardial infarction. J Am Coll Cardiol 34, 1420-1426.

184. Celi A, Pellegrini G, Lorenzet R, De Blasi A, Ready N, Furie BC, and Furie B. (1994) P-selectin induces the expression of tissue factor on monocytes. Proc Natl Acad Sci USA 91, 8767-8771.

185. Elstad MR, Pine TRL, Cowley FS, McEver RP, McIntyre TM, Prescott SM, and Zimmerman GA. (1995) P-selectin regulates platelet-activating factor synthesis and phagocytosis by monocytes. J Immunol 155, 109-122.

186. Weyrich AS, Elstad MR, McEver RP, McIntyre TM, Moore KL, Morrissey JH, Prescott SM, and Zimmerman GA. (1996) Activated platelets signal chemokine synthesis by human monocytes. J Clin Invest 97, 1525-1534.

187. Szebeni J, Weinstein JN. (1991) Dipyridamole binding to proteins in human plasma and tissue culture media. J Lab Clin Med 117, 485-492.

188. Lenz TL, Hillema DE. (2000) Aggrenox: a fixed dose combination of aspirin and dipyridamole. Ann Pharmacother 34, 1283-1290.

189. Pashko LL, Lewbart ML, and Schwartz AG. (1991) Inhibition of 12-Otetradecanoyl-13-acetate-promoted skin tumor formation in mice by $16-\alpha$-fluoro5-androsten-17-one and its reversal by deoxyribonucleosides. Carcinogenesis 12, 2189-2192.

190. Schwartz AG, Lewbart ML, and Pashko LL. (1992) Inhibition of tumorigenesis by dehydroepiadrosterone and structural analogs. In: Watternburg L, Lipkin M, and Boone CW (eds). Cancer Chemoprevention, CRC Press, Boca Raton, Fl.

191. Shibata MA, Shirai T, Asakawa E, Hirose M, and Fukushima S. (2006) Inhibition by dehydroepiandrosterone of butylated hydroxyanisole (BHA) promotion of ratbladder carcinogenesis and enhancement of BHA-induced forestomach hyperplasia. Int J Cancer 53, 819-823.

192. Bettger WJ, McKeeehan WL. (1986) Mechanisms of cellular nutrition. Physiol $\operatorname{Rev}$ 66, $1-35$.

193. Meckling-Gill KA, Cass CE. (1992) Effects of transformation by v-fps on nucleoside transport in rat-2 fibroblasts. Biochem $J$ 282, 147-154.

194. Wiley JS, Cebon JS, Jamieson GP, Szer J, Gibson J, Woodruff RK, McKendrick JJ, Sheridan WP, Biggs JC, Snook MB, Brocklebank AM, Rallings MC, and 
Patterson ARP. (1994) Assessment of proliferative responses to granulocytemacrophage colony stimulating factor (GM-CSF) in acute myeloid leukaemia using a fluorescent ligand for the nucleoside transporter. Leukemia 8, 181-185.

195. Wiley JS, Snook MB, and Jamieson GP. (1989) Nucleoside transport in acute leukaemia and lymphoma: close relation to proliferative rate. Br J Haematol 71, 203-207.

196. Smith CL, Pilarski LM, Egerton ML, and Wiley JS. (1989) Nucleoside transport and proliferative rates in human thymocytes and lymphocytes. Blood 74, 20382042.

197. Goh L-B, Lee CW. (1997) Reduction of equilibrative nitrobenzylthioinosinesensitive nucleoside transporter in tamoxifen-treated MCF-7 cells: an oestrogenreversible phenomenon. Biochem J 327, 31-36.

198. Lin W, and Buolamwini JK. (2007) Synthesis, flow cytometric evaluation, and identification of highly potent dipyridamole analogues as equilibrative nucleoside transporter 1 inhibitors. $J$ Med Chem 50, 3906-3920.

199. Hou D-X, Kai K, Li J-J, Lin S, Terahara N, Wakamatsu M, Fujii M, Young MR, and Colburn NH. (2004) Anthocyanidins inhibit activator protein 1 activity and cell transformation: structure-activity relationship and molecular mechanisms. Carcinogenesis 25, 29-36.

200. Dong Z, Ma W., Huang C, and Yang CS. (1997) Inhibition of tumor promoterinduced activator protein 1 activation and cell transformation by tea polyphenols, (-)-epigallocatechin gallate, and theaflavins. Cancer Res 57, 4414-4419.

201. Kang NJ, Lee KW, Rogozin, EA, Cho Y-Y, Heo Y-S, Bode AM, Lee HJ, and Dong Z. (2007) Equol, a metabolite of the soybean isoflavone daidzein, inhibits neoplastic cell transformation by targeting the MEK/ERK/p90RSK/activator protein-1 pathway. $J$ Biol Chem 282, 32856-32866.

202. Cai J, Lee CW. (1996) Tamoxifen inhibits nitrobenzylthioinosine-sensitive equilibrative uridine trasport in human MCF-7 breast cancer cells. Biochem J 320, 991-995.

203. Tsao AS, Kim ES, and Hong WK. (2005) Chemoprevention of cancer. CA Cancer J Clin 54, 150-180.

204. Fisher B, Constantino JP, Wickerham DL, Redmond CK, Kavanah M, Cronin WM, Vogel V, Robidous A, Dimitrov N, Atkins J, Daly M, Wieand S, Tan-Chiu E, Ford L, and Wolmark N. (1998) Tamoxifen for prevention of breast cancer: a report of the National Surgical Adjuvant Breast and Bowel Project P-1 Study. $J$ Natl Cancer Inst 90, 1371-1388.

205. Cass CE, Tan TH, and Selner M. (1979) Antiproliferative effects of 9-beta-Darabinofuranosyladenine 5'-monophosphate and related compounds in combination with adenosine deaminase inhibitors against mouse L1210/C2 cells in culture. Cancer Res 29, 1563-1569.

206. Boleti H, Coe IR, Baldwin SA, Young JD, and Cass CE. (1997) Molecular identification of the equilibrative NBMPR-sensitive (es) nucleoside transporter and demonstration of an equilibrative NBMPR-insensitive (ei) transport activity in human erythroleukemia (K562) cells. Neuropharmacology 36, 1167-1179.

207. Steele VE, Kelloff GJ, Balentine D, Boone CW, Mehta R, Bagheri D, Sigman CC, Zhu C, and Sharma S. (2000) Comparitive chemopreventive mechanisms of 
green tea, black tea and selected polyphenol extracts measure by in vitro bioassays. Carcinogenesis 21, 63-67.

208. Jain AK, Shimoi K, Nakamura Y, Sano M, and Tomita I. (1989) Effect of tea on 12-O-tetradecanoyl-phorbol-13 acetate (TPA) induced promotion on transformation of JB6 mouse epidermal cells. Indian J Cancer 26, 92-98.

209. Zhen Y, Cao S, Xue Y, and Wu S. (1991) Green tea extracts inhibit nucleoside transport and potentiates the antitumor effect of antimetabolites. Chin Med Sci J 6, 1-5.

210. Angel P, Karin M. (1991) The role of Jun, Fos and the AP-1 complex in cellproliferation and transformation. Biochim Biophys Acta 1072, 129-157.

211. Pang L, Sawada T, Decker SJ, and Saltiel AR. (1995) Inhibition of MAP kinase blocks the differentiation of PC-12 cells induced by nerve growth factor. $\mathrm{J} \mathrm{Biol}$ Chem 270, 13585-13588.

212. Nordberg J, Arner SJ. (2001) Reactive oxygen specie, antioxidants, and the mammalian thioredoxin system. Free Radic Biol Med 31, 1287-1312.

213. Naka K, Muraguchi T, Hoshii T, and Hirao A. (2008) Regulation of reactive oxygen species and genomic stability in hematopoietic stem cells. Antioxid Redox Signal 10, 1883-1894.

214. Klaunig JE, Xu Y, Isenberg JS, Bachowski S, Kolaja KL, Jian J, Stevenson DE, and Walborg EF Jr. (1998) The role of oxidative stress in chemical carcinogenesis. Environ Health Perspect 106, 289-295.

215. Curtin JF, Donovan M, and Cotter TG. (2002) Regulation and measurement of oxidative stress in apoptosis. J Immunol Methods 265, 49-72.

216. Nakamura Y, Colburn NH, and Gindhart TD. (1985) Role of reactive oxygen in tumor promotion: implication of superoxide anion in promotion of neoplastic transformation in JB-6 cells by TPA. Carcinogenesis 6, 229-235.

217. Nakamura Y, Gindhart TD, Winterstein IT, Seed JL, and Colburn NH. (1988) Early superoxide dismutase-sensitive event promotes neoplastic transformation in mouse epidermal JB6 cels. Carcinogenesis 9, 203-207.

218. Nepomuceno MF, Alonso A, Pereira-da-Silva L, and Tabak M. (1997) Inhibitory effect of dipyridamole and its derivatives on lipid peroxidation in mitochondria. Free Radic Biol Med 23, 1046-1054.

219. Iuliano L, Violi F, Ghiselli A, Alessandri C, and Balsano F. (1989) Dipyridamole inhibits lipid peroxydation and scavenges oxygen radicals. Lipids 24, 430-433.

220. Iuliano L, Pratico D, Ghiselli A, Bonavita MS, and Violi F. (1992) Reaction of dipyridamole with the hydroxyl radical. Lipids 27, 349-353.

221. Pedulli GF, Lucarini M, Marchesi E, Paolucci F, Roffia S, Fiorentini D, and Landi L. (1999) Medium effects on the antioxidant activity of dipyridamole. Free Rad Biol Med 26, 295-302.

222. Iuliano L, Pedersen J, Rotilio G, Ferro D, and Violi F. (1995) A potent chain breaking activity of the cardiovascular drug dipyridamole. Free Radic Biol Med 18, 239-247.

223. Janssen-Heininger YM, Poynter ME, and Baeurle PA. (2000) Recent advances towards understanding redox mechanisms in the activation of of nuclear factor kappaB. Free Radic Biol Med 28, 1317-1327. 
224. Li JJ, Westergard C, Ghosh P, Colburn NH. (1997) Inhibitors of both nuclear factor-kappaB and activator protein-1 activation block the neoplastic transformation response. Cancer Res 61, 3569-3576.

225. Hsu TC, Nair R, Tulsian P, Camalier CE, Hegamyer GA, Young MR, and Colburn NH. (2001) Transformation nonresponsive cells owe their resistance to lack of p65/nuclear factor-kappaB activation. Cancer Res 61, 4160-4168.

226. Curtis K, Borisy A, Zimmerman G, Jost-Price ER, Manivasakam P, Hurst N, and Foley A, inventors. (2007) Combinations for the treatment of immunoinflammatory disorders. 


\section{APPENDIX A: DATA TABLES USED FOR REGRESSION ANALYSIS}

Table A.1. Cytotoxicity, nucleoside transport inhibition, and antitumor promotion data for Group 1 DPM analogues.

\begin{tabular}{cccccc}
\hline & & & \multicolumn{3}{c}{ \% Inhibition } \\
\cline { 3 - 6 } Compound \# & \% Viability & Std. Dev & ENT1 Uptake & ENT2 Uptake & $\begin{array}{c}\text { Tumor } \\
\text { Promotion }\end{array}$ \\
\hline $\mathbf{1 0 1}$ & 60.22 & 0.04 & 85.7 & 66.0 & 97.0 \\
$\mathbf{1 0 2}$ & 65.70 & 0.03 & 70.5 & 24.0 & 76.7 \\
$\mathbf{1 0 3}$ & 70.89 & 0.04 & 88.4 & 81.7 & 70.6 \\
$\mathbf{1 0 4}$ & 71.44 & 0.06 & 58.7 & 33.0 & 76.9 \\
$\mathbf{1 0 5}$ & 80.04 & 0.06 & 28.9 & 18.3 & 51.3 \\
$\mathbf{1 0 6}$ & 69.34 & 0.01 & 89.2 & 72.3 & 94.7 \\
$\mathbf{1 0 7}$ & 54.47 & 0.04 & 64.8 & 19.5 & 89.2 \\
$\mathbf{1 0 8}$ & 99.91 & 0.03 & 83.4 & 33.4 & 80.9 \\
$\mathbf{1 0 9}$ & 50.59 & 0.10 & 94.1 & 75.9 & 100.0 \\
$\mathbf{1 1 0}$ & 23.65 & 0.02 & 88.8 & 65.9 & 99.0 \\
$\mathbf{1 1 1}$ & 72.32 & 0.04 & 36.3 & 50.6 & 65.6 \\
$\mathbf{1 1 2}$ & 73.39 & 0.09 & 88.0 & 32.4 & 71.6 \\
$\mathbf{1 1 3}$ & 83.39 & 0.09 & 74.5 & 3.7 & 100.0 \\
ARA-A & 60.81 & 0.01 & --- &.-- &.-- \\
CAMPTO & 43.30 & 0.01 & --- & -- & -- \\
DPM & 82.78 & 0.02 & 97.4 & 98.2 & 79.5 \\
\hline
\end{tabular}


Table A.2. Cytotoxicity, nucleoside transport inhibition, and antitumor promotion data for Group 2 DPM analogues.

\begin{tabular}{cccccc}
\hline & & & \multicolumn{3}{c}{ \% Inhibition } \\
\cline { 3 - 6 } Compound \# & \% Viability & Std. Dev & ENT1 Uptake & ENT2 Uptake & $\begin{array}{c}\text { Tumor } \\
\text { Promotion }\end{array}$ \\
\hline $\mathbf{1 1 4}$ & 72.78 & 0.03 & 83.2 & 77.2 & 65.6 \\
$\mathbf{1 1 5}$ & 83.25 & 0.07 & 88.4 & 75.1 & 94.0 \\
$\mathbf{1 1 6}$ & 85.93 & 0.04 & 77.4 & 84.0 & 37.4 \\
$\mathbf{1 1 7}$ & 62.99 & 0.04 & 88.9 & 71.5 & 98.7 \\
$\mathbf{1 1 8}$ & 41.72 & 0.02 & 51.8 & 40.5 & 59.3 \\
$\mathbf{1 1 9}$ & 82.31 & 0.06 & 31.8 & 84.6 & 33.9 \\
$\mathbf{1 2 0}$ & 44.28 & 0.03 & 84.0 & 56.3 & 88.2 \\
$\mathbf{1 2 1}$ & 99.49 & 0.10 & 58.8 & 92.6 & 93.7 \\
$\mathbf{1 2 2}$ & 79.00 & 0.08 & 19.4 & 5.7 & 31.4 \\
$\mathbf{1 2 3}$ & 103.07 & 0.11 & 31.3 & 11.8 & 31.3 \\
$\mathbf{1 2 4}$ & 100.04 & 0.01 & 68.0 & 77.2 & 66.0 \\
$\mathbf{1 2 5}$ & 77.01 & 0.02 & 64.3 & 69.2 & 39.6 \\
$\mathbf{1 2 6}$ & 80.56 & 0.00 & 53.2 & 21.0 & 43.7 \\
$\mathbf{1 2 7}$ & 82.45 & 0.08 & 7.5 & 5.3 & 76.0 \\
ARA-A & 60.81 & 0.01 & --- &.-- &.-- \\
CAMPTO & 43.30 & 0.01 & --- & --- & --- \\
DPM & 82.78 & 0.02 & 97.4 & 98.2 & 79.5 \\
\hline
\end{tabular}


Table A.3. Cytotoxicity, nucleoside transport inhibition, and antitumor promotion data for Group 3 DPM analogues.

\begin{tabular}{|c|c|c|c|c|c|}
\hline \multirow[b]{2}{*}{ Compound \# } & \multirow[b]{2}{*}{ \% Viability } & \multirow[b]{2}{*}{ Std. Dev } & \multicolumn{3}{|c|}{$\%$ Inhibition } \\
\hline & & & ENT1 Uptake & ENT2 Uptake & $\begin{array}{c}\text { Tumor } \\
\text { Promotion }\end{array}$ \\
\hline 128 & 85.99 & 0.15 & 7.3 & 3.2 & 15.6 \\
\hline 129 & 61.26 & 0.04 & 52.7 & 2.7 & 12.8 \\
\hline 130 & 81.92 & 0.10 & 30.6 & -0.3 & 12.4 \\
\hline 131 & 71.05 & 0.10 & 89.5 & 35.6 & 34.8 \\
\hline 132 & 87.77 & 0.03 & 25.0 & 1.0 & 41.7 \\
\hline 133 & 77.39 & 0.08 & 89.7 & 71.1 & 70.9 \\
\hline 134 & 70.62 & 0.04 & 68.5 & 26.5 & 69.3 \\
\hline 135 & 73.60 & 0.02 & 92.3 & 82.8 & 84.8 \\
\hline 136 & 77.75 & 0.01 & 57.1 & 10.8 & 56.7 \\
\hline 137 & 85.76 & 0.03 & 92.6 & 68.7 & 83.2 \\
\hline 138 & 83.58 & 0.02 & 95.4 & 89.2 & 90.6 \\
\hline 139 & 82.29 & 0.10 & 86.7 & 17.5 & 72.0 \\
\hline 140 & 76.74 & 0.01 & 79.2 & 23.3 & 54.3 \\
\hline 141 & 53.57 & 0.07 & 85.4 & 89.8 & 90.3 \\
\hline 142 & 58.05 & 0.05 & 38.1 & 11.7 & 46.3 \\
\hline 143 & 53.07 & 0.03 & 94.9 & 78.5 & 99.7 \\
\hline 144 & 57.14 & 0.10 & 61.7 & 34.9 & 95.1 \\
\hline 145 & 81.73 & 0.12 & 85.5 & 37.4 & 97.6 \\
\hline 146 & 109.05 & 0.13 & 67.8 & 24.4 & 76.8 \\
\hline 147 & 68.26 & 0.08 & 77.7 & 75.8 & 49.6 \\
\hline 148 & 73.98 & 0.00 & 22.9 & 26.4 & 35.6 \\
\hline 149 & 66.21 & 0.03 & 89.1 & 89.3 & 90.2 \\
\hline 150 & 77.84 & 0.03 & 94.3 & 63.0 & 100.0 \\
\hline 151 & 91.97 & 0.06 & 27.8 & 21.4 & 97.2 \\
\hline 152 & 45.41 & 0.05 & 87.4 & 33.3 & 100.0 \\
\hline 153 & 76.44 & 0.09 & 13.3 & 38.0 & 50.9 \\
\hline 154 & 65.44 & 0.07 & 71.6 & 34.3 & 85.7 \\
\hline 155 & 62.89 & 0.10 & 13.3 & 2.1 & 37.9 \\
\hline 156 & 46.94 & 0.05 & 27.0 & 0.5 & 98.4 \\
\hline 157 & 56.71 & 0.01 & 26.4 & 5.7 & 55.0 \\
\hline ARA-A & 60.81 & 0.01 & --- & --- & --- \\
\hline САМРТО & 43.30 & 0.01 & --- & --- & --- \\
\hline DPM & 82.78 & 0.02 & 97.4 & 98.2 & 79.5 \\
\hline
\end{tabular}


Table A.4. Cytotoxicity, nucleoside transport inhibition, and antitumor promotion data for Group 4 DPM analogues.

\begin{tabular}{cccccc}
\hline & & & \multicolumn{3}{c}{ \% Inhibition } \\
\cline { 3 - 6 } Compound \# & \% Viability & Std. Dev & ENT1 Uptake & ENT2 Uptake & $\begin{array}{c}\text { Tumor } \\
\text { Promotion }\end{array}$ \\
\hline $\mathbf{1 5 8}$ & 97.84 & 0.10 & 71.0 & 25.7 & 45.0 \\
$\mathbf{1 5 9}$ & 63.33 & 0.09 & 83.2 & 76.9 & 98.1 \\
$\mathbf{1 6 0}$ & 49.60 & 0.04 & 96.7 & 75.0 & 99.1 \\
$\mathbf{1 6 1}$ & 91.34 & 0.13 & 89.8 & 86.8 & 89.1 \\
$\mathbf{1 6 2}$ & 100.97 & 0.03 & 60.8 & 0.0 & 34.2 \\
$\mathbf{1 6 3}$ & 88.04 & 0.04 & 21.1 & 1.8 & 22.7 \\
$\mathbf{1 6 4}$ & 93.07 & 0.02 & 94.1 & 79.5 & 100.0 \\
ARA-A & 60.81 & 0.01 & --- & --- & -- \\
CAMPTO & 43.30 & 0.01 & --- & --- & -- \\
DPM & 82.78 & 0.02 & 97.4 & 98.2 & 79.5 \\
\hline
\end{tabular}


APPENDIX B: ANTITUMOR PROMOTION DOSE RESPONSE CURVES AND IC $_{50}$ DATA FOR DPM AND ANALOGUES 

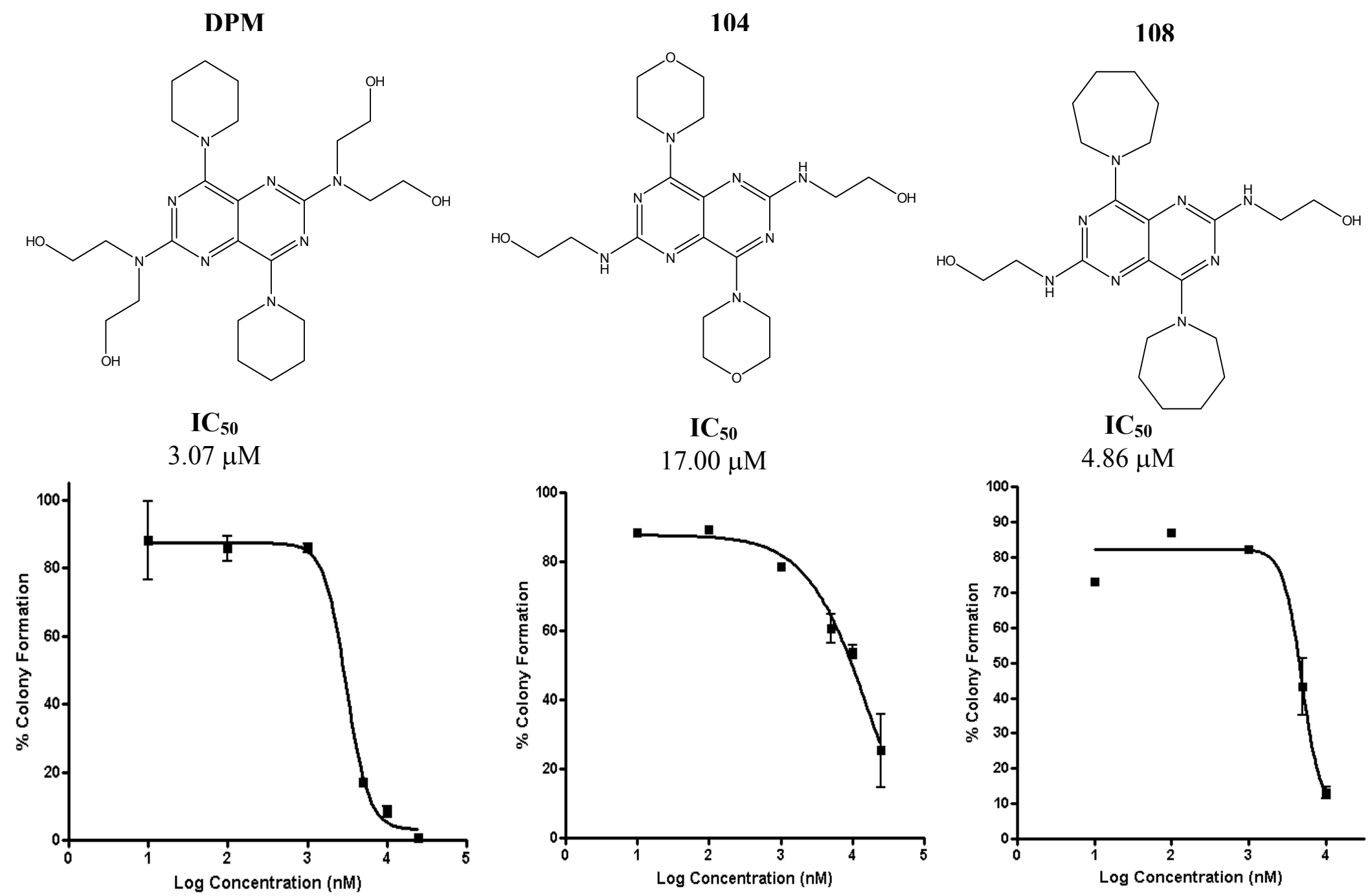

Figure B.1. Antitumor promotion dose response curves and $\mathrm{IC}_{50}$ data for DPM, 104, and 108. 
113

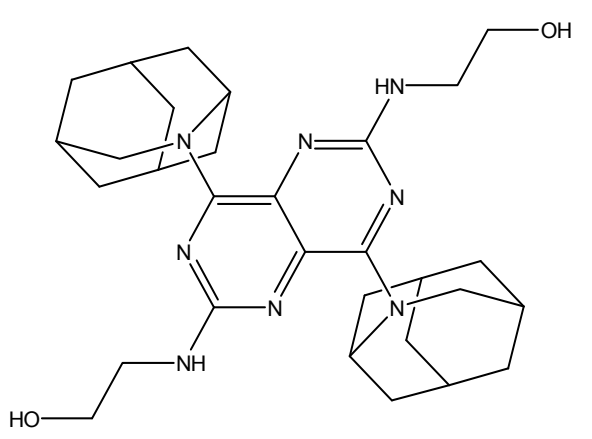

IC $_{50}$

$5.10 \mu \mathrm{M}$

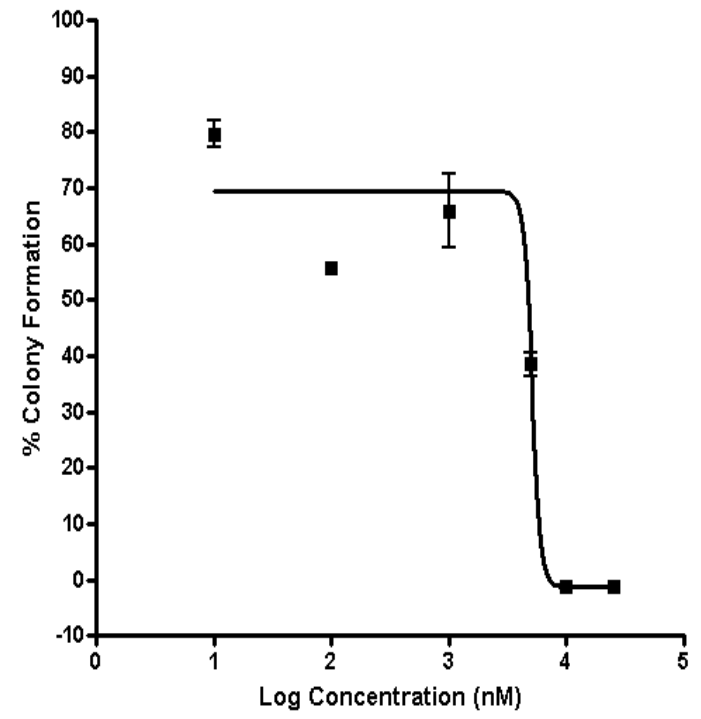

115

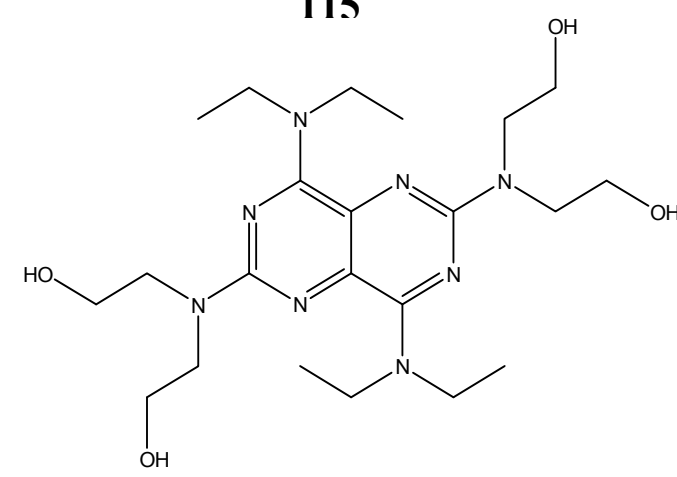

$\mathbf{I C}_{\mathbf{5 0}}$

$2.36 \mu \mathrm{M}$

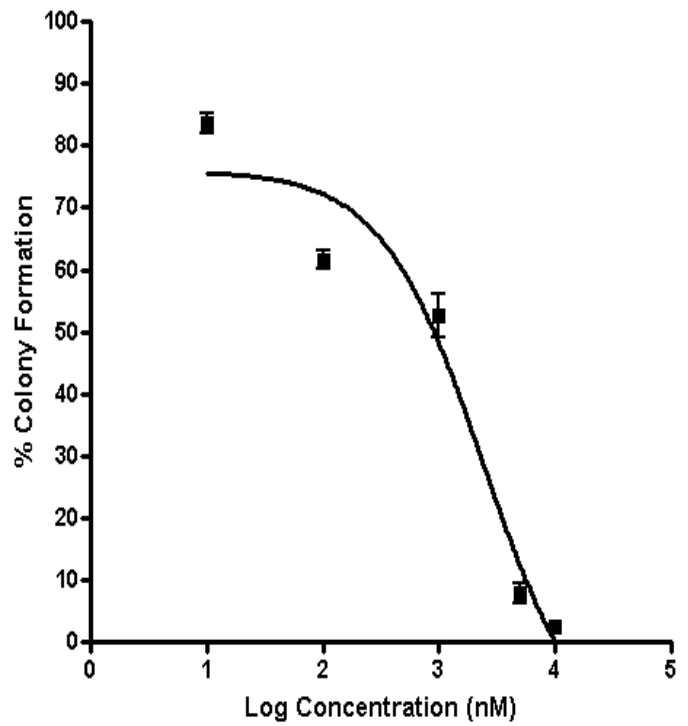

121
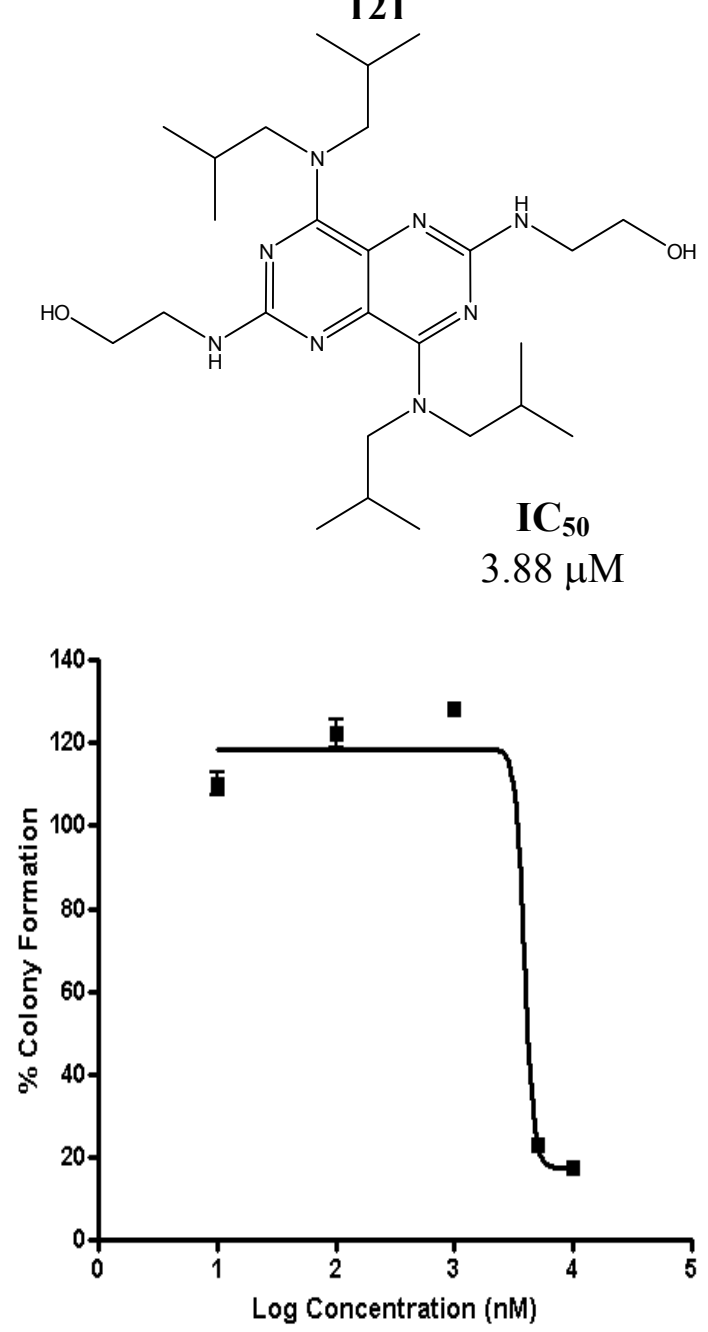

Figure B.2. Antitumor promotion dose response curves and $\mathrm{IC}_{50}$ data for 113,115 , and 121 . 

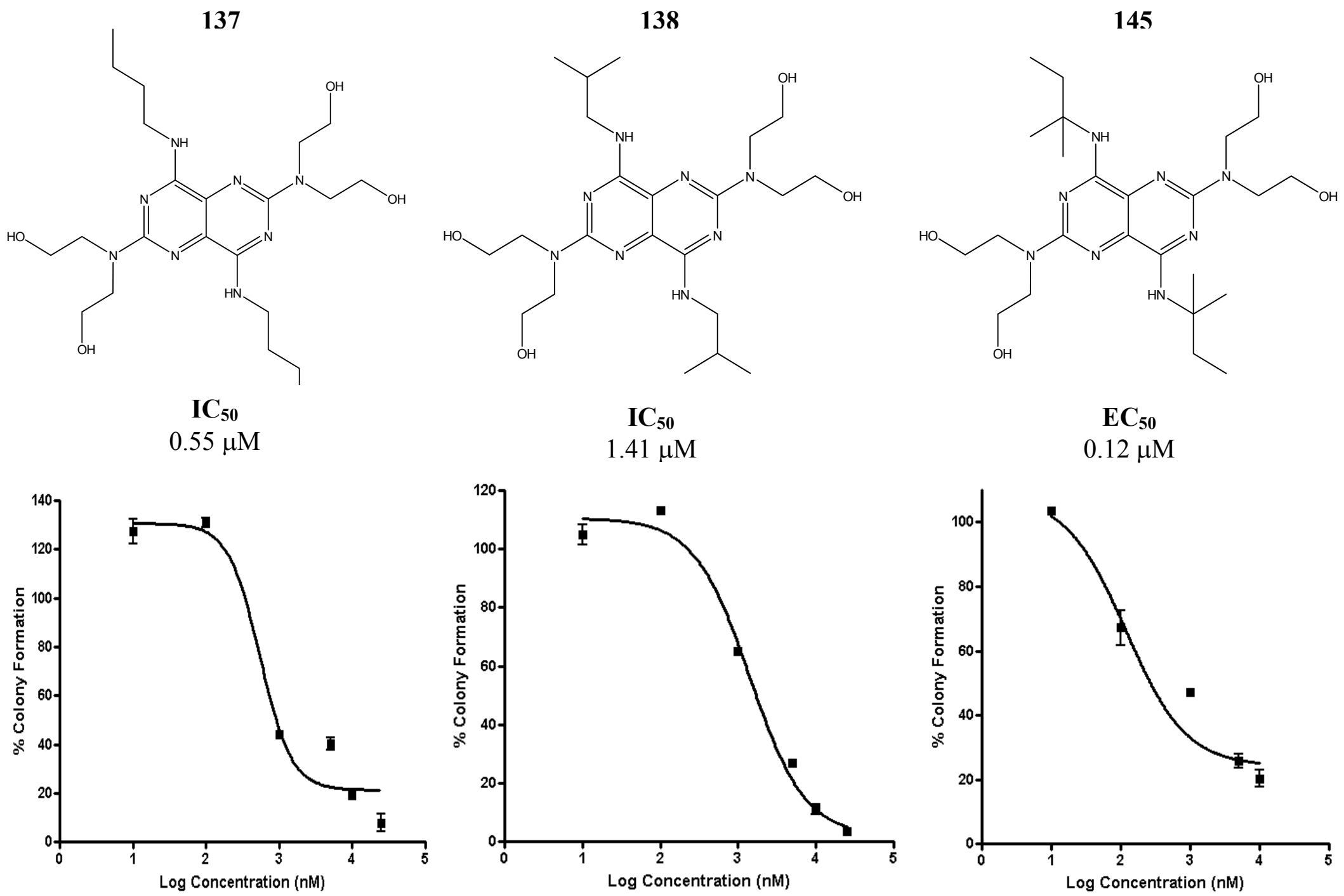

Figure B.3. Antitumor promotion dose response curves and $\mathrm{IC}_{50}$ data for 137, 138, and 145 . 

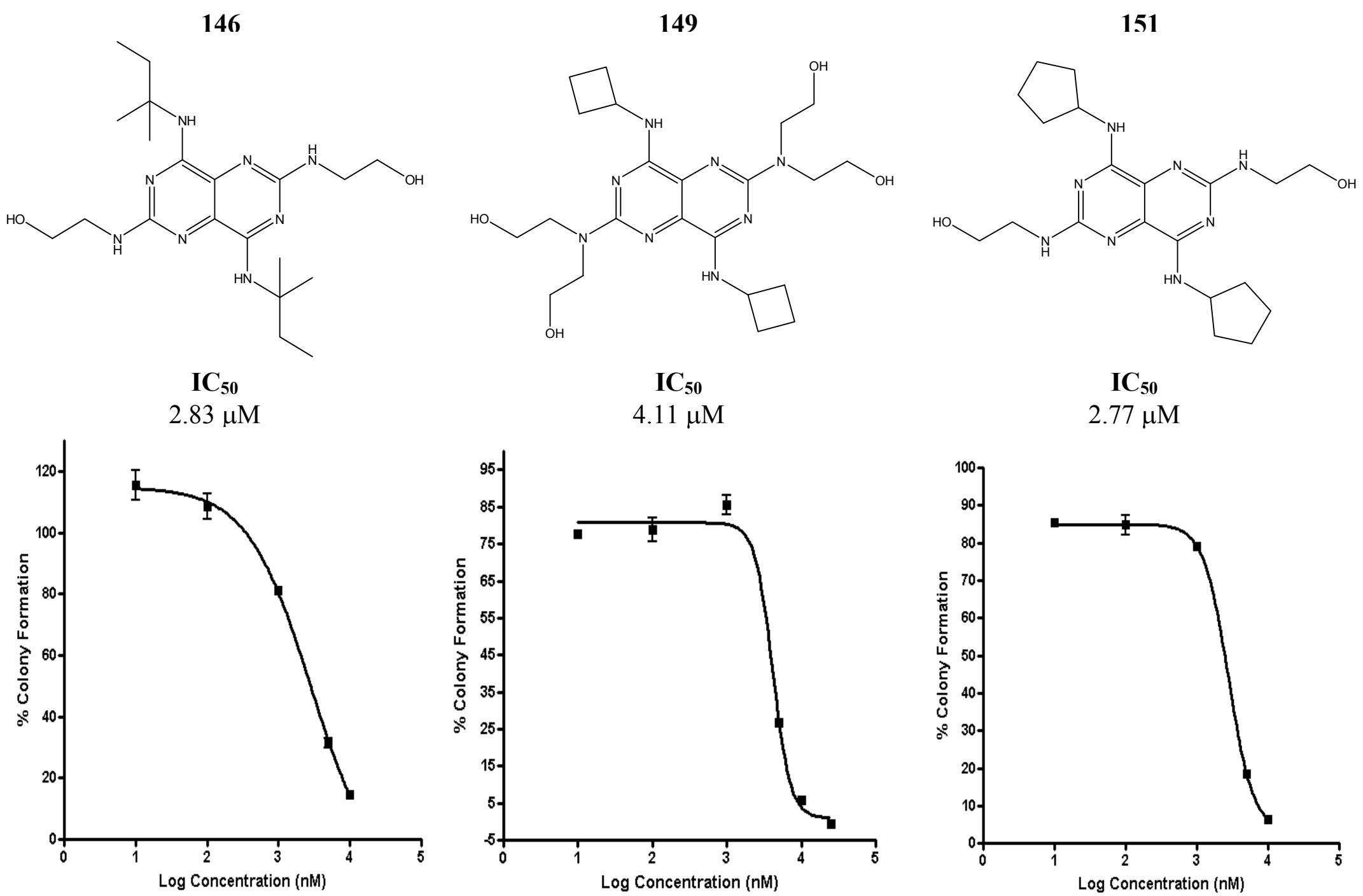

Figure B.4. Antitumor promotion dose response curves and $\mathrm{IC}_{50}$ data for 146, 149, and 151 . 
161

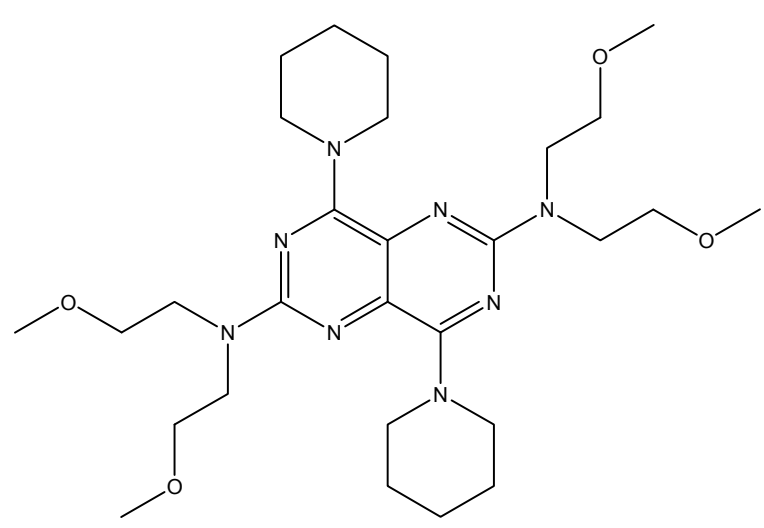

$\mathrm{IC}_{50}$ '

$4.90 \mu \mathrm{M}$

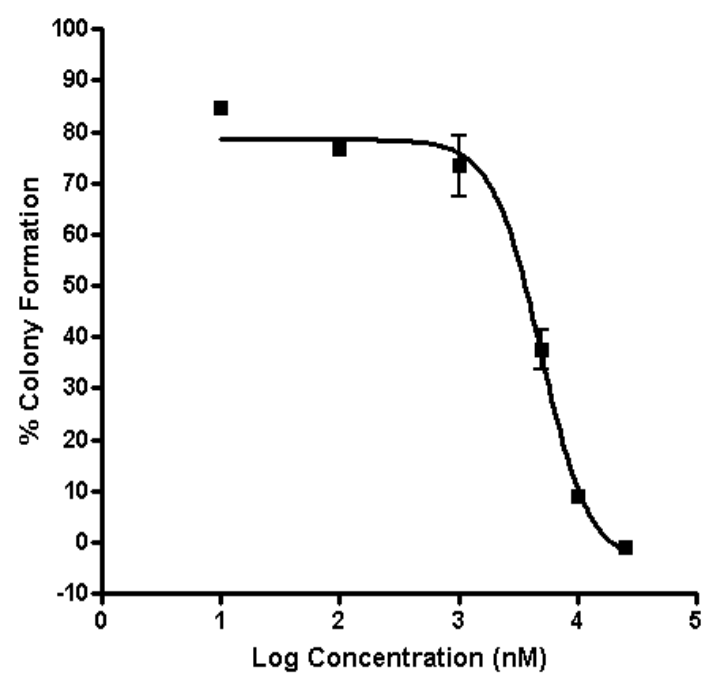

164

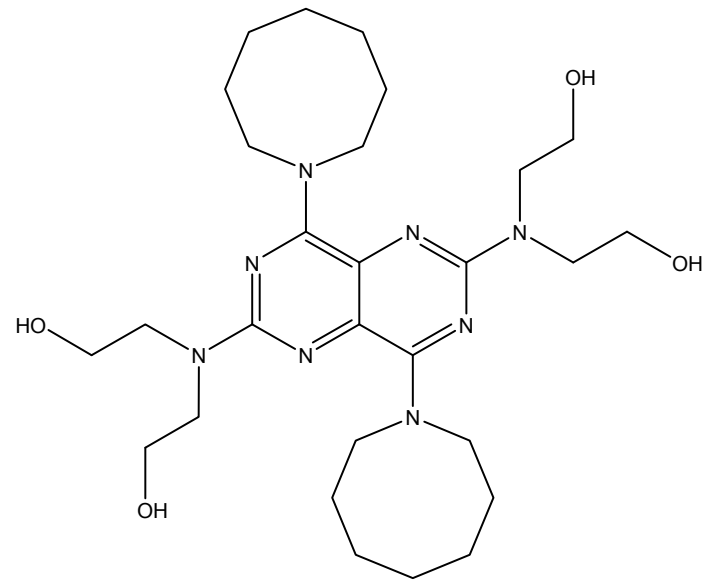

$\mathbf{I C}_{50}$

$1.76 \mu \mathrm{M}$

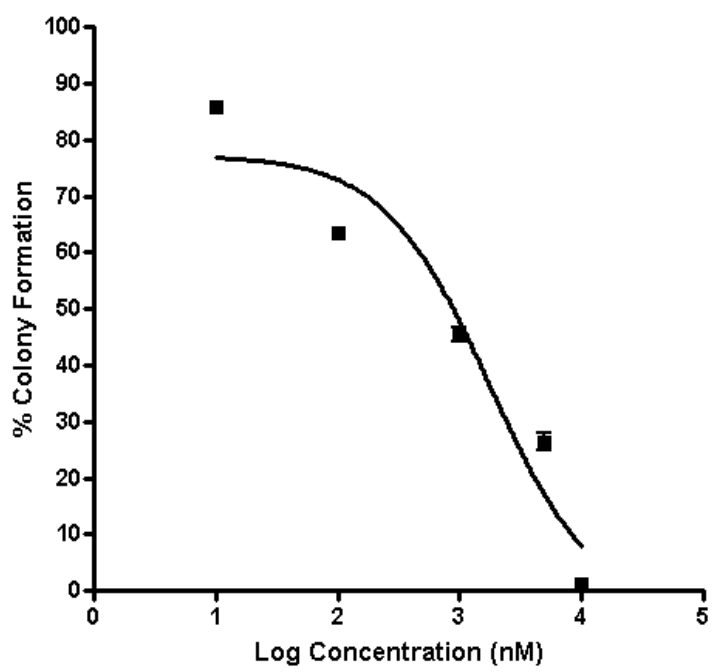

Figure B.5. Antitumor promotion dose response curves and $\mathrm{IC}_{50}$ data for 161, and 164 . 


\section{VITA}

Ja'Wanda Shavon Grant was born on October 1, 1979 in Charleston, SC. In May 2002, Ja'Wanda received a Bachelor of Science degree in Chemical Engineering with a minor in Russian from the University of Mississippi (Oxford, MS). She joined the Interdisciplinary Sciences Program at the University of Tennessee Health Science Center in August 2002. She joined the medicinal chemistry lab of Dr. John K. Buolamwini in the Department of Pharmaceutical Sciences in May 2003. During her graduate studies, she had the opportunity to work on several multidisciplinary projects. Ja'Wanda expects to graduate from the Interdisciplinary Program in December 2008 with the degree of Doctor of Philosophy. 